\title{
IMPACT OF CLIMATE CHANGE AND BIOENERGY ON NUTRITION
}

This paper was prepared by:

Dr Marc J. Cohen,

Food Consumption and Nutrition Division,

International Food Policy Research Institute (IFPRI),

Dr Cristina Tirado, Consultant, IFPRI,

Ms Noora-Lisa Aberman, IFPRI and

Mr Brian Thompson,

Nutrition and Consumer Protection Division, FAO.

The positions and opinions presented are those of the authors alone, and are not intended to represent the views of FAO. 


\section{TABLE OF CONTENTS}

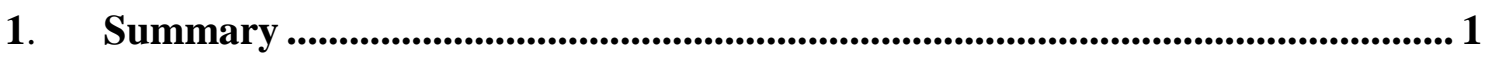

Background: Unacceptably Slow Progress against Hunger and

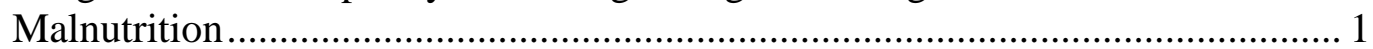

Climate Change, Food Security and Nutrition ......................................................... 3

Nutrition and Bioenergy ………………………………………………….... 7

Policies and Programmes for Improving Nutrition ............................................... 8

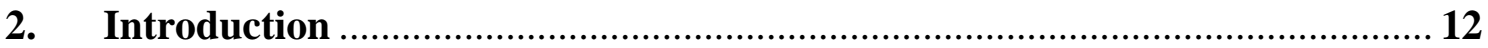

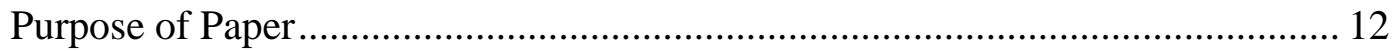

Concept and Content ……………………………………............................... 13

3. World Food Insecurity and Malnutrition: Scope, Trends, Causes

and Consequences........................................................................................................ 14

Dimensions of the Nutrition Problem...................................................................... 14

Causations and Linkages: Conceptual and Analytical Frameworks ...................... 22

Future Challenges and Major Issues and Risks ..................................................... 24

4. Climate Change, Food Security and Nutrition .......................................................30

Overview of Climate Change - Evidence for and Potential Effects ...................... 30

Climate Change Impacts on the Human and Global Environment .......................... 31

Impacts on the Four Food Security Dimensions: Availability,

Stability, Access and Utilization ……………………………………………...... 33

Global Climate Change Impacts on Food and Water Security,

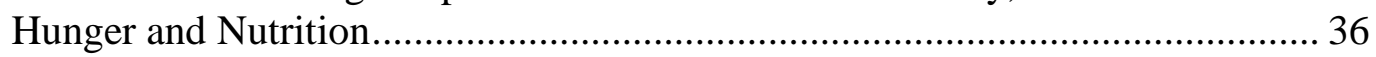

Climate Change and Sustainable Development ………………………………..... 39

Social Impacts of Climate Change …………………………………………..... 40

Adaptation and Mitigation Strategies ............................................................... 41

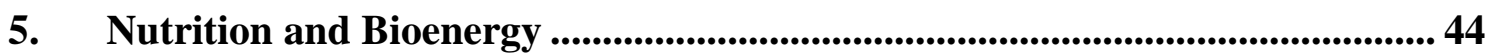

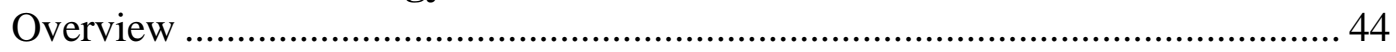

Nutrition Impacts ......................................................................................... 44

Mitigation of Negative Impacts of Biofuels ......................................................... 47

6. Policies and Programmes for Improving Nutrition ................................................51

International Initiatives................................................................................ 51

Policies and Programmes ................................................................................ 53

Priorities and Approaches for Responding to Threats to Nutrition from

Climate Change and Biofuel Demand.

7. Conclusions and Recommendations …………......................................................... 70

Responding to Climate Change ........................................................................ 70

Assuring Pro-Poor and Sustainable Biofuel Development ................................... 71

Making Nutrition a Development Priority .............................................................. 72

8. References …..................................................................................................................... 74 
TABLE OF CONTENTS (cont.)

Appendix 1: Scenarios of the IPCC's Special Report on Emissions Scenarios ............. 85

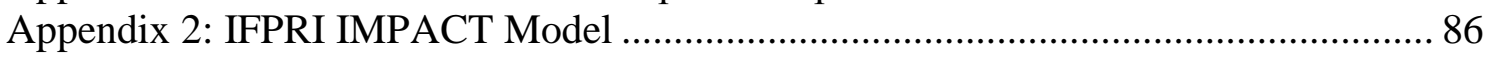

Table 1: Projected undernourishment in the developing world ................................... 23

Table 2: Some effective interventions to reduce maternal and child

undernutrition

Figure 1: FAO/FIVIMS Framework: linkages between the overall development context, the food economy, households and individual measures of

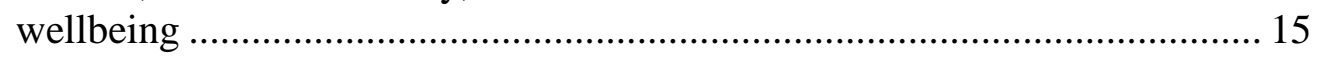

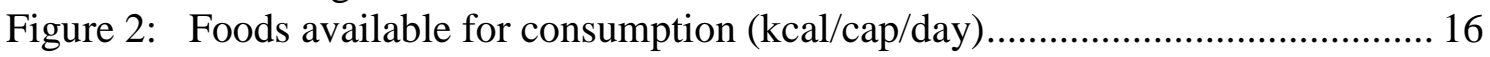

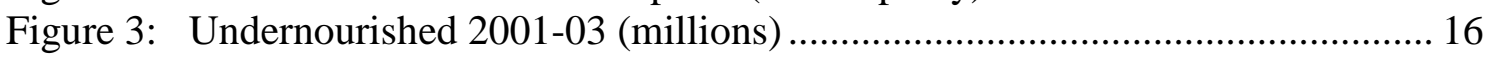

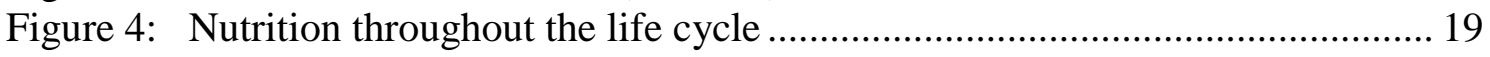

Figure 5: UN humanitarian appeals and donor response (US\$) .................................. 20

Figure 6: Number of undernourished people in the developing world ........................ 21

Figure 7: Changes in number of undernourished in subregions from 1990-92

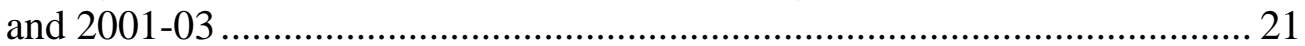

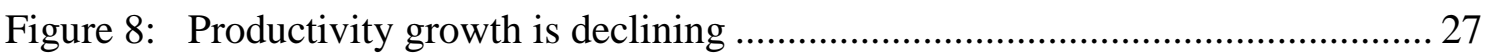

Figure 9: Impact of food price increases on calorie consumption ............................... 47

Figure 10: Impact of price increase on root and grain consumption in Malawi: cross-price vs. own-price elasticity ........................................... 49

Figure 11: Impact of biofuel demand on calorie availability in 2020 (\% change) ......... 50

Figure 12: Changes in number of malnourished preschool children from baseline by 2020 (thousands) under two biofuel scenarios ......................... 50

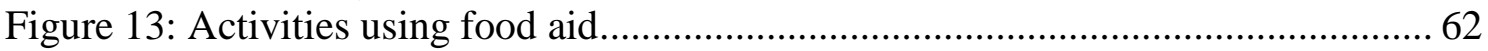

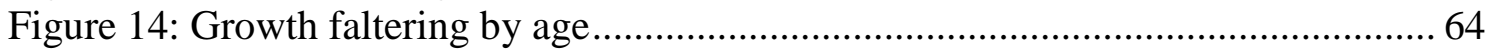

Figure 15: Sources of reduction in developing country child malnutrition, 1970-95.

Box 3.1: Twenty countries are home to $80 \%$ of the world's stunted preschoolers ....... 17

Box 4.1: Impacts on traditional food systems of indigenous peoples in polar regions

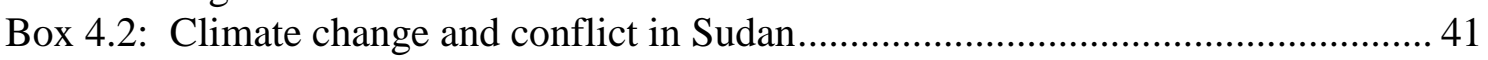

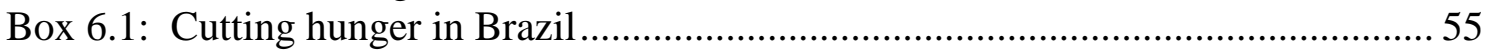




\section{IMPACT OF CLIMATE CHANGE AND BIOENERGY ON NUTRITION}

\section{Summary}

\section{Background: Unacceptably Slow Progress against Hunger and Malnutrition}

Food security has deteriorated since 1995 and reductions in child malnutrition are proceeding too slowly to meet the Millennium Development Goal (MDG) target for halving hunger by 2015. Three major challenges threaten to drastically complicate efforts to overcome food insecurity and malnutrition: climate change, the growing use of food crops as a source of fuel and soaring food prices.

Food security has four dimensions: food availability, access to food, stability of supply and access and safe and healthy food utilization. It is a key factor in good nutrition, along with health, sanitation and care practices. Globally, one billion people are currently without access to safe water and over 2 billion lack adequate sanitation facilities.

Present global food supplies are more than adequate to provide everyone with all the needed calories, if the food were equally distributed. But over 820 million people in developing countries have calorie-deficient diets; over 60 percent live in Sub-Saharan Africa and South Asia.

Even if a person consumes enough calories, this does not guarantee adequate intake of essential micronutrients - vitamins, minerals and trace elements. Micronutrient malnutrition ("hidden hunger") 'has serious public health consequences. For example, over one billion people consume diets deficient in iron. Iron deficiency is responsible for roughly half of the global prevalence of anaemia. Iron deficiency anaemia causes 20 percent of global maternal mortality, can impair children's health and development and reduce adult work performance. Vitamin A deficiency disorders affect 40 million people causing blindness and contributing to infections and death.

One in three developing-country children under the age of five - 178 million children suffers stunting due to chronic undernutrition and poor quality diets. Eighty percent of them live in just 20 African and Asian countries. Stunting is associated with higher rates of illness and death, reduced cognitive ability and school performance in children and lower adult productivity and lifetime earnings. Chronic malnutrition during the first two years of life usually results in irreversible harm.

At each stage in the lifecycle, malnutrition has consequences for each successive stage and/or the next generation. Malnourished mothers are more likely to have low birthweight babies, that face higher mortality and disease rates, impaired mental and physical development and increased risk of adult chronic diseases. Stunted children living with inadequate food, health and care become stunted adolescents; the girls among them too often grow up as the next generation of malnourished mothers.

HIV/AIDS interacts negatively with malnutrition. Poor nutrition can accelerate the spread of HIV, both by increasing people's vulnerability to the virus and by increasing the risk of infection following exposure. In turn, HIV infection can lead to nutritional deficiencies 
through decreased food intake and malabsorption, which hasten the onset of AIDS. The disease impairs the immune system and so can lead to additional infections.

In 2008, the United Nations is appealing for humanitarian assistance for over 100 million people in two dozen countries affected by conflict and political and economic breakdown. Displaced people are susceptible to malnutrition because they frequently depend on food aid that may for a variety of reasons be inadequate in both quantity and quality. The number of natural disasters has increased, due to more frequent extreme weather events. Aid donors routinely fail to provide all of the resources requested through UN humanitarian appeals.

\section{Causations and Linkages: Conceptual and Analytical Frameworks}

The costs of inaction are considerable, so efforts to accelerate progress against malnutrition in all its forms should have a high place on the global policy agenda. Inadequate dietary intake and disease are the immediate causes of malnutrition. Inadequate food consumption heightens vulnerability to infectious diseases, which, in turn, can keep the body from absorbing adequate food. These immediate causes stem from insufficient access to safe and wholesome food, poor maternal and child rearing practices and inadequate access to clean drinking water, safe sanitation and health services. Ultimately, these factors are embedded in the larger political, economic, social and cultural environment. Food insecurity, ill health and suboptimal caring practices are all closely related to poverty. Poor people generally consume fewer than 2,100 calories per day. Lower-income households experience significantly higher rates of preschooler stunting and illness and worse caring practices than better-off families. Taken together, chronic and acute child malnutrition, low birthweights, suboptimal breastfeeding and micronutrient deficiencies lead to the deaths of 3.6 million mothers and preschool children each year, accounting for 35 percent of all preschooler deaths and 11 percent of the global disease burden. Difficult pregnancies and illnesses due to malnutrition cost developing countries $\$ 30$ billion annually. Lost productivity and income resulting from early deaths, poor school performance, disability and absenteeism raise the yearly total into the hundreds of billions of dollars. Malnutrition also reflects and contributes to inequity, disproportionately affecting poor, marginalized and extremely vulnerable groups. While the policies and programmes needed to address malnutrition will require substantial resources, the costs of not tackling malnutrition are considerable. Furthermore, food insecurity and malnutrition infringe on the human right to adequate food.

\section{Future Challenges and Major Issues and Risks}

In addition to climate change and rising bioenergy demand, the following factors will constrain efforts to reduce malnutrition in the coming years:

- demographic forces;

- widespread land degradation and scarcity of fresh water resources, resulting from both bad management practices, inappropriate land uses for a certain land class and impacts from climate change and extreme climate variations;

- structural shifts in the food and agricultural system;

- transboundary movement of diseases;

- environmental and energy pressures. 
World population will increase by 37 percent, to 9.2 billion people by 2050 . Anticipated economic growth of 6 percent per year in developing countries during the next few years and rapid urbanization will also lead to increases in demand and structural shifts in diets.

Productivity growth in cereals, the main staple food crops, declined dramatically in the 1990s and continues to decline for maize. A major reason is underinvestment in agriculture by aid donors and developing-country governments.

The global food system has a dualistic structure. The vast majority of farms ( 85 percent) remain operations of less than two hectares. But the 0.5 percent of farms that exceed 100 hectares capture a disproportionate share of global farm income, enjoy privileged access to policy makers and, particularly in developed countries, receive generous subsidies. Outside of farming, buying power is increasingly concentrated in the hands of supermarkets and other powerful corporate actors. Preferences of affluent consumers in high- and middle-income countries are shaping global food and agricultural systems, offering smallholders opportunities and niche markets. However, they may face difficulties in being able to produce up to the standards of the buying agents.

Agricultural intensification, rapid growth in international trade and more frequent international travel offer opportunities to bolster rural livelihoods. However, there are also substantial risks from the spread of plant and plant pests, animal diseases and invasive species across international borders and climate change will heighten these risks.

Efforts to intensify agricultural production have helped boost food output, but some agricultural practices have taken a severe toll on the natural resource base. In the absence of a yield-boosting technological breakthrough, increases in food production will have to come from area expansion. That would require cultivation of fragile or marginal land and destruction of forests and wildlife habitat, causing biodiversity loss and increased greenhouse gas (GHG) emissions. Food and agricultural production faces growing competition for water from home and industrial use.

By April 2008, crude petroleum prices reached an all-time high of US\$120 per barrel and helped to raise demand for biofuels. This means increased costs for fertilizer, operating farm machinery and transportation of both inputs and output.

\section{Climate Change, Food Security and Nutrition}

The large and expanding populations in developing countries derive their livelihoods from agriculture and will, therefore, be especially vulnerable to climate change. Climate change and variability will have significant impacts on food security and malnutrition. They will lead to more intense and longer droughts and the frequency of heavy precipitation events has increased over most land areas. It is very likely that heat waves and heavy precipitation events will continue to become more frequent and that future tropical cyclones will become more intense. Droughts and water scarcity diminish dietary diversity and reduce overall food consumption and this may lead to malnutrition. The risk of flooding may increase, from both sea-level rise and increased heavy precipitation in coastal areas. This is likely to result in an increase in the number of people exposed to diarrhoeal and other infectious diseases, thus lowering their capacity to utilise food effectively. During the course of the $21^{\text {st }}$ century, water 
supplies stored in glaciers and snow cover are projected to decline, reducing water availability in regions that are home to one-sixth of the world's population.

Deforestation, agriculture and livestock production systems further accelerate climate change. The expansion of livestock and biofuel sectors has a major role in deforestation and land degradation. Vulnerability to adverse effects from climate change differs by region, ecosystem, population group and gender. The most vulnerable people will suffer earliest and most, so climate change should be addressed in a way that is fair and just and adherent to the human rights principles of non-discrimination and equality. The regions likely to be adversely affected are those already most vulnerable to food insecurity and malnutrition, notably SubSaharan Africa. In seasonally dry and tropical regions, crop productivity is projected to decrease with even small local temperature increases. In Africa, by 2020, 75-250 million people will be exposed to increased water stress due to climate change. In much of Africa, agricultural production and access to food are projected to be severely compromised.

Projected climate-change related exposures are likely to affect the health status of millions of people, particularly those with low adaptive capacity, through:

- increased deaths, disease and injury due to heat-waves, floods, storms, fires and droughts;

- increases in malnutrition;

- increased frequency of cardio-respiratory diseases;

- altered spatial distribution of some infectious-disease vectors; and

- increased burden of diarrhoeal diseases.

Due to the very large number of people that may be affected, malnutrition, linked to extreme climatic events, may be one of the most important consequences of climate change. Populations at greater risk of food insecurity include smallholder and subsistence farmers, pastoralists, traditional societies, indigenous people, coastal populations and artisanal fisherfolk. Men and women are affected differently in all phases of climate-related extreme weather. Many of the world's poorest people are rural women in developing countries who depend on subsistence agriculture to feed their families. Climate change could add to water and food insecurity and increase these women's work levels.

\section{Impacts on Food and Water Security and Nutrition}

There are many pathways through which climate change and variability may impact food and water security and nutrition:

- increased frequency of extreme climatic events;

- sea-level rise and flooding of coastal lands, leading to salination and or contamination of water and agricultural lands;

- impacts of temperature increase and water scarcity on plant or animal physiology;

- beneficial effects to crop production through $\mathrm{CO}_{2}$ "fertilization";

- influence on plant and livestock diseases and pest species and livestock diseases;

- damage to forestry, livestock, fisheries and aquaculture; and

- impaired sustainability: socio-economic, political/armed conflict and demographic impacts. 
Multiple socio-economic and environmental stresses, such as globalization, limited availability of water resources, loss of biodiversity, the HIV/AIDS pandemic and conflicts, are further increasing sensitivity to climate change and reducing agricultural resilience.

Climate change is likely to exacerbate the declining reliability of irrigation water supplies leading to increased competition for water. Water scarcity may lead to multiple adverse health outcomes, including waterborne diseases, exposure to chemicals, vector-borne diseases associated with water-storage systems and malnutrition. Drought and water scarcity can have negative effects on nutrition and the HIV/AIDS epidemic may further amplify these effects.

Children in poor rural and urban slum areas are at high risk of diarrhoeal disease mortality and morbidity. Childhood mortality due to diarrhoea in low-income countries, especially in subSaharan Africa, remains high and child malnutrition is projected to persist in regions of lowincome countries.

\section{Impacts on Food Security}

Climate change will affect all four dimensions of food security. Agricultural output in developing countries is expected to decline by $10-20$ percent by 2080 . Globally, the potential for food production is projected to grow with increases in local average temperature over a range of $1-3^{\circ} \mathrm{C}$, but above this it is projected to decrease. In seasonally dry and tropical regions, even slight warming $\left(1-2^{\circ} \mathrm{C}\right)$ reduces yield. Temperature increases of more than $3^{\circ} \mathrm{C}$ may cause food prices to increase by up to 40 percent. Temperature increases are leading to changes in the distribution of marine fisheries. Increases in atmospheric $\mathrm{CO}_{2}$ are raising ocean acidity. Rising seawater temperature is associated with increased densities of Vibrio spp in shellfish, which is a major cause of diarrhoea.

Changes in the patterns of extreme weather events will affect the stability of, as well as access to, food supplies. Increasing frequency of crop loss due to these extreme events may overcome positive effects of moderate temperature increases. For forests, elevated risks of fires, insect outbreaks and wind damage are projected. Food insecurity and loss of livelihoods would be further exacerbated by the loss of cultivated land and nursery areas for fisheries through inundation and coastal erosion in low-lying areas.

Climate-related animal and plant pests and diseases and alien invasive aquatic species will reduce food availability, influence production system stability and reduce food access through reduction of income from animal production, lower crop yields, lessened forest productivity and changes in aquatic populations, as well as increased costs of control.

Climate change may affect health outcomes and food utilization with additional malnutrition consequences. For example, populations in water-scarce regions are likely to face decreased water availability. Flooding, increased precipitation and higher temperatures are likely to increase the incidence of infectious and diarrhoeal diseases. Climate change is projected to increase the burden of diarrhoeal diseases in low-income regions by approximately 2-5 percent by 2020 . In the long term, in some areas the geographical range of malaria will contract due to the lack of the necessary humidity and water for mosquito breeding, but elsewhere, it will expand and the transmission season may be changed. It is estimated that in Africa, climate change will increase the number of person-months of exposure to malaria by 16-28 percent by 2100 which will affect food availability, access and utilization. 


\section{Climate Change and Sustainable Development}

Sustainable development can reduce vulnerability to climate change by enhancing adaptive capacity and increasing resilience. For example, sustainable intensification of livestock production can reduce GHG emissions and other negative environmental impacts. On the other hand, climate change can slow the pace of progress towards sustainable development, either directly through increased exposure to adverse impact or indirectly through erosion of the capacity to adapt.

\section{Social Impacts of Climate Change}

Smallholder and subsistence farming households in the dryland tropics are particularly vulnerable to increasing frequency and severity of droughts. These may lead to a higher likelihood of crop failure; increased diseases and mortality of livestock, indebtedness, outmigration and dependency on food relief; and impacts on human development indicators such as health, nutrition and education. Drought and the consequent loss of livelihoods are also a major trigger for population movements, particularly rural to urban migration. Population displacement to urban slums can lead to increases in diarrhoeal and other communicable diseases and poor nutritional status. The United Nations projects that up to 50 million people will flee environmental deterioration by 2020, possibly leading to food and water emergencies, ill health and malnutrition and increased likelihood of conflict.

\section{Adaptation and Mitigation Strategies}

Adaptation strategies to climate change for food security could be autonomous or planned. Many autonomous adaptation options are extensions or intensifications of existing riskmanagement or production-enhancement activities. There has been little evaluation of how effective and widely adopted these may actually be, given the complex nature of agriculture decision-making, the diversity of responses within regions and the possible interactions between different adaptation options and economic, institutional, human and environmental health and cultural barriers to change. Many options for policy-based planned adaptation to climate change have been identified for agriculture, forests and fisheries. These can involve developing infrastructure or building the capacity to adapt in the broader user community and institutions. Policy-based adaptations will interact with, depend on, or perhaps even be just a subset of policies on natural resource management, human and animal health, governance and human rights.

Agriculture, land use and waste account for 35 percent of GHG emissions. At the same time, agricultural practices can make a significant contribution at low cost to increasing soil carbon sinks and GHG emission reductions. Reduced deforestation, more sustainable forest management and adoption of agroforestry (integration of tree and crop cultivation) have particularly good potential to capture significant amounts of carbon and other GHGs and, at the same time, contribute to poverty reduction. Agroforestry helps maintain soil health through nitrogen fixation and provides fodder, fruit, timber, fuel, medicines and resins. This can help improve nutrition in cultivator households through higher incomes and more diverse diets. Improved waste management can enhance public health. However, not all the land can be in agroforestry, thus it is important to consider also the appropriate land-water management practices for a particular soil type and agro-ecosystems to reduce GHGs. 


\section{Nutrition and Bioenergy}

Rising petrol prices have made new biofuels, such as ethanol and biodiesel, an attractive alternative energy source. Technological development has recently made them more costeffective and energy-efficient, but biofuels offer only a very small gain in energy efficiency and their production minimally reduces GHG emissions. Research is underway to develop cellulosic biofuels from low value non-food crops, such as grasses or wood, but these are more difficult to process than starch or sugar crops and it is not clear that their production will expand significantly in the near future.

Biofuel production can have negative impacts on nutrition through increased GHG emissions that may result from burning forests to clear land for crop cultivation, as well as through direct effects on health and sanitation and reduced food availability and associated price effects.

Growth of the biofuel sector may lead to water shortages and contamination. Use of sugarcane as a feedstock is particularly water-intensive. Water scarcity in developing countries is a cause of concern for agricultural productivity, health and sanitation. Poorly managed input use in energy crop cultivation could pollute drinking water, adversely affecting human and animal health. Increasing prices are leading to the diversion of food and feed crops to biofuel production. This can reduce food availability and may consign food and feed production to less productive land, reducing yields.

In relation to such effects, the International Food Policy Research Institute (IFPRI) estimates that rising bioenergy demand accounted for 30 percent of the increase in weighted average grain prices between 2000 and 2007. The impact was 39 percent of the real increase in maize prices.

A rise in the food bill for households that are net buyers of food may lead to the substitution of starchy staples for micronutrient-rich animal source foods, legumes, processed foods, fruits and vegetables and to a reduction in the average number of meals and the amount of food consumed and therefore to reduced micronutrient intakes among poor people. Extremely poor people will experience decreased calorie consumption. IFPRI projects that in 2020, if biofuel development proceeds at or exceeds its current pace, calorie availability will decline and child malnutrition will increase substantially, particularly in Sub-Saharan Africa.

Appropriate policies can make bioenergy development more pro-poor and environmentally sustainable. Poor farmers might be able to grow energy crops on degraded or marginal land not suitable for food production. Further investment is needed in developing technologies to convert cellulose to energy, which could provide smallholders with a market for crop residues. Biofuel production is labour-intensive, offering new job opportunities. Organizing groups of smallholders through contract farming schemes to grow and market biomass would be more pro-poor than plantation production. Technologies, institutional arrangements and bioenergy crop choice are important to determining impacts on poverty and the environment. Outgrower schemes could allow for technology spillovers to food crops, meaning additional growth and poverty reduction benefits, as well as increased food availability. There may be barriers to female farmers taking advantage of opportunities, as they have less access than men to land, water, credit, inputs and services. 


\section{Policies and Programmes for Improving Nutrition}

The ultimate causes of food insecurity and undernutrition are social, economic, cultural and political. Therefore, it is essential that efforts to achieve food security and good nutrition address these causes.

At the regional and national level, developing countries have issued national policies and plans of action on nutrition, but these often do not prioritize nutrition actions, assure adequate budgetary allocations, or incorporate appropriate specific actions to address the problems identified. Accelerated progress against food insecurity and malnutrition requires that governments put appropriate policy responses much higher on their agendas, with adequate resources provided. Brazil's Zero Hunger (Fome Zero) program shows the tremendous difference it makes when governments make food security and nutrition high priorities. Donors must provide technical and financial support. The potential impacts of climate change and bioenergy demand increase the urgency of action. Harmonised, large-scale, multicomponent programmes are required to make a difference and should include the following steps:

- create an enabling environment to promote peace, eradicate poverty and remove gender inequality;

- promote a fair and market-oriented world trade system;

- increase investments in human resources, sustainable food production systems and rural development;

- implement policies to improve physical and economic access by all to sufficient, nutritionally adequate and safe food and its effective utilization;

- focus on participatory and sustainable agriculture;

- use a "nutrition lens" to direct multi-sectoral actions to improve household food security; improve food quality and safety; prevent, control and manage infectious diseases and micronutrient deficiencies; promote appropriate diets, including breastfeeding and healthy lifestyles; provide care for the vulnerable, including people living with HIV/AIDS; introduce productive safety nets; and provide direct assistance;

- prevent and prepare for emergencies; and

- build anti-hunger alliances.

\section{Governance Issues}

A number of governance issues have a considerable bearing on food security and nutrition. Both food security and nutrition are multi-sectoral issues, but developing country governments are composed of sectoral ministries that frequently view budgetary allocation as a zero-sum game. Nor do senior policy-makers always recognize the costs of undernutrition. Many developing countries lack adequate human resources. A fragmented and incoherent international nutrition system complicates these problems.

Resources for nutrition are inadequate. Annual donor funding runs at less than US\$300 million, compared to US $\$ 2.2$ billion for HIV/AIDS and several billion dollars in food aid. In real terms, aid to agriculture is about half the level of 25 years ago. Governments of lowincome countries devote 19 percent of their budgets to military expenditures, compared to less than 5 percent for agriculture. Military expenditures account for 2.6 percent of GDP in lowincome countries, compared to one percent for public health. There are some indications that priorities are changing. The African Union seeks to boost agriculture to 10 percent of member 
budgets and bring agricultural growth to six percent per year. The World Bank is putting renewed stress on both nutrition and agriculture.

There is an urgent need to reform the global humanitarian response, for example by moving towards a more insurance-oriented approach that guarantees a rapid response.

\section{A Revitalised Twin Track Approach}

At the International Conference on Financing for Development held in 2002, FAO, the International Fund for Agricultural Development (IFAD) and the World Food Programme (WFP) agreed upon a "twin-track approach" for combating hunger and poverty: strengthening the productivity and incomes of hungry and poor people, targeting the rural areas; and direct and immediate access to food by hungry people and social safety nets. The latter include food transfers, conditional and unconditional cash transfers and public work programmes and may be targeted or universal.

Introducing improved water management, use of green manures, agroforestry and other lowcost, simple technologies not only enhances the productivity and incomes of small farmers, but also their role as stewards of natural resources. Investing in rural infrastructure can reduce the lethal impact of water-borne illnesses, improve access to health care, prevent thousands of needless child and maternal deaths and open links to markets where farmers can sell surplus produce and acquire fertilizer and other inputs at reasonable prices. Measures to provide direct access to food for the neediest families such as feeding programmes for mothers and infants target the hub of the vicious cycle of hunger and malnutrition that undermines maternal health, stunts children's physical and cognitive growth, impairs school performance and impedes progress towards gender equality and the empowerment of women.

High food prices exacerbate food insecurity and create social tensions, but high agricultural commodity prices also present a potential opportunity for reversing the decline in public investment in agriculture. More food needs to be produced where it is urgently needed to contain the impact of soaring prices on poor consumers and simultaneously boost productivity and expand production to create more income and employment opportunities for rural poor people. Smallholder farmers need to have proper access to resources, infrastructure and services. This will allow them to increase their supply response to higher prices. Agricultural research needs to enhance its focus on mitigation of and adaptation to climate change and on pro-poor biofuel development. Increased agricultural productivity can increase food availability, rural employment and access to food by reducing prices. Agricultural growth will stimulate growth in other sectors. Appropriate policies and institutions, such as organization and collective action, can help facilitate smallholder participation in value chains on a fair basis. Agricultural and rural development strategies must recognize the important roles that women play in food security and nutrition and take into account the need for sustainable natural resource management.

FAO needs to retain its focus on a twin-track approach. This now needs to be made more explicit to ensure that policies and programmes are put into effect to boost supply, not only by the larger commercial farmers but also targeted to smallholders, while at the same time designing social protection and safety nets that protect the vulnerable and direct nutrition interventions. 


\section{Direct Nutrition Interventions}

Good nutrition makes an essential contribution to the fight against poverty. It protects and promotes health; reduces mortality, especially among mothers and children; encourages and enables children to attend and benefit from school; and enhances productivity and incomes in adulthood. The increased participation of poor and vulnerable people and of women in the development process that may arise from effective community nutrition programmes will likely lead to more effective demands for improved services and to better use of existing resources.

With regard to preschooler malnutrition, the crucial "window of opportunity" is from conception through the first 18-24 months of a child's life. Effective interventions targeting infants and young children include improving food consumption and nutrient intakes through improved complementary feeding and dietary diversity, breastfeeding promotion, salt iodisation, vitamin A and zinc supplementation, vitamin A fortification, hand-washing and hygiene interventions and treatment of severe acute malnutrition. Interventions should not neglect other age groups, other family members, or low-income childless households who may equally be in need of support. The care of adolescent girls and pregnant women is vital for protecting their own health and that of their future children.

A new approach to tackling micronutrient malnutrition is through "biofortification," which involves developing micronutrient-dense crop varieties. Breeding efforts also aim to develop varieties with agronomically desirable traits. Biofortification may be more sustainable than supplementation or fortification, as it has lower recurrent costs.

For those living with the disease, better nutrition can postpone HIV/AIDS-related illnesses, such as diarrhoea, pneumonia and tuberculosis. Nutrition policies can provide incentives for improving diets, for strengthening the nutrition focus of health services and for ensuring nutritionally balanced food aid as a safety net.

\section{Educating Girls}

IFPRI research has shown that improvements in girls' education had the biggest impact on reducing child malnutrition in developing countries during 1970-95, but at present, 100 million primary school-aged children are not enrolled and 57 percent of these children are girls. School meals and food-for-education programs can help achieve full enrolments, educational gender equality and improved food security.

\section{Priorities and Approaches for Responding to Threats to Nutrition from Climate Change and Biofuel Demand}

A combination of adaptation and mitigation measures, sustainable development and research to enhance both adaptation and mitigation can diminish the threats to nutrition from climate change. On average, cereal cropping system adaptations such as changing varieties and planting times enable avoidance of a 10-15 percent reduction in yield corresponding to a 1 to $2^{\circ} \mathrm{C}$ local temperature increase. The benefits of adaptation tend to increase with the degree of climate change up to a $3^{\circ} \mathrm{C}$ temperature increase, at which point adaptive capacity in low latitudes is exceeded. Changes in policies and institutions will be needed to facilitate adaptation. Adaptation measures should be integrated with development strategies and programmes. The development of adaptation strategies should consider that adaptation 
capacity depends on geographical situation, economic development, natural resources, social context, institutions, governance and technology. With regard to mitigation, financial incentives can help promote improved land management, maintenance of soil carbon content and efficient use of fertilizers and irrigation. This could encourage synergy with sustainable development and reducing vulnerability. It can also help improve the health environment. Incentives to improved waste management, as well as stronger regulation, would improve the sanitary environment. Sustainable development can reduce vulnerability to climate change by enhancing adaptive capacity and increasing resilience. Sustainable development should promote adaptive and mitigation strategies.

Agriculture, food and nutrition issues need to be placed onto national and international climate change agendas, in order to devise effective and pro-poor policies. The expiration of the Kyoto Protocol in 2012 offers an opportunity to bring these issues to the table. FAO and other international organizations should assist countries to assess capacity building needs. Adopting a human rights' perspective when tackling the challenge of climate change puts people at the centre of attention of decision-making. Sustaining and protecting the environment against degradation will be enhanced through the protection and promotion of human rights. At the same time, human rights cannot be fully realized without securing ecosystem services.

Biofuel production in developing countries should be carefully designed, so as not to crowd out other development investments. Policies should ensure that smallholders, including women farmers, have access to resources so that they can participate in biofuel production on a fair basis. Policies need to examine and regulate the environmental consequences of biofuel development. Increased investment in agricultural productivity will help developing countries increase their own food production and be able to engage in the biofuel market. Global cooperation is needed on $R \& D$ to bring technologies on line that will allow production of biofuels from non-food crops. Developed-country governments should remove trade barriers to developing-country biofuel exports and, along with international organizations such as FAO and the international financial institutions, provide financial and technical assistance to pro-poor, sustainable biofuel projects in developing countries. Developing-country governments need to conduct food security and nutrition impact assessments before launching biofuel projects. 


\section{Introduction}

\section{Purpose of Paper}

Despite a dozen years of solemn pledges by global leaders to take action to drastically decrease world hunger - promises made at the World Food Summit in 1996, the Millennium Summit of 2000 and high-level follow-up meetings held during the course of the present decade - food security in the world has deteriorated since 1995. This has contributed to the unacceptably slow pace of cutting the prevalence of malnutrition: between 1990 and 2005, the prevalence of child underweight in the developing world only fell from 30 to 23 percent. At that rate, it will not be possible to meet the Millennium Development Goal (MDG) target of halving the underweight prevalence between 1990 and 2015.

Against this very disappointing background, three major challenges have arisen that threaten to drastically complicate efforts to overcome food insecurity and malnutrition: climate change, the growing use of food crops as a source of fuel (bioenergy) and soaring food prices. As a result of climate change, agricultural production and the availability of and access to food are likely to decline drastically in Sub-Saharan Africa and South Asia. That will increase the risk of hunger and malnutrition in the two regions that are home to three of every five undernourished people. Furthermore, climate change is expected to increase undernutrition through its effects on illnesses, such as diarrhoea and other infectious diseases. The expected increases in the frequency and intensity of droughts and floods and their potential impact on crops and cattle losses are especially worrisome. Drier weather may reduce the transmission of malaria in some places in Sub-Saharan Africa, while in others, the geographical range will expand and the transmission season may be changed (Metz et al., 2007).

For its part, rising bioenergy demand is likely to affect nutrition through a number of pathways. First, production of staple food crops, particularly maize, for biofuel markets can have a negative impact on the availability of grain for direct consumption as food and for use as feed for livestock to produce meat and milk. As demand for biofuels is likely to remain high and to be met with food crops for the foreseeable future, this may lead to the clearing of biodiversity-rich land for cultivation, including tropical forests and wetlands. Burning of forests will mean additional emissions of the greenhouse gases (GHGs) that cause global warming. Intensified production of energy crops such as sugarcane, as well as increased cereal production to meet competing demand for food, feed, fibre and fuel, may mean excessive or poorly managed use of water and farm chemicals, causing illnesses and deterioration in environmental health, with negative implications for nutrition.

In addition, bioenergy demand is a significant driver of recent dramatic increases in food prices; according to an analysis by IFPRI, it accounted for 30 percent of the escalation in global cereal prices between 2000 and 2007 and for nearly 40 percent of the increase in the real global price of maize (Rosegrant, 2008). Increased food prices are likely to result in calorie deficits, but even more importantly, they will probably cause micronutrient malnutrition, as low-income people may reduce their consumption of micronutrient-rich foods (such as animal products, fruit and vegetables) in an effort to maintain consumption of increasingly expensive staples. Jean Ziegler, the former Special Rapporteur on the Right to Food of the UN Human Rights Council, has gone so far as to call the growing use of food crops to produce biofuels "a crime against humanity" (Ferrett, 2007). 
Nevertheless, strong bioenergy demand also offers opportunities to smallholder farmers. If the right policies are in place, they may be able to boost their incomes and take advantage of technological spillovers to improve food crop production alongside their energy crops. This has positive implications for both food availability and access, key inputs for good nutrition.

A human rights-based approach - a conceptual framework that is normatively based on international human rights standards and operationally directed to promoting and protecting human rights - can provide the tools for balancing many factors, reaching easier consensus and conducting a more effective and complete analysis, as well as a more authoritative basis for advocacy and for claims on resources. The human rights framework also offers the opportunity of embracing environmental concerns more explicitly and is thus highly relevant to assessing the challenges of climate change and bioenergy for nutrition.

To explore these issues in greater depth, the Food and Agriculture Organization of the United Nations (FAO) has organized a special event on Climate Change and Bioenergy: Implications for Nutrition, Food Safety and Human Health, to be held during the High-Level Conference on World Food Security: The Challenges of Climate Change and Bioenergy, on 5 June 2008 in Rome. This paper is one of three background documents prepared for this side event. It was jointly written by teams from FAO and the International Food Policy Research Institute (IFPRI). The paper examines the consequences of climate change and rising bioenergy demand for sustainable development, food security and nutrition throughout the lifecycle.

\section{Concept and Content}

The paper begins by laying out the current state of global food insecurity and malnutrition, including magnitude, trends and future projections. The causes, consequences and costs of food insecurity and malnutrition are explored. Malnutrition is clearly a severe impediment to sustainable development and human security as it slows down economic growth and the achievement of equity. The paper briefly lays out a number of factors besides climate change, bioenergy and rising prices that will likely contribute to malnutrition in the future.

The paper then explores the implications of climate change and rising bioenergy demand for nutrition. Agricultural activities contribute to climate change, but can also play an important role in adaptation and mitigation strategies, as well as in boosting food availability.

Next, the paper examines the direct nutrition effects of rising bioenergy demand, as well as its contribution to rising food prices. It also discusses potential strategies for cultivation of bioenergy crops that can contribute to poverty reduction, food security and sustainable natural resource management.

A chapter on policy implications provides a number of options for improving food security and nutrition, as well as for addressing the links between climate change and bioenergy demand on the one hand and nutrition on the other. The paper concludes with recommendations. 


\section{World Food Insecurity and Malnutrition: Scope, Trends, Causes and Consequences}

\section{Dimensions of the Nutrition Problem}

Apart from any consideration of the impact of current and future climate change and bioenergy demand, the world food security and nutrition situation and outlook are worrisome. Food insecurity and malnutrition represent serious impediments to sustainable development, poverty reduction, equity and achievement of the Millennium Development Goals (MDGs).

Food security exists when all people, at all times, have physical and economic access to sufficient, safe and nutritious food to meet their dietary needs and food preferences for an active and healthy life (FAO, 1996). It has four dimensions (see Figure 1): food availability, access to food, stability of supply and access, and safe and healthy food utilization. Stability depends on food production, incomes, markets and transfer programmes (both public and private) and can be adversely affected by shocks due to weather, price fluctuations, humaninduced disasters and political and economic factors. Utilization refers to the proper use of food and includes the existence of appropriate food processing and storage practices, adequate knowledge and application of nutrition and child care and adequate health and sanitation services (FAO, 2000; FANTA, 2006). Food security is a key factor in good nutrition, together with health, sanitation and care practices (Figure 1).

With regard to food availability, present global food supplies are more than adequate to provide everyone with all the calories he or she needs for an active and healthy life, if the food were equally distributed. As Figure 2 indicates, per capita daily calorie availability currently exceeds 2,100 (the average energy requirement for adults undertaking light activity) in all global regions, though barely so in Sub-Saharan Africa. However, this abundance of food is not, in fact, equally distributed, so hundreds of millions of people in developing countries actually consume less than their minimum requirements. According to the latest data, over 820 million people in developing countries are undernourished, i.e., their diets are calorie-deficient. More than 60 percent of these food insecure people live in South Asia and Sub-Saharan Africa, which form hunger's centre of gravity (Figure 3). This can be viewed as an infringement on the human right to adequate food, which implies availability and accessibility of food in sufficient quantity for all (UNCESCR, 1999).

Ironically, fully half of all food-insecure people are small farmers. Even though they grow food, they lack the resources to meet all of their needs through either production or purchase. Another 30 percent of hungry people are fishers, herders, or landless rural people and the remainder are poor urban dwellers (UN Millennium Project, 2005).

\section{Hidden Hunger}

Even if a person consumes enough calories, this does not guarantee adequate intake of essential micronutrients - vitamins, minerals and trace elements. Micronutrient malnutrition often called "hidden hunger" because it is not readily apparent from clinical signs of a wasted body - afflicts a far greater swath of humanity than insufficient calorie intake. 
Figure 1

FAO/FIVIMS Framework: linkages between the overall development context, the food economy, households and individual measures of wellbeing

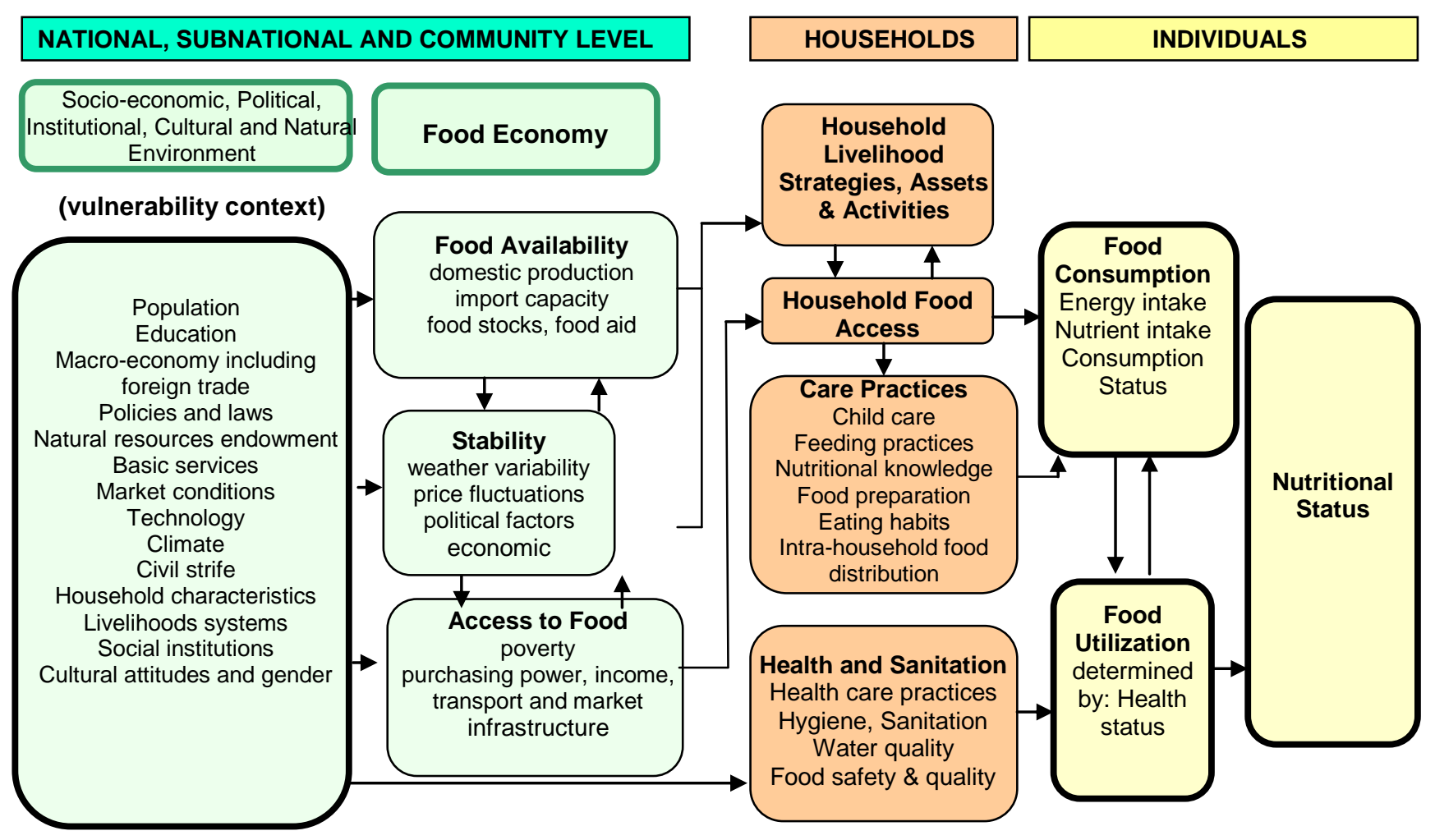

Source: FAO (2000).

Moreover, insufficient calorie consumption often goes hand-in-hand with micronutrient malnutrition (FAO, 2004). Micronutrient deficiencies can have grave public health consequences (as noted below). Micronutrient malnutrition can likewise be viewed as an infringement on the human right to adequate food, which implies availability and accessibility of food in quality sufficient to satisfy the dietary needs of everyone (UNCESCR, 1999).

Over one billion people consume diets deficient in iron (Trowbridge and Martorell, 2002). Iron deficiency is responsible for roughly half of the global prevalence of anaemia, which affects about half of all pregnant women, 56 percent of pregnant women in developing countries and over three-quarters of pregnant women in South and Southeast Asia, as well as 63 percent of preschool children in the latter two regions and 39 percent of all developingcountry preschoolers (ACC/SCN and IFPRI, 2000; Harvest Plus, 2007). 
Figure 2: Foods Available for Consumption (kcal/cap/day)

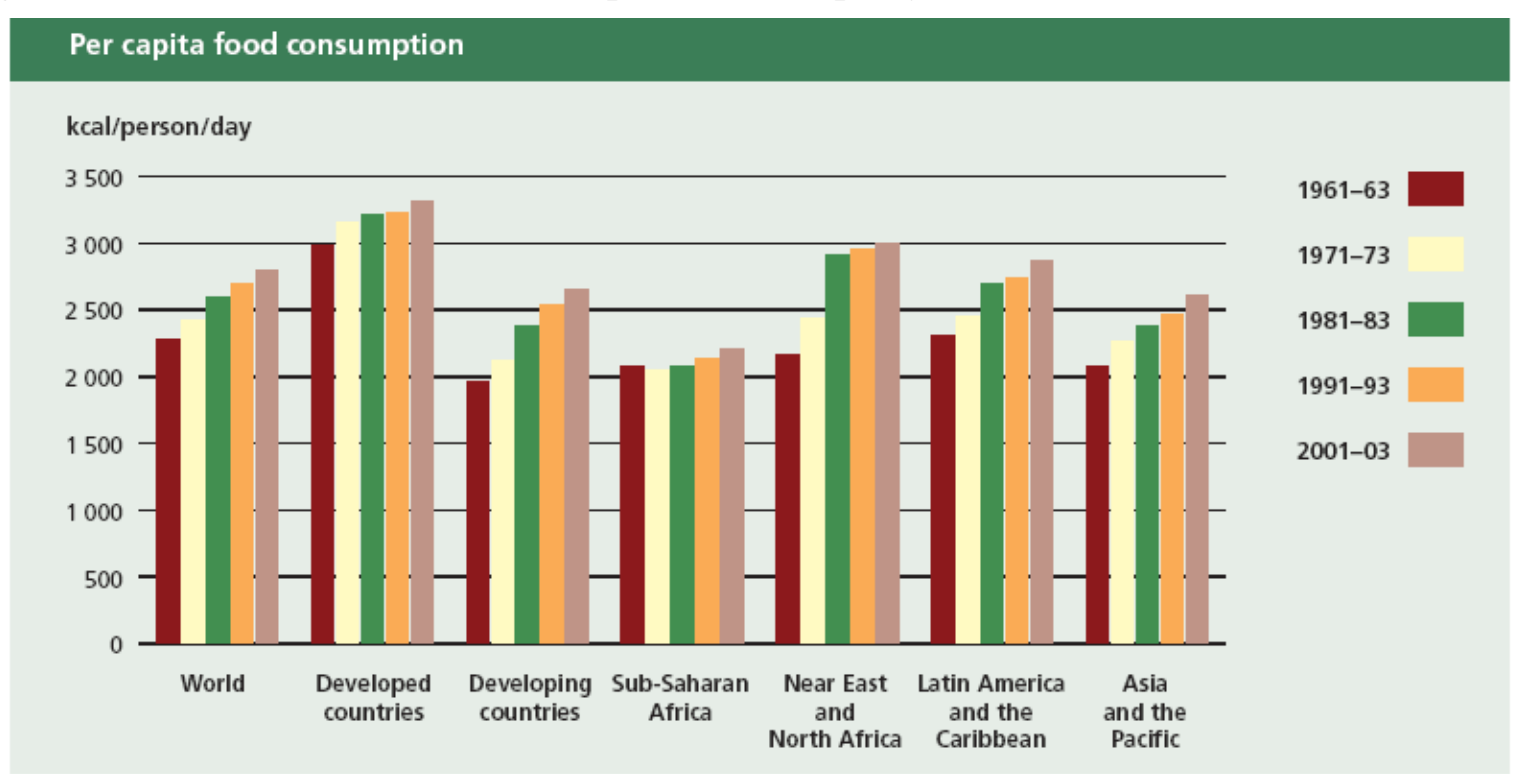

Source: FAO (2007).

Figure 3

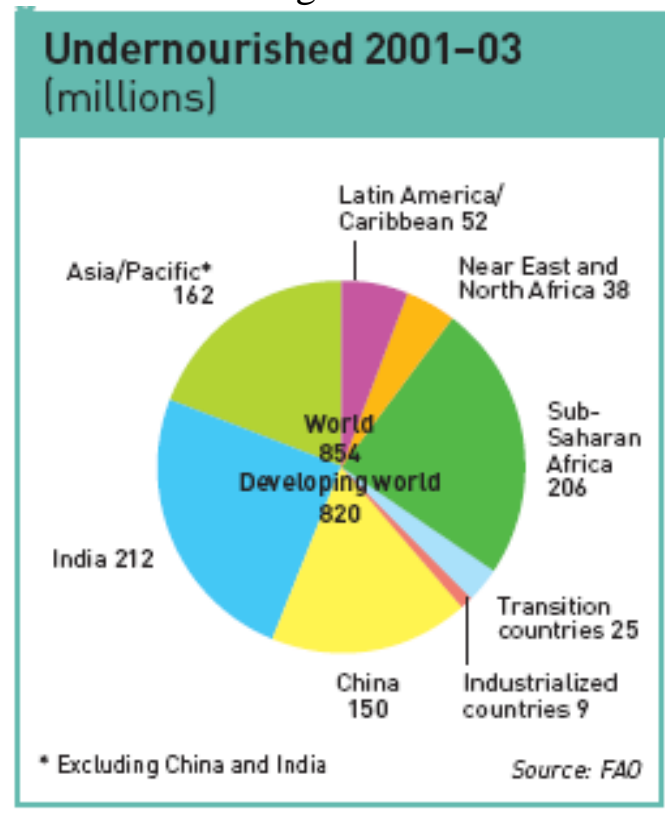

Around 115,000 women die in childbirth each year as a result of iron deficiency anaemia, accounting for 20 percent of global maternal mortality (ACC/SCN and IFPRI, 2000; Black et al., 2008). Anaemic mothers are more likely to deliver prematurely, to deliver babies with low birthweights and to have babies who die as newborns. Anaemia among children can impair health and development, limit learning capacity, impair immune systems and reduce adult work performance. Iron deficiency can reduce work performance even if it does not result in anaemia (ACC/SCN and IFPRI, 2000). 
Lack of adequate iodine in maternal diets can lead to spontaneous abortion and stillbirths. The children who survive face cretinism, a serious and irreversible form of mental retardation, as well as milder retardation (WHO, 2006).

Insufficient vitamin A intake among developing-country children causes blindness and contributes to infections and death. About 20 million pregnant women in developing countries have vitamin A deficiency (VAD); they face increased risk of mortality and mother-to-child HIV transmission, as well as blindness (WHO, 2001). VAD impairs the immune system of about 40 percent of the children under the age of five in developing countries, causing about one million child deaths annually. In India, the prevalence of VAD among preschoolers is 60 percent. The prevalence of VAD declined in all developing regions during the 1990s, but at extremely slow rates and has remained unchanged in Sub-Saharan Africa since the mid-1990s (MI and UNICEF, 2005).

Inadequate dietary zinc can lead to stunting (i.e., lower than expected height for one's age) and greater susceptibility to infections. Over 60 percent of the populace of the developing world is thought to be at risk of low zinc intake; the figure is 70 percent in Southeast Asia and fully 95 percent in South Asia (de Benoist et al., 2007).

\section{The Deadly Scourge of Child Malnutrition}

Malnutrition takes a particularly severe toll among preschool children. One in three developing-country preschoolers - 178 million children under the age of five - suffers stunting as a result of chronic undernutrition (Black et al., 2008). Eighty-percent of these children live in just 20 countries in Africa and the Asia-Pacific region (see Box 3.1). In India, 61 million preschoolers (51 percent of the children under the age of five) are stunted. Both the number and the prevalence of under-five stunting in India exceed the figures for all of Africa (57 million and 40 percent) (Black et al., 2008).

\section{Box 3.1: Twenty countries are home to 80 percent of the world's stunted preschoolers}

\section{Africa}

Democratic Republic of Congo

Egypt

Ethiopia

Kenya

Madagascar

Nigeria

South Africa

Sudan

Tanzania

Uganda

\section{Asia-Pacific}

Afghanistan

Bangladesh

India

Indonesia

Myanmar

Nepal

Pakistan

Philippines

Viet Nam

Yemen

Source: Bryce et al. (2008). 
Stunting is associated with higher rates of illness and death, reduced cognitive ability and school performance in children and lower productivity and lifetime earnings for adults. Indeed, height-for-age among two-year-olds is the best predictor of adult human and physical capital. Chronic malnutrition during the first two years of life usually results in irreversible harm. Children become stunted not only as a result of insufficient calorie intakes, but also because of poor quality diets. Children who become stunted in the first two years of life and gain weight rapidly after that may be at high risk of nutrition-related chronic diseases, such as obesity, diabetes and hypertension (Hoddinott et al., 2008; Victora et al., 2008; World Bank, 2006; FAO, 2004).

Another 55 million preschool children in developing countries are wasted (i.e., they have lower than expected weight for their height) due to acute malnutrition. Severe wasting afflicts more than a third of these children (19 million) (Black et al., 2008).

Each year, over 19 million babies are born in developing countries with low birthweights (less than 2.5 kilograms), accounting for 16 percent of the developing world's annual births. In South and Central Asia, the figure is 27 percent. These children face four times the risk of neonatal death of those with normal birthweights and if they survive, they have much higher rates of illness and stunting in both childhood and as adults (Black et al., 2008; FAO, 2004).

\section{Nutrition Throughout the Lifecycle}

As Figure 4 indicates, at each stage in the lifecycle, malnutrition has consequences for each successive stage and/or the next generation, particularly among low-income households in developing countries. Mothers who suffer chronic caloric or micronutrient deficiencies are more likely to have low birthweight babies: in effect, they pass their malnutrition on to the next generation (Black et al., 2008; World Bank, 2006; FAO, 2004). These mothers also face increased risk of death in childbirth. Low birthweight babies face higher mortality rates, impaired mental and physical development and increased risk of adult chronic diseases. If these conditions are combined with poor care and feeding practices, inadequate food and health and, as a result, frequent infections, the child will either die prematurely or face high risk of reduced mental capacity. Stunted children living with inadequate food, health and care remain stunted as adolescents and face reduced physical capacity. The girls among them, with continued inadequate food, health and care, grow up too often as another generation of malnourished mothers who have low birthweight babies of their own. Adults affected by malnutrition may have a low body mass index or nutritional oedema (retention of fluid). If malnourished adults continue to have inadequate food, health and care into old age, they remain malnourished and are less able to assist in caring for children (Victora et al., 2008; SCN, 2004).

\section{HIV/AIDS and Nutrition}

HIV/AIDS currently affects 33 million people, 70 percent of whom are in Sub-Saharan Africa and is spreading rapidly in some other developing regions (UNAIDS, 2007). The disease interacts negatively with malnutrition. Poor nutrition and food insecurity can accelerate the spread of HIV, both by increasing people's exposure to the virus and by increasing the risk of infection following exposure. In turn, HIV infection can lead to nutritional deficiencies through decreased food intake and malabsorption, which hasten the onset of AIDS. The disease impairs the immune system and so can lead to additional infections, such as 
tuberculosis and malaria that worsen nutritional status and may be fatal (Gillespie and Kadiyala, 2005).

Figure 4: Nutrition throughout the life cycle

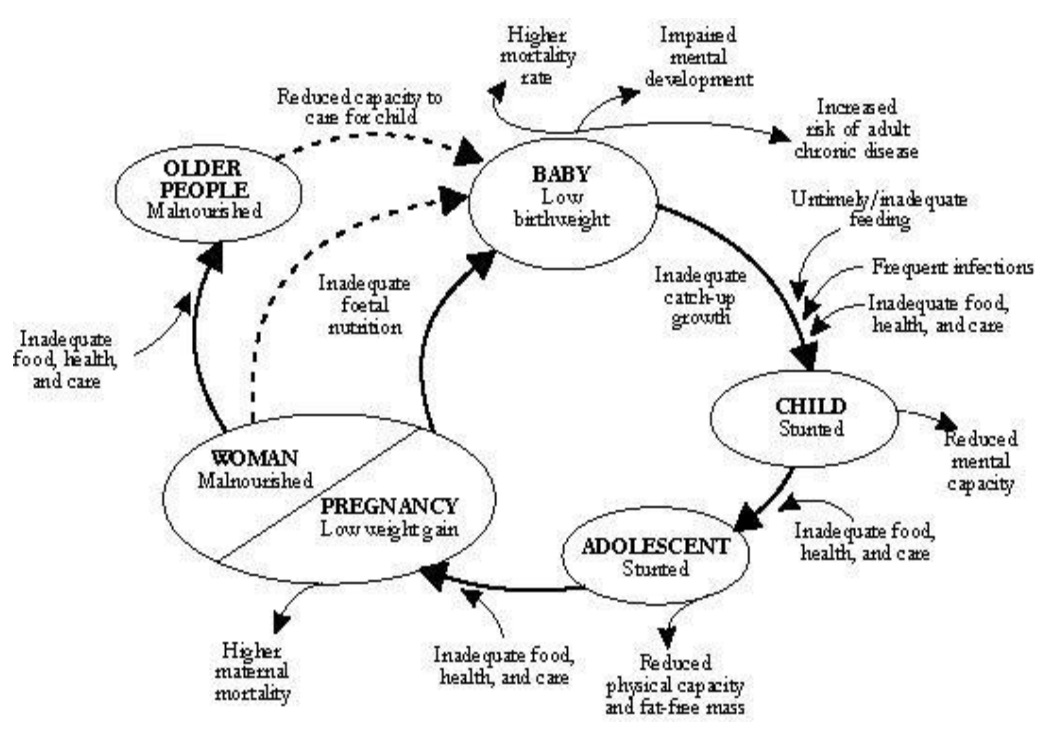

Source: ACC/SCN and IFPRI (2000).

\section{Water, Sanitation, and Nutrition}

Efforts to achieve the MDG hunger target aim principally at increasing food and therefore caloric intakes among the hungry. But the human energy balance depends on caloric use as well as on caloric intake. Many impoverished people expend significant calories collecting water over great distances or waste them because their bodies are unable to absorb food properly because of diarrhoeal disease. Populations suffering from hunger are often the same as those that lack adequate water and sanitation. Globally, one billion people are currently without access to safe water and over 2 billion lack adequate sanitation facilities. ${ }^{1}$ Roberto Lenton, former director of the UN Development Programme's (UNDP) Sustainable Energy and Environment Division has commented, "We need to develop strategies ensuring that policies that target caloric intake are accompanied by strategies to reduce caloric losses through better water, sanitation and hygiene" (Rahman, 2008).

\section{Hunger Crises}

In 2008, the United Nations is appealing for food and other humanitarian assistance for 25 million people in 24 countries affected by conflict and its aftermath or serious political and economic breakdown (OCHA, 2007). Refugees and internally displaced people are particularly susceptible to malnutrition because they frequently depend on food aid rations that are often inadequate in both quantity and quality. An analysis of 41 mortality and

\footnotetext{
${ }^{1}$ See HTTP://WWW.WSSINFO.ORG/EN/WELCOME.HTML, website of the World Health Organization/UN Children's Fund Joint Monitoring Programme for Water Supply and Sanitation.
} 
malnutrition surveys carried out in refugee camps in 2005 found that half indicated an acute malnutrition emergency and among these emergency situations, 90 percent featured a "critical" prevalence of global acute malnutrition, in excess of 15 percent (CE-DAT, 2006). According to the Office of the UN High Commissioner for Refugees, micronutrient deficiencies are widespread in camps due to unbalanced rations. For example, lack of B vitamins is a serious problem in camps in Nepal and Bangladesh (UNHCR, 2005). Nevertheless, aid donors routinely fail to provide all of the resources called for in UN humanitarian aid appeals (Figure 5). The UN Office for the Coordination of Humanitarian Affairs reports that in 2007, donors provided just 72 percent of the amount requested for all sectors in its consolidated appeal for complex emergencies (those due to conflict and related causes) and flash appeals for natural disasters. Although the food aid response was somewhat better at 88 percent, neither water and sanitation nor health appeals (both nutrition-related) garnered even 50 percent of the requested funds (OCHA, 2008). In April 2008, the WFP informed donors that it would immediately need an additional $\$ 755$ million just to maintain current commitments, due to skyrocketing food prices (Sullivan, 2008).

Figure 5

UN Humanitarian Appeals and Donor Response (US\$)

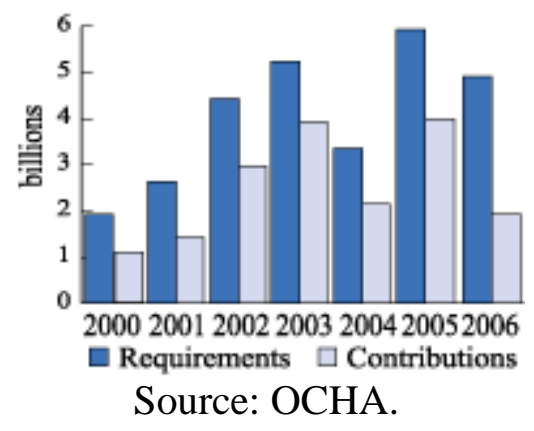

\section{Unacceptably Slow Progress in Reducing Hunger and Malnutrition}

The world is not making sufficient progress toward meeting the 1996 World Food Summit goal of halving the number of undernourished people (i.e., those with calorie deficient diets) from 1990 levels by 2015 and progress on the MDG target of cutting the proportion of people living in hunger to half of the 1990 level by that same year is uneven. The UN Millennium Project has adopted two indicators to measure progress toward the MDG target: the prevalence of underweight ${ }^{2}$ among children under five years of age and the undernourished proportion of the total population.

Although the number of undernourished people slowly but steadily declined between 1970 and 1990, since 1995, the number has actually increased (Figure 6). As a result, the total number of undernourished people in developing countries was only marginally changed from 1990 levels by 2003, the last year for which data are available ( 820 million people vs. 823 million). In contrast, the proportion of undernourished people in the total population of developing countries declined during the same period from 20 to 17 percent (FAO, 2006a).

\footnotetext{
${ }^{2}$ See HTTP://WWW.UNMILLENNIUMPROJECT.ORG/GOALS/GTI.HTM\#GOAL1. "Underweight" means children with lower weights than expected for their age. Unlike stunting and wasting, it does not distinguish between the effects of chronic and acute malnutrition.
} 
As Figure 7 indicates, these disappointing aggregate figures mask substantial progress against hunger in some regions and understate the alarming increases in the number of undernourished people in others. Tens of millions of people in China achieved freedom from hunger during 1990-2003, while Southeast Asia and South America also recorded substantial gains. However, large increases in the undernourished populations of South Asia outside India, Eastern Africa and the Near East, plus a doubling of the ranks of the hungry in Central Africa (driven by war and political chaos in the Democratic Republic of the Congo) offset these gains (FAO, 2006a).

Figure 6

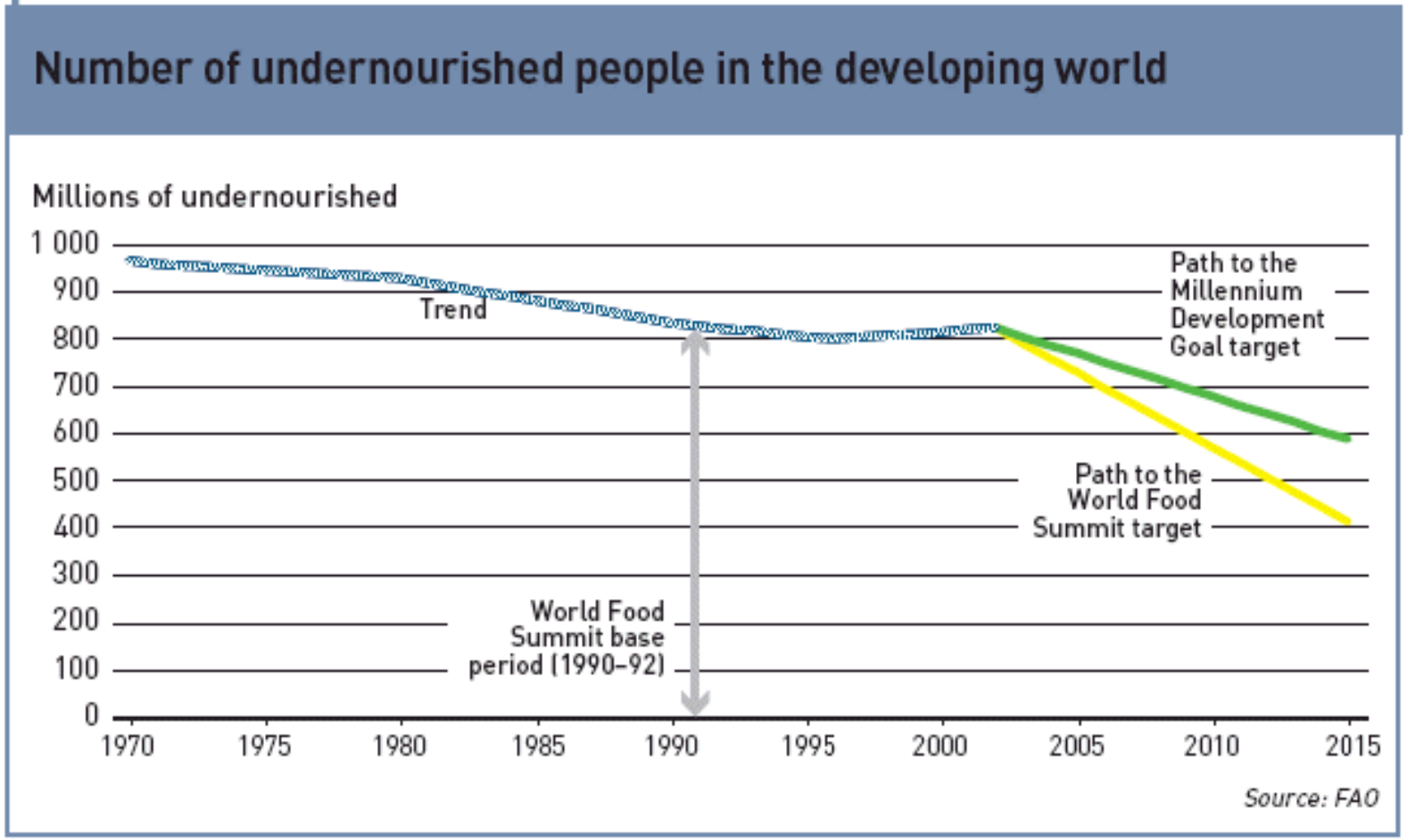

Figure 7

\section{Changes in number of undernourished \\ in subregions from 1990-92 to 2001-03}

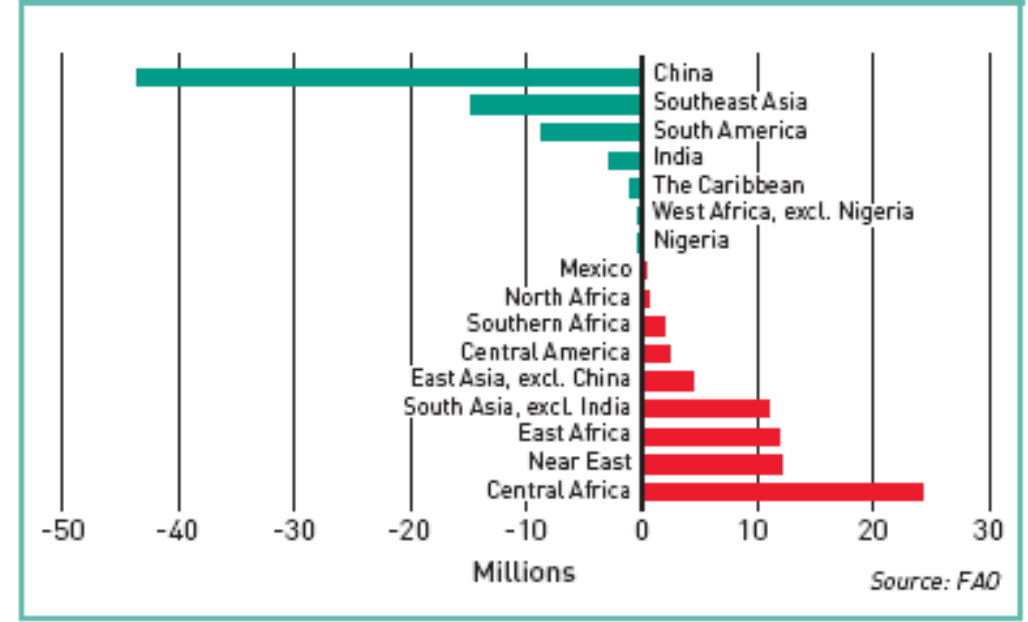


The Food and Agriculture Organization of the United Nations projects that the developing world as a whole and most of its regions will fall short of the World Food Summit hunger reduction goal in 2015 and that more people will be undernourished than in 1990 in SubSaharan Africa and the Near East. However, East and Southeast Asia will succeed in cutting their undernourished populations beyond the target, due to policies emphasizing growth with equity in many countries of the region. The developing world is projected to meet the MDG target on cutting the undernourished proportion of its population, reducing the level by a bit more than half, with Latin America and the greater Asia-Pacific region on target and SubSaharan Africa and the Near East falling short (Table 1).

Between 1990 and 2005, the prevalence of underweight among children under the age of 5 in developing countries fell from 30 percent to 23 percent. That rate of reduction is inadequate to achieve the MDG target of halving the prevalence from 1990 levels by 2015. Moreover, child malnutrition increased in Sub-Saharan Africa while it declined in the rest of the developing world. Again, however, both the number of malnourished children (67 million) and the prevalence of child malnutrition (37 percent) in South and Central Asia exceeded the levels for all of Africa (34.5 million and 25 percent) (SCN, 2004). This disparity is known as the "Asian enigma," because on most indicators of human wellbeing (access to safe water, school enrolment, food availability per person, income per person, degree of democratic governance), people in South Asia are better-off than those in Africa. But the female-to-male life expectancy ratio - a measure of women's social status relative to that of men - is higher in Africa than in South Asia. Also, South Asia has less favourable climate and population density (Smith and Haddad, 2000).

\section{Causations and Linkages: Conceptual and Analytical Frameworks}

An understanding of the causes and consequences of malnutrition is essential for formulating appropriate policies to improve nutrition as strategies need to be tailored to local conditions. For example, low food production caused by insufficient agricultural productivity is a primary reason for hunger in tropical Africa and remote parts of Asia and Latin America, whereas poverty is more likely the primary reason for hunger in South and East Asia, Latin America, Central Asia and the Middle East. The rights-based approach to food security provides the framework for a more effective and complete analysis of the underlying causes of hunger and malnutrition by, for example, requiring the assessment of existing policies, laws and institutions and the identification of the most vulnerable to food insecurity and malnutrition. The costs of inaction are considerable, so efforts to accelerate progress against malnutrition in all its forms should have a high place on the global policy agenda.

As Table 1 indicates, inadequate dietary intake is one of the main immediate causes of malnutrition, along with disease. The two interact in a vicious downward spiral. Inadequate food consumption heightens vulnerability to infectious diseases. In turn, infections, particularly malaria, measles, persistent diarrhoea and pneumonia, can keep the body from absorbing adequate food (WHO, 1997). These immediate causes stem from a complex set of underlying causes at the household level: insufficient access to food - one aspect of food insecurity - poor maternal and child caring practices and inadequate access to clean drinking water, safe sanitation and health services. Ultimately, these factors are embedded in the larger political, economic, social and cultural environment in which households find themselves. 
Food insecurity, ill health and sub-optimal caring practices are all closely related to poverty. The one billion people who live in extreme poverty - on the equivalent of less than US\$1 per day - generally also consume fewer than 2,100 calories per day. The world's 163 million ultra poor people, whose incomes are less than half that level, on average consume less than 1,600 calories a day (Ahmed et al., 2007). Moreover, in all regions of the developing world, lowerincome households experience significantly higher rates of preschooler stunting than betteroff families (Van de Poel et al., 2008). Poverty assessments in Bangladesh, Viet Nam and Guatemala similarly indicate a higher incidence of illness in poor households than among better-off families (Ahmed et al., 2007). With regard to caring practices, even when exclusive breastfeeding for the first six months of life is widely practiced, poor households often engage in sub-optimal complementary feeding practices once children reach six months of age. Poor families cannot afford to purchase animal source foods that are rich in protein and bioavailable micronutrients (Black et al., 2008).

\section{Table 1}

\section{Projected undernourishment in the developing world}

\begin{tabular}{|c|c|c|c|c|c|c|}
\hline & \multicolumn{3}{|c|}{$\begin{array}{l}\text { Number of undernourished people } \\
\text { (miltions) }\end{array}$} & \multicolumn{3}{|c|}{$\begin{array}{l}\text { Prevalence of undernourishment } \\
\text { (percentage of population) }\end{array}$} \\
\hline & $1990-92^{*}$ & 2015 & WFS target & $1990-92^{*}$ & 2015 & MDG target \\
\hline Developing countries & 823 & 582 & 412 & 20.3 & 10.1 & 10.2 \\
\hline Sub-Saharan Africa & 170 & 179 & 85 & 35.7 & 21.1 & 17.9 \\
\hline Near East and North Africa & 24 & 36 & 12 & 7.6 & 7.0 & 3.8 \\
\hline Latin America and the Caribbean & 60 & 41 & 30 & 13.4 & 6.6 & 6.7 \\
\hline South Asia & 291 & 203 & 146 & 25.9 & 12.1 & 13.0 \\
\hline East Asia** & 277 & 123 & 139 & 16.5 & 5.8 & 8.3 \\
\hline \multicolumn{7}{|l|}{ Notes } \\
\hline \multicolumn{7}{|c|}{$\begin{array}{l}\text { The base period for projections is } 1999-2001 \text { and not } 2001-03 \text {. Some small countries have also been excluded } \\
\text { from the projections. }\end{array}$} \\
\hline \multicolumn{7}{|c|}{$\begin{array}{l}\text { Data for 1990-92 may differ slightly from numbers reported elsewhere in the report as the projections are } \\
\text { based on undernourishment estimates that do not include the latest revisions. }\end{array}$} \\
\hline ** Includes Southeast Asia. & & & & & & Source: FAC \\
\hline
\end{tabular}

A high percentage of the world's extremely poor people live in South Asia. However, ultra poverty is heavily concentrated in Sub-Saharan Africa. While South Asia made progress against the deepest poverty during the 1990s and the first years of the present decade, both extreme poverty and ultra poverty increased in Sub-Saharan Africa (Ahmed et al., 2007).

Discrimination, geography and environmental factors also play a role in poverty, food insecurity and malnutrition. In both South Asia and Latin America, indigenous people, members of ethnic minority groups and socially excluded people, such as members of "secluded" and "backward" castes in India, are over-represented among poor people and especially among ultra poor people. In Guatemala, the proportion of indigenous preschoolers who are stunted is more than double the rate for non-indigenous children. Gender discrimination also influences malnutrition: in South Asia, there is evidence that women consume less food and lower quality diets than men, mainly as a result of food distribution within households (Ahmed et al., 2007).

Poverty rates tend to be higher in more remote areas with difficult access to roads, markets, communications infrastructure, schools and health services (Ahmed et al., 2007). Such areas 
are often "less-favoured" in terms of their natural resource endowments as well as in socioeconomic and political terms. Most of the rural poor people in developing countries (who account for the vast majority of all poor people) live in such resource-poor areas (Pender and Hazell, 2000).

\section{Costs of Malnutrition}

Taken together, stunting, severe wasting, low birthweights due to intrauterine growth restriction, sub-optimal breastfeeding (non-exclusive for six months and discontinued before one to two years) and deficiencies of vitamin A, zinc and iron lead to the deaths of 3.6 million children under five years of age each year (Black et al., 2008). Moreover, these forms of malnutrition together account for 35 percent of all preschooler deaths and 11 percent of the global burden of disease, i.e., the total gap between current global health status and an ideal situation where everyone lives into old age in full health (Black et al., 2008). Thus, malnutrition is a calamity that deprives humanity of countless scientists, creative artists, community and national leaders and productive workers who die prematurely or grow up without reaching their full potential.

Malnutrition puts heavy charges on the economies of developing countries. Difficult pregnancies and the illnesses that malnourished mothers and their children experience cost an estimated $\$ 30$ billion annually. Lost productivity and income due to early deaths, poor school performance, disability and absenteeism likely raise the yearly total into the hundreds of billions of dollars (Victora et al., 2008; Behrman, Alderman and Hoddinott, 2006; FAO, 2004). Lost income due to iron deficiency alone reduces gross domestic product by as much as 8 percent in Bangladesh and a still significant 2 percent in Honduras (SCN, 2004). Not only is malnutrition a significant drain on economic growth, but it also reflects and contributes to inequity, as it disproportionately affects poor, marginalized and extremely vulnerable groups. While the policies and programmes needed to address malnutrition will require substantial resources, it is essential to recognize that the costs of not tackling malnutrition are considerable.

\section{Future Challenges and Major Issues and Risks}

Chapters 4 and 5 examine the effects of climate change and rising bioenergy demand on nutrition. However, some additional factors will constrain efforts to reduce malnutrition in the coming years:

- demographic forces;

- widespread land degradation and scarcity of fresh water resources, resulting from both bad management practices, inappropriate land uses for a certain land class and impacts from climate change and extreme climate variations;

- structural shifts in the food and agricultural system;

- transboundary movement of diseases;

- environmental and energy forces.

\section{Demographic Forces}

According to UN population data, between 2007 and 2050, world population will increase by 37 percent, from 6.7 billion to 9.2 billion people, with the net increase equivalent to the total 
global population in 1950. Africa will have the highest rate of population growth of any region during this period, 1.7 percent per year (UN Population Division 2007, 2008).

Population growth alone will mean increased demand for food, requiring a 50 percent increase in production. Anticipated economic growth of 6 percent per year in developing countries during the next few years will lead to additional increases in demand, as will rapid urbanization (von Braun, 2007a).

Virtually all global population growth between 2007 and 2050 will occur in the cities of the developing world. Indeed, the net increase in urban population during that period will exceed the net growth in overall population, as cities will also absorb migrants from rural areas. The world's urban population will nearly double during this period, rising from 3.3. billion to 6.4 billion people. By 2019, a majority of the developing world's populace will live in cities and towns (UN Population Division, 2008). These trends have implications for food demand and nutrition. People in cities and towns have fewer opportunities than rural people to produce their own food and so must rely on purchases and the cash economy to eat. A sharp increase in food prices will have a large impact on people who rely almost entirely on cash income, especially the poor. Urban women have higher opportunity costs on their time, so they cannot spend as much time as their rural sisters do on purchasing and preparing food. As a result, city folk tend to shift their consumption to foods that are easier to prepare (e.g., from sorghum, millet, maize and root crops to rice and wheat) and to more meat, milk, fruit, vegetables and processed foods (Garrett and Ruel, 2000).

Street foods are a significant contributor of urban dwellers' daily energy and nutrient intakes and play a particularly prominent role in food access by the urban poor. Street foods provide cheap sources of often nutritious food and are a good source of income for informal food sector workers, most of whom are women and more likely than men to invest that income in the wellbeing of their children. In Nigeria, city dwellers spend as much as half their food budgets on street foods. In Bamako, Mali, street foods provided 134-417 kcal/person per day (Ag Bendech et al., 2000). With rising costs for food and cooking fuel, the use of street foods tends to increase as prices in this informal sector are inclined to rise slower due to the economies of scale of production. Lack of infrastructure (i.e. water, sanitation), lack of basic training in food hygiene of vendors and weak or arbitrary enforcement of the legal framework (if street foods-specific regulations do exist at all) are all factors contributing to the variable and sometimes poor safety of these foods. However, the contribution of street foods to food security (ensuring cheap, nutritious and easily available food to urban dwellers), as well as to poverty reduction, is such that high priority should be given by local authorities (for example, municipalities) to reduce the threats to food safety. In particular, emphasis should be given to training of street foods' vendors in food hygiene, insisting on an adequate and consistent enforcement of local food regulations and improving basic infrastructure to the vendors allowing them to respect the most basic principles for hygienic food preparation.

\section{Structural Changes in the Food and Agricultural System}

Productivity growth in cereals, the main staple food crops, declined dramatically in the 1990s and continues to decline for maize (which is important as a source of feed and fuel as well as food) (Figure 8). A major reason for this is underinvestment in agriculture. Growth of public agricultural research expenditures slowed in the 1990s and in 2000, developing countries excluding China and India accounted for only a small share of that spending. Funding for the international agricultural research centres supported by the Consultative Group on 
International Agricultural Research (CGIAR) has stagnated (Pardey et al., 2006). Public research is essential for addressing the problems of poor farmers and consumers in developing countries, as private firms are unlikely to do so.

Increasingly, the preferences of affluent consumers in high- and middle-income countries are shaping global food and agricultural systems. Production and value chains no longer respond simply to price signals. Such concerns as quality, food safety, convenience and choice have become decisive. For example, developed-country consumers seek pre-washed, pre-cut and bagged salads that are ready to eat, rather than just the raw materials for making a salad. The mad cow, foot-and-mouth and highly pathogenic avian influenza scares in Europe and North America over the past 10 years have also heightened attention to food safety and quality, health and environmental issues. Consumers demand to know where food came from and how it was produced. Animal welfare is also increasingly an issue in food marketing. There are standards organizations that award products labels indicating their status as organic, fair trade, environment-friendly and cruelty-free. This new situation offers smallholders opportunities and niche markets among high-income buyers. But being able to produce up to the standards to get the appropriate label and undergoing periodic audits may require investment in knowledge and equipment and also has high transaction costs that may be too heavy for lowincome farmers (Hazell et al., 2007). This will constrain their ability to earn income and has implications for food security.

The global food system now has a dualistic structure. On the one hand, the vast majority of farms (85 percent) remain smallholder operations, of less than two hectares in size, that are home to more than 2 billion people (Hazell et al., 2007). In many countries, small farmers account for a considerable share of output. In India, they grow more than 40 percent of the cereal grains, own the majority of the livestock and account for most dairy production. In SubSaharan Africa, smallholders account for 90 percent of all agricultural production (IFPRI, 2005). On the other hand, the 0.5 percent of the world's farms that exceed 100 hectares in size claim a disproportionate share of global farm income, enjoy privileged access to policy makers and, particularly in developed countries, receive the lion's share of tens of billions of dollars in subsidies each year (OECD, 2007).

Moreover, outside of farming, growing concentration and consolidation characterizes the global food system. At the top of the food chain, the 10 leading food retailers enjoy a 24 percent share of the $\$ 3.5$ billion global market and grocery stores have expanded their operations in developing countries at a rapid pace (ETC Group, 2005, 2007). Between 2004 and 2006, the sales of agricultural input firms grew 8 percent, the revenues of food processors and traders jumped 13 percent and retail food sales grew by a whopping 40 percent (von Braun, 2007a). At the end of February 2008, the giant agricultural input and grain trading firm Cargill announced a nearly 100 percent increase in revenues over a year earlier due to rising cereal prices (Washington Post Staff and Wire Reports, 2008).

Thus, buying power is increasingly concentrated in the hands of supermarkets and other powerful corporate actors, especially in Latin America, Southeast Asia and China. Small farmers often find themselves at a disadvantage. The buyers increasingly have stringent demands regarding quality, timeliness and conditions of production and it is not clear that small farmers will be able to comply with all these requirements (Hazell et al., 2007). Even if they can, their ability to bargain for a fair share of the value of their produce may be limited. 
Figure 8

\section{Productivity growth is declining}

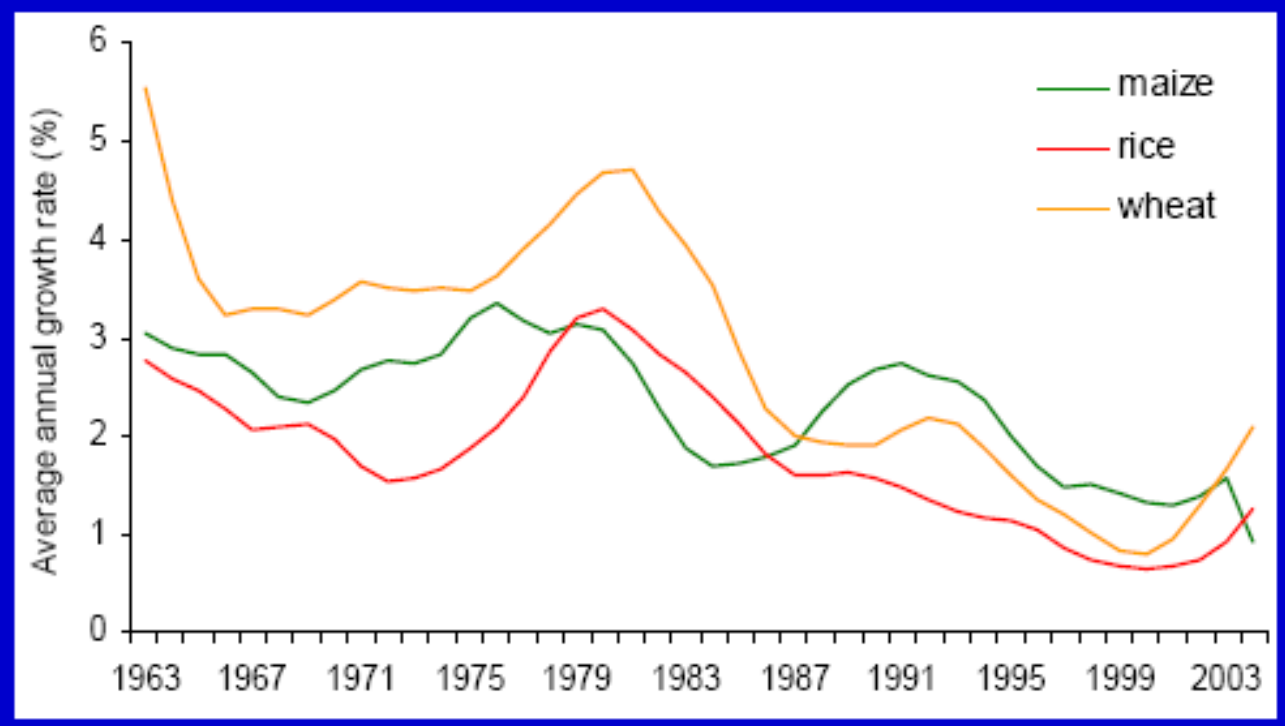

Source: World Bank (2008a).

\section{Transboundary Pests and Diseases}

Agricultural intensification, rapid growth in international trade and more frequent international travel offer opportunities to bolster rural livelihoods through productivity gains, entry into export markets, earnings from ecotourism and the ability to purchase a wider array of affordable goods and services. However, there are also substantial risks from the spread of plant and plant pests, animal diseases and invasive species across international borders and climate change will heighten these risks. This threatens ecosystems, water and biodiversity (World Bank, 2008a). For example, the wind-borne Ug99 wheat rust fungus has spread from Uganda to Kenya, Ethiopia, Yemen and Iran and threatens crops in South and Central Asia. It has devastated entire fields and in 2007 caused substantial losses in both Kenya and Ethiopia. Up to 80 percent of African and Asian wheat varieties are susceptible to wheat stem rust, so the disease has the potential to help drive further escalation of wheat price inflation and severely harm rural livelihoods, with negative implications for nutrition (FAO, 2008a). Also, some trans-boundary animal diseases pose serious and costly threats not only to rural livelihoods, but to human health as well, e.g., highly pathogenic avian influenza (bird flu) (World Bank, 2008a).

\section{Environmental and Energy Pressures}

Many key ecosystem services provided by biodiversity, such as nutrient cycling in soils, pest regulation and pollination, sustain intensive agricultural productivity. Promoting the healthy functioning of ecosystems ensures the resilience of agriculture as it intensifies to meet the stress of growing demands for food production.

For the past 40 years or more, efforts to intensify agricultural production have helped boost food output, but some agricultural practices have taken a toll on the natural resource base on 
which agriculture depends. Some 1.4 billion people live in river basins where water use exceeds recharge rates (UNDP, 2006). Poor management of irrigation systems has contributed to land degradation, causing salination and waterlogging of soils. Overgrazing and deforestation also contribute to land degradation and climate change (UNDP-Global Environmental Facility, 2004; Scherr, 1999). In Sub-Saharan Africa, where farmers apply an average of 9 kilograms of fertilizer per hectare (compared to 142 kilograms in South-east Asia), insufficient fertilizer use (rather than overuse) leads to degradation, as the cultivation and harvesting of products lead to a net loss of soil nutrients. Agricultural practices (such as failure to maintain soil cover or obstruct water run-off) can contribute to soil erosion. Degraded soils reduce agricultural productivity and eventually become unable to produce crops (Scherr, 1999). Large-scale livestock operations and inappropriate management of farm chemicals have contributed to degradation of freshwater ecosystems, causing pollution that can threaten the health of humans and livestock (Millennium Ecosystem Assessment, 2005). Crop genetic diversity is essential for food security, as it is the basis of both farmers' livelihoods and agricultural innovation. However, repeated planting of a limited number or even a single variety can erode genetic diversity (Bioversity International, 2008).

Without the wider utilization of effective and efficient existing technologies and in the absence of a technological breakthrough that will boost yields on existing farmland, increases in food production to meet growing demand will have to come from the expansion of agriculture into new areas. This would likely put more fragile marginal land under cultivation, as well as destroy forests and wildlife habitat, cause loss of biodiversity and increase GHG emissions from burning, decomposition of organic matter and loss of carbon sinks. We need to examine the efficiency of the constraints that are facing existing farmland productivity, otherwise we may only aggravate the environmental pressure. An additional serious constraint, especially in fast-growing Asia, is the rapid conversion of farmland to such other uses as residential, commercial and industrial (Reuters, 2008; Ding, 2004). Furthermore, food and agricultural production faces growing competition for water for home and industrial use, although agriculture continues to account for over 80 percent of water use (FAO, 2008b; UNDP, 2006). All of these factors constrain food availability.

According to the UN Office for the Coordination of Humanitarian Affairs (OCHA), the number of natural disasters has increased, due to more frequent extreme weather events, such as hurricanes, cyclones, droughts and floods. In 2007, OCHA appealed for nearly $\$ 400$ million in food and other emergency aid for people affected by 14 such calamities in developing countries (OCHA, 2007). While these disasters stem from natural events, human activity - frequently related to agriculture, fisheries, or forestry - often magnifies their impact. Logging, forest clearing for agricultural development and destruction of mangroves for aquaculture development dismantle natural barriers to storms and floods, creating "unnatural disasters." The devastating effects of the recent cyclone in Myanmar are a prime example: clear-cutting of mangroves heightened the vulnerability of coastal lands. Deforestation on the hillsides of Honduras meant large-scale mudslides when Hurricane Mitch hit in 1998. Total losses exceeded the combined national incomes of Honduras and Nicaragua, the two most severely affected countries. Natural disasters in the 1990s caused losses of over $\$ 600$ billion, more than those of the previous four decades (Abramovitz, 2001).

With regard to energy, by April 2008, crude petroleum prices reached an all-time high of US $\$ 120$ per barrel (Lazo, 2008) and helped to raise demand for biofuels as an alternative source of energy. Energy costs are likely to remain high for the foreseeable future, due to war and political instability in the Middle East, the supply-constraining policies of the 
Organisation of Petroleum Exporting Countries and the growing consolidation of the petroleum industry into transnational megafirms that are using windfall profits to repurchase shares and pay dividends instead of aggressively exploring for new reserves (Science Daily, 2007). These costs have a direct bearing on food production and rural livelihoods, as they mean increased costs for operating farm machinery, inputs and transportation of both inputs and farm products (von Braun, 2008). In addition, the price of fertilizer, a by-product of fossil fuels, increased 150 percent over the past five years. However, according to the World Bank, higher energy and fertilizer costs account for only about 15 percent of recent increases in food prices (World Bank, 2008b). 


\section{Climate Change, Food Security and Nutrition}

\section{Overview of Climate Change - Evidence for and Potential Effects}

According to the Fourth Assessment Report of the Intergovernmental Panel on Climate Change (IPCC), ${ }^{3}$ climate change and variability will have significant impacts on food security and malnutrition.

Climate change will lead to more intense and longer droughts than have been observed over wider areas since the 1970s, particularly in the tropics and subtropics (Trenberth et al., 2007). In addition, the frequency of heavy precipitation events has increased over most land areas. It is very likely that heat waves and heavy precipitation events will continue to become more frequent and that future tropical cyclones (typhoons and hurricanes) will become more intense (Meehl et al., 2007; Trenberth et al., 2007). It is primarily via these impacts that climate change will have negative effects on food security and nutrition.

Droughts and water scarcity diminish dietary diversity and reduce overall food consumption and this may lead to malnutrition problems including undernutrition, protein-energy malnutrition and/or micronutrient deficiencies. The risk of flooding of human settlements may increase, from both sea-level rise and increased heavy precipitation in coastal areas. This is likely to result in an increase in the number of people exposed to diarrhoeal and other infectious diseases, thus lowering their capacity to utilise food effectively.

Global atmospheric concentrations of greenhouse gases (GHGs), carbon dioxide $\left(\mathrm{CO}_{2}\right)$, methane and nitrous oxide have increased markedly since 1750 as a result of human activities. By 2005, the global atmospheric concentration of $\mathrm{CO}_{2}$ far exceeded the natural range of the preceding 650,000 years (Forster et al., 2007). Total temperature increases during the $20^{\text {th }}$ century have been $0.76^{\circ} \mathrm{C}$ (Trenberth et al., 2007). Average arctic temperatures increased at almost twice the global average rate during the past 100 years.

Continued GHG emissions at or above current rates would cause further warming and induce many changes in the global climate system during the 21 st century that would very likely be larger than those observed during the 20th century (Meehl et al., 2007). The best estimate for the low scenario, among the Special Report on Emissions Scenarios (SRES) ${ }^{4}$ projected by the $4^{\text {th }}$ IPCC assessment, is an increase of $1.8^{\circ} \mathrm{C}$ and the best estimate for the high SRES scenario is $4.0^{\circ} \mathrm{C}$ (Meehl et al., 2007).

Mountain glaciers and snow cover have declined on average in both hemispheres (Lemke, 2007). During the course of the century, water supplies stored in glaciers and snow cover are projected to decline, reducing water availability in regions supplied by meltwater from major mountain ranges; these regions are home to more than one-sixth of the world's population (Kundzewicz, 2007).

Widespread decreases in glaciers and ice caps have contributed to sea-level rise (Lemke, 2007). According to the $4^{\text {th }}$ IPCC report's estimations for unmitigated emissions, the sea-level

\footnotetext{
${ }^{3}$ IPCC is a scientific intergovernmental body set up by the UN World Meteorological Organization and the UN Environment Programme to provide decision-makers and others with objective information about climate change. The scientific community generally regards its reports as authoritative (Sample 2007).

4 See Appendix 1 for details on these scenarios.
} 
will rise by 40 centimetres by the 2080s, with 60 percent of this increase occurring in South Asia and 20 percent in South East Asia (Meehl et al., 2007).

\section{Climate Change Impacts on the Human and the Global Environment}

Global environmental hazards to human health, environment and sustainability include climate change, stratospheric ozone depletion, loss of biodiversity, changes in hydrological systems and the supplies of freshwater, land degradation and stresses on food-producing systems (WHO, 2005a). These factors are closely interrelated. For example deforestation, agriculture and livestock production systems further accelerate climate change. Vulnerability to adverse effects from climate change differs by region, ecosystem, population group and gender.

\section{Vulnerable Regions}

The regions likely to be adversely affected by climate change are those already most vulnerable to food insecurity and malnutrition, notably Sub-Saharan Africa, which may lose substantial agricultural land. The numbers of people affected will be largest in the mega-deltas of Asia and Africa, while small islands are especially vulnerable (Nicholls et al., 2007). It should be noted that IPCC assessments do not provide much information on a regional or national basis.

In seasonally dry and tropical regions, crop productivity is projected to decrease with even small local temperature increases $\left(1-2^{\circ} \mathrm{C}\right)$, which would increase the risk of hunger due to reduced food availability (Easterling et al., 2007). In Africa, by 2020, between 75 million and 250 million people are projected to be exposed to increased water stress due to climate change. If coupled with increased demand, this will adversely affect livelihoods and exacerbate water-related problems (Boko et al., 2007; Kundzewicz et al., 2007). In much of Africa, agricultural production and access to food are projected to be severely compromised by climate variability and change. This would further adversely affect food security and exacerbate malnutrition on the continent.

Coastal areas, especially heavily-populated mega-delta regions in South, East and South-east Asia, will be at greatest risk due to increased flooding from the sea and, in some mega-deltas, flooding from the rivers (Cruz et al., 2007). Sea-level rise will extend areas of salination of groundwater and estuaries, resulting in a decrease in coastal freshwater availability for humans and ecosystems (Kundzewicz et al., 2007). Small islands, whether located in the tropics or higher latitudes, are especially vulnerable to the effects of climate change, sea-level rise and extreme events (Mimura et al. 2007). Deterioration in coastal conditions, for example through erosion of beaches and coral bleaching, is expected to affect local resources, e.g., fisheries and reduce the value of these destinations for tourism (Mimura et al., 2007).

In the Polar Regions, the main projected biophysical effects are reductions in thickness and extent of glaciers and ice sheets and changes in natural ecosystems with detrimental effects on many organisms including migratory birds, mammals and higher predators (Anisimov et al., 2007). 
The resilience of many ecosystems is likely to be exceeded this century by an unprecedented combination of climate change, associated disturbances (e.g., flooding, drought, wildfire, insects, ocean acidification) and other global change drivers (e.g., land use change, pollution, overexploitation of resources) (Fischlin et al., 2007). Examples of delicate ecosystems that are already being affected include the tundra, boreal forests, mountains and the Mediterranean region. Approximately 20-30 percent of plant and animal species assessed so far are likely to be at increased risk of extinction if increases in global average temperature exceed $1.5-2.5^{\circ} \mathrm{C}$ (Fischlin et al., 2006).

\section{Vulnerable Populations}

The most vulnerable people will suffer earliest and most from climate change. Climate change therefore should be addressed in a way that is fair and just, cognizant of the needs and risks faced by the vulnerable groups and adherent to the human rights principles of nondiscrimination and equality. Any sustainable solution to climate change must take into account its human impact and the needs of all communities in a holistic manner.

Humans are exposed to climate change directly through changing weather patterns and indirectly through changes in water, air, food quality and quantity, ecosystems, agriculture and economies. Climate change during 1970-2000 is estimated to have caused at least 160,000 deaths and 5 million disability-adjusted life years from only four factors: malaria, diarrhoea, malnutrition and flooding (McMichael, 2004). Projected climate-change related exposures are likely to affect the health status of millions of people, particularly those with low adaptive capacity, through:

- increased deaths, disease and injury due to heat-waves, floods, storms, fires and droughts;

- increases in malnutrition and consequent disorders, with implications for child growth and development;

- increased frequency of cardio-respiratory diseases due to higher concentrations of ground-level ozone related to climate change;

- altered spatial distribution of some infectious-disease vectors; and

- increased burden of diarrhoeal diseases, which will affect nutrient absorption and food utilization.

Due to the very large number of people that may be affected, malnutrition, linked to extreme climatic events, may be one of the most important consequences of climate change Confalonieri et al., 2007).

Populations at greater risk from food insecurity, including smallholder and subsistence farmers, pastoralists, traditional societies, indigenous people, coastal populations and artisanal fisherfolk, will suffer complex, localized impacts of climate change. These groups, whose adaptive capacity is constrained, will experience the negative effects on yields of low-latitude crops, combined with a high vulnerability to extreme events. Indigenous people who rely on their natural resources for the provision of traditional foods will be particularly affected. Box 4.1 presents an example of the impacts of climate change in the ecosystems and the traditional food systems of indigenous peoples of the circumpolar regions. 
In the longer term, there will be additional negative impacts of other climate-related processes such as snow-pack decrease, sea-level rise and spread in prevalence of human diseases affecting agricultural labour supply such as malaria, tick-borne diseases, cholera and other diarrhoeal diseases.

\section{Gender Vulnerability}

Men and women are affected differently in all phases of climate-related extreme weather events, from exposure to risk and risk perception; to preparedness behaviour, warning communication and response; physical, psychological, social and economic impacts; emergency response; and ultimately to recovery and reconstruction (Fothergill, 1998). Many of the world's poorest people are women living in rural areas in developing countries who are currently dependent on subsistence agriculture to feed their families and who are disproportionately affected by the lack of modern fuels and power sources for farming, household maintenance and productive enterprises (Lambrou and Piana, 2006). Climate change could add to water and food insecurity and increase these women's work levels, particularly in Africa and Asia (Parikh and Denton, 2002).

\section{Box 4.1: Impacts on traditional food systems of indigenous peoples in polar regions}

Indigenous peoples rely on their natural resources for the provision of traditional foods, fuel and medicines and will be particularly affected by the impacts of climate change on ecosystems and the environment. Traditional food systems are also threatened because of increasing loss of indigenous peoples' traditional territories due to climate change mitigation measures such as carbon sinks and renewable energy projects.

Indigenous peoples are often the most marginalized and disadvantaged groups in terms of receiving the resources needed for wellbeing, including food and health care. Extreme poverty and food insecurity often characterizes these groups, who rely on the intact environment for harvesting their traditional foods and medicines (Kuhnlein, 2003). The traditional food systems of indigenous peoples contain a wealth of micronutrients.

The approximately 10 percent of the circumpolar population that is indigenous is particularly vulnerable to climate change (ACIA, 2005). The traditional diet of populations in circumpolar regions is likely to be negatively affected by changes in animal migrations and distribution and human access to them (Confalonieri, 2007). Persistent contaminants are present in Inuit Arctic traditional food species in areas very distant from industrial emissions, with dietary exposure of some contaminants exceeding federal tolerance levels in Canada (Kuhnlein et al., 2002). Further, increasing temperatures may indirectly influence human exposure to environmental contaminants in some foods (e.g. fish and marine mammal fats).

\section{Impacts on the Four Food Security Dimensions: Availability, Stability, Access and} Utilization

Climate change will affect all four dimensions of food security, namely food availability (i.e., production and trade), stability of food supplies, access to food and food utilization (FAO, 2003a). Food security depends not only on climate and socio-economic impacts, but also and crucially so, on changes to trade flows, stocks and food-aid policy. 
Climate Change Impacts on Food Availability - Production and Trade

\section{Pasture, Crops, Livestock Production}

Agricultural output in developing countries is expected to decline by 10-20 percent by 2080 , depending on whether there are beneficial effects from $\mathrm{CO}_{2}$ fertilization. Technological change over the next decade is unlikely to be sufficient, which underlines the need for the wider utilization of effective and efficient existing technologies to alleviate the losses or to increase yields enough to keep pace with growing food demand (Cline, 2007).

Climate change and variability impacts on food production (food availability) will be mixed and vary regionally (FAO, 2003b, 2005b). Recurrent severe droughts in several countries in Africa over the past three decades illustrate the potentially large effects of local and/or regional climate variability on crops and livestock. A reduction in the production potential of tropical developing countries, many of which have poor land and water resources and are already faced with serious food insecurity, may add to the burden of these countries (Hitz and Smith, 2004; Fischer et al., 2005; Parry et al., 2005).

Globally, the potential for food production is projected to increase with increases in local average temperature over a range of $1-3^{\circ} \mathrm{C}$, but above this it is projected to decrease.

Evidence from models from the $4^{\text {th }}$ IPCC assessment suggests that moderate local increases in temperature $\left(1-3^{\circ} \mathrm{C}\right)$, along with associated $\mathrm{CO}_{2}$ increase and rainfall changes, can have small beneficial impacts on major rain-fed crops (maize, wheat, rice) and pastures in mid- to highlatitude regions. In seasonally dry and tropical regions, even slight warming $\left(1-2^{\circ} \mathrm{C}\right)$ reduces yield. Further warming (above a range of $1-3^{\circ} \mathrm{C}$ ) has increasingly negative impacts on global food production in all regions.

\section{Fisheries and Aquaculture Production}

Increases in temperature are leading to changes in the distribution of marine fisheries and community interactions (Parry et al., 2005). Brackish water species from delicate estuarine eco-systems are particularly sensitive to temperature and salinity changes. Water temperature increases lead to mortalities of crustacean and shrimp postlarvae (Tirado et al., 1993). Regional changes in the distribution and productivity of particular fish species are expected due to continued warming and local extinctions will occur at the edges of ranges, particularly in freshwater and diadromous species such as salmon or sturgeon (Easterling et al., 2007). Increases in atmospheric $\mathrm{CO}_{2}$ are raising ocean acidity (The Royal Society, 2005), which affects calcification processes, coral reefs' bleaching and the balance of the food web.

In relation to aquaculture production, increases in seawater temperature have been associated with increased densities of Vibrio spp in shellfish and algal blooms in the aquaculture industry, which are major causes of diarrhoea and food toxicity, respectively.

Global warming will confound the impact of natural variation on fishing activity and complicate management. The sustainability of the fishing industries of many countries will depend on increasing flexibility in bilateral and multilateral fishing agreements, coupled with international stock assessments and management plans (Easterling et al., 2007). 
Trade in cereal crops, livestock and forestry products is projected to increase in response to climate change, with increased dependence on food imports for most developing countries. Exports of temperate zone food products to tropical countries will rise, while the reverse may take place in forestry in the short-term (Easterling et al., 2007).

\section{Climate Change Impacts on Food Availability, Stability, and Access}

Changes in the patterns of extreme weather events will affect the stability of, as well as access to, food supplies. Recent modelling studies suggest that increasing frequency of crop loss due to these extreme events may overcome positive effects of moderate temperature increases (Easterling et al., 2007). For forests, elevated risks of fires, insect outbreaks, wind damage and other forest-disturbance events are projected. This change in frequency of extreme events is likely to disproportionately impact smallholder farmers and artisanal fishers (Easterling et $a l ., 2007)$. Food insecurity and loss of livelihood would be further exacerbated by the loss of cultivated land and nursery areas for fisheries through inundation and coastal erosion in lowlying areas (FAO, 2003c).

Climate-related animal and plant pests and diseases and alien invasive aquatic species will reduce the availability of quantities of food, influence the stability of the production system and reduce food access through reduction of income from animal production, reduction of yields of food and cash crops, lowered forest productivity and changes in aquatic populations, as well as increased costs of control (FAO, 2008c).

Food prices may have an impact on food access of households, by limiting the acquisition of appropriate foods for a nutritious diet and the purchasing power of food aid programmes. Climate variability and change will likely contribute substantially to rising food prices (Cline, 2007; von Braun, 2007a). Temperature increases of more than $3^{\circ} \mathrm{C}$ may cause prices to increase by up to 40 percent (Easterling et al., 2007).

\section{Climate Change Impacts on Health and Food Utilization}

Climate change may affect health outcomes and food utilization with additional malnutrition consequences. For example, populations in water-scarce regions are likely to face decreased water availability, particularly in the sub-tropics, with implications for the consumption of safe food and drinking water. Flooding and increased precipitation are likely to contribute to increased incidence of infectious and diarrhoeal diseases. The risk of emerging zoonosis may increase due to changes in the survival of pathogens in the environment, changes in migration pathways, carriers and vectors and changes in the natural ecosystems. The increased livestock population in new areas with concomitant disease threats need to be addressed.

\section{Vector-borne Diseases}

Climate change plays an important role in the spatial and temporal distribution of vectorborne diseases such as malaria. Climate change will have mixed effects on malaria distribution. In the long term, in some areas the geographical range will contract due to the lack of the necessary humidity and water for mosquito breeding. ${ }^{5}$ Elsewhere, the geographical

\footnotetext{
5 The northern limit of Plasmodium falciparum malaria in Africa is the Sahel, where rainfall is an important limiting factor in disease transmission
} 
range of malaria will expand and the transmission season may be changed. It is estimated that in Africa climate change will increase the number of person-months of exposure to malaria by 16-28 percent by 2100 (McMichael, 2004). Malaria affects food availability, access and utilization of humans as well as of livestock.

\section{Diarrhoeal Diseases}

Most of the projected climate-related disease burden will result from increases in diarrhoeal diseases and malnutrition. Diarrhoeal diseases particularly affect nutrient absorption and food utilization. Associations between monthly temperature and diarrhoeal episodes and between extreme rainfall events and monthly reports of outbreaks of water-borne disease have been reported worldwide. Higher temperatures have been associated with increased episodes of diarrhoeal disease in adults and children in Peru, where diarrhoeal reports increased 8 percent for each degree of temperature increase (Checkley et al., 2000). Diarrhoeal food-borne diseases such as Salmonellosis have been found to increase by 12 percent for each degree increase in weekly or monthly temperature above $6^{\circ} \mathrm{C}$ ambient temperature (Kovats et al., 2004). Increased ocean temperatures are leading to increased densities of Vibrio spp. (diarrhoeal agent) in shellfish (Zimmerman et al., 2007).

Climate change is projected to increase the burden of diarrhoeal diseases in low-income regions by approximately 2-5 percent in 2020 and will impact low-income populations already experiencing a large burden of disease (Campbell-Lendrum et al., 2003; McMichael, 2004). Countries with an annual GDP per capita of US $\$ 6,000$ or more are assumed to have no additional risk of diarrhoea.

\section{Food Contamination}

Climate change and variability influences food contamination with non-infectious hazards such as biotoxins (e.g. mycotoxins or marine toxins) and chemicals, which may have an impact on food and animal feed stability, access and/or utilization.

Chemical food contamination may lead to recommendations to limit consumption of locally produced food in order to protect human health, thus reducing the dietary options of rural communities and indigenous peoples and compromising their traditional diets. For example, high contamination with dioxins associated with severe droughts in Central Asia have led to recommendations that poor rural communities limit the consumption of locally produced foods (Mountean et al., 2003). Higher ocean temperatures are leading to increased levels of methyl mercury in fish and marine mammals, prompting recommendations to limit the intake of fish and marine fats by pregnant women and indigenous people in the polar regions (Kuhnlein et al., 2002; Booth and Zeller, 2005).

\section{Global Climate Change Impacts on Food and Water Security, Hunger and Nutrition}

The impacts of global climate change on food and water security and safety and on nutrition are a great concern, particularly for developing countries. These changes, in sum, will have a profound impact on the fulfilment of human rights, in particular on the right to water which is closely linked to the right to food. By 2080, it is estimated that 1.1 to 3.2 billion people will be experiencing water scarcity (depending on the Special Report on Emissions Scenarios of 
socio-economic development); 200 to 600 million, hunger; and 2 to 7 million more per year, coastal flooding (Yohe et al., 2007).

There are many pathways through which global climate change and variability may impact food and water security and safety and nutrition, including:

- increased frequency of extreme climatic events;

- sea-level rise and flooding of coastal lands, leading to salination and/or contamination of water and agricultural lands;

- impacts of temperature increase and water scarcity on plant or animal physiology;

- beneficial effects to crop production through $\mathrm{CO}_{2}$ "fertilization;"

- influence on plant diseases and pest species and livestock diseases including zoonosis, leading to crop and animal losses;

- damage to forestry, livestock, fisheries and aquaculture; and

- impaired sustainability: socio-economic, political/armed conflict and demographic impacts.

Multiple socio-economic and environmental stresses, such as globalization, limited availability of water resources, loss of biodiversity, the HIV/AIDS pandemic and social and armed conflicts, are further increasing sensitivity to climate change and reducing resilience in the agricultural sector (FAO, 2003a). For example, health stressors such as HIV/AIDS, particularly in Southern Africa, are impacting agriculture through mass deaths of prime-age adults, which divert labour resources to caring, erode household assets, disrupt intergenerational transmission of agricultural knowledge and weaken the capacity of agricultural service providers, reducing resilience of smallholder agriculture to climate change.

\section{Water Insecurity}

Access to safe water remains an extremely important global health issue. More than 2 billion people live in the dry regions of the world and suffer disproportionately from malnutrition, infant mortality and diseases related to contaminated or insufficient water (WHO, 2005a).

The impacts of climate change on freshwater systems and their management are mainly due to observed and projected increases in temperature, sea-level and precipitation variability. Climate change is likely to exacerbate declining reliability of irrigation water supplies leading to increased competition for water for industrial, household, agricultural and ecosystem uses. In coastal areas, sea-level rise will extend areas of salination of groundwater, resulting in a decrease in freshwater availability (Kundzewicz et al., 2007).

Water insecurity constitutes a serious constraint to sustainable development, particularly in savannah regions which cover approximately 40 percent of the world's land area (Rockstrom, 2003). Water scarcity may lead to multiple adverse health outcomes, including water-borne diseases, exposure to chemicals, vector-borne diseases associated with water-storage systems and malnutrition. 


\section{Links to Malnutrition}

Attribution of current and future climate-change-related malnutrition burdens is problematic because the determinants of malnutrition are complex. Both acute and chronic nutritional problems are associated with climate variability and change.

Research and information on the links between climate-change-related food and water insecurity and malnutrition are necessary. There is also a need for methodologies to convert estimated losses in regional yields into estimates of changes in numbers of malnourished people. This has been recognized as one of the critical research needs by the $4^{\text {th }}$ IPCC assessment report.

Drought and water scarcity can lead to negative effects on nutrition through increased infections, mortality and reduced food availability (in terms of both quantity and quality). In Gujarat, India, during the 2000 drought, diets were found to be deficient in energy and several vitamins. In this population, serious effects of drought on anthropometric indices may have been prevented by public-health measures (Hari Kumar et al., 2005). The HIV/AIDS epidemic may have further amplified the effect of drought on nutrition in countries such as those in Southern Africa (Mason et al., 2005). On the other hand, malnutrition increases the risk both of acquiring and of dying from an infectious disease. For example in Bangladesh both the impacts of drought and lack of food are associated with an increased risk of mortality from a diarrhoeal illness (Aziz et al., 1990).

Children in poor rural and urban slum areas are at high risk of diarrhoeal disease mortality and morbidity. Childhood mortality due to diarrhoea in low-income countries, especially in subSaharan Africa, remains high and child malnutrition is projected to persist in regions of lowincome countries. Children may survive the acute illness but may later die due to persistent diarrhoea or malnutrition.

\section{People at Risk of Hunger}

Overall, climate change is projected to increase the number of people at risk of hunger (FAO, 2005a). For example, climate change is projected to increase the percentage of the Malian population at risk of hunger from 34 percent to between 64 and 72 percent by the 2050s, although this could be substantially reduced by the effective implementation of a range of adaptive strategies (Butt et al., 2005).

The increase in the number of people at risk of hunger due to climate change must be viewed within the overall large reductions due to socio-economic development. Compared to 820 million undernourished today, the IPCC Special Report on Emissions Scenarios (SRES) scenarios of socio-economic development without climate change project a reduction to 100230 million (range is over A1, B1, B2 SRES scenarios ${ }^{6}$ ) undernourished by 2080 (or 770 million under the A2 SRES scenario) (Easterling et al., 2007).

IPCC SRES scenarios with climate change project 100-380 million (range includes with and without $\mathrm{CO}_{2}$ effects and A1, B1, B2 SRES scenarios) undernourished by 2080 (740-1,300 million under A2). Climate and socio-economic changes combine to alter the regional

\footnotetext{
${ }^{6}$ See Appendix 1 for an explanation of these IPCC scenarios.
} 
distribution of hunger, with large negative effects on Sub-Saharan Africa (Easterling et al., 2007).

\section{Climate Change and Sustainable Development}

Sustainable development can reduce vulnerability to climate change by enhancing adaptive capacity and increasing resilience. On the other hand, climate change can slow the pace of progress towards sustainable development, either directly through increased exposure to adverse impact or indirectly through erosion of the capacity to adapt (Yohe et. al., 2007). Degradation of ecosystem services poses a barrier to achieving sustainable development and to meeting the MDGs (Millennium Ecosystem Assessment, 2005).

In order to meet the MDGs, it would be necessary to balance competition for land for agriculture, livestock, forestry and biofuels production. The expansion of livestock and biofuel sectors has a major role in deforestation and land degradation and thereby contributes to climate change.

\section{Livestock's Long Shadow}

The Livestock, Environment and Development (LEAD) Initiative has identified the livestock sector as a major player in climate change, responsible for 18 percent of GHG emissions measured in $\mathrm{CO}_{2}$ equivalent. The livestock sector is a key player in increasing water use, accounting for over 8 percent of global human water use, mostly for the irrigation of feedcrops. It is probably the largest sectoral source of water pollution, contributing to eutrophication, human health problems, emergence of antibiotic resistance and many other problems. This sector may be the leading player in the reduction of biodiversity, since it is the major driver of deforestation, as well as one of the leading drivers of land degradation, pollution, climate change, sedimentation of coastal areas and facilitation of invasions by alien species (LEAD, 2006).

There are measures that can help reduce the overall impact of livestock production. Among them, sustainable intensification can reduce effects on deforestation, pasture degradation, wildlife biodiversity and resource use. Intensification should be addressed through technologies and policies that can enhance the overall sustainability of livestock production (Delgado et al., 1999). Emissions can be reduced through improved diets to reduce fermentation in ruminants' digestive systems and improved manure and biogas management. Water pollution and land degradation can be tackled through better irrigation systems, better management of waste and improved diets that increase nutrient absorption.

The LEAD Initiative emphasizes the need to approach these problems using economic tools such as removing damaging subsidies and establishing correct pricing of water, grazing and waste, as well as payment for environmental services. LEAD proposes using the Kyoto Protocol's Clean Development Mechanism to finance the spread of biogas and silvopastoral (mixed herding and tree cultivation) initiatives involving afforestation and reforestation. In order to properly address all these issues, there is a need to develop suitable institutional and policy frameworks at the local, national and international levels (LEAD, 2006). 


\section{Social Impacts of Climate Change}

\section{Implications for Rural and Urban Populations}

Climate change could adversely impact rural populations' food security through reduced crop yields, geographical shifts in optimum crop-growing conditions, reduced water resources for agriculture and human consumption, loss of cropping land and yields through floods, droughts and sea-level rise and increased rates of adverse health outcomes, including diarrhoeal diseases and malnutrition (Confalonieri et al., 2007).

Smallholder and subsistence farming households in the dryland tropics are particularly vulnerable to increasing frequency and severity of droughts. These may lead to a higher likelihood of crop failure; increased diseases and mortality of livestock, indebtedness, outmigration and dependency on food relief; and impacts on human development indicators such as health, nutrition and education (Easterling et al., 2007).

Drought and the consequent loss of livelihoods is also a major trigger for population movements, particularly rural to urban migration. Population displacement to urban slums can lead to increases in diarrhoeal and other communicable diseases and poor nutritional status resulting from overcrowding and a lack of safe water, food and shelter. Recently, rural to urban migration has been implicated as a driver of HIV transmission and unplanned urbanization has contributed to the spread of Plasmodium vivax malaria and dengue fever in urban slums (Confalonieri et al., 2007).

\section{Environmental Refugees and Social Conflict}

The UN projects that there will be up to 50 million people escaping the effects of environmental deterioration by 2020 . The spectrum of associated health risks includes food and water emergencies and infectious, nutritional and mental diseases. By increasing the scarcity of basic food and water resources, environmental degradation increases the likelihood of violent conflict (LEAD, 2006). The Southern African Millennium Ecosystem Assessment suggests a bidirectional causal link between ecological stress and social conflict: conflict may cause environmental degradation but the latter may also trigger conflict (Biggs et al., 2004). Conflict could emerge as a result of climate change environmentally induced migration. Political refugees from violent regions are more likely to become involved in militant activities. (Gleditsch et al., 2007).

In sub-Saharan Africa, where cropping and grazing are often practised by different ethnic groups, the advance of crops into pasture land often results in conflict, as shown by major disturbances in the Senegal river basin between Mauritania and Senegal and in North-east Kenya, between the Boran and the Somalis (Nori et al,. 2005). According to UNEP, the conflict in Darfur has been driven in part by climate change and environmental degradation, which threaten to trigger a succession of new wars across Africa (UNEP, 2007) (see Box 4.2). 


\section{Adaptation and Mitigation Strategies}

\section{Adaptation Strategies}

Adaptation strategies to climate change for food security could be autonomous or planned. Autonomous adaptation is the ongoing implementation of existing knowledge and technology in response to the changes in climate experienced. Planned adaptation is the increase in adaptive capacity by mobilizing institutions and policies to establish or strengthen conditions favourable for effective adaptation and investment in new technologies and infrastructure.

\section{Autonomous Adaptation}

Many of the autonomous adaptation options are extensions or intensifications of existing riskmanagement or production-enhancement activities for cropping systems, livestock, forestry and fisheries production (Easterling et al., 2007).

While autonomous adaptations have the potential for limiting damage from climate changes, there has been little evaluation of how effective and widely adopted these adaptations may actually be, given the complex nature of agriculture decision-making, the diversity of responses within regions and the possible interactions between different adaptation options and economic, institutional, human and environmental health and cultural barriers to change among others (Easterling et al., 2007).

\section{Box 4.2: Climate Change and Conflict in Sudan (UNEP 2007)}

Environmental issues and competition over agricultural land use are important causative factors in the instigation and perpetuation of conflict in Sudan. Resource-based conflicts between traditional farmers and nomadic herders have been present in Sudan throughout recorded history. The introduction of mechanized rain-fed agriculture systems that compete for resources has been found to exacerbate and trigger conflict.

A UNEP post-conflict environmental assessment indicates that there is a very strong link between land degradation, desertification and the conflict in Darfur. Tensions between farmers and herders over disappearing pasture and evaporating water holes threaten to reignite other long-standing conflicts within Sudan. The southern Nuba tribe, for example, has warned it could re-start the war as Arab nomads, pushed southwards into their territory by drought, are cutting down trees to feed their camels.

The assessment reveals that in the past 30 years, rainfall has dropped by 16 percent in southern Darfur and 34 percent in northern Darfur; the desert climate in Sudan has advanced southwards by $100 \mathrm{~km}$ over 40 years; deforestation has been accelerated while underground aquifers are being drained; and yields of the local staple, sorghum, could drop by 70 percent by 2060 .

At the same time the Darfur conflict has exacerbated Sudan's environmental degradation, forcing more than two million people into refugee camps. Currently, Sudan has the world's largest population of displaced persons, with over five million internally displaced persons and international refugees. This massive population displacement has led to human rights abuses, conflicts over resources, food insecurity and a high prevalence of severe malnutrition. 
Adaptation strategies to climate change for food security and nutrition are particularly complex and often have limitations. For example, shifts to drought-resistant and less labourintensive crops such as cassava or sweet potatoes in African countries that are severely affected by droughts or HIV/AIDS should take into consideration that these crops could be less nutritious. Efforts to breed micronutrient-dense staple crops should be integrated with climate change adaptations such as breeding drought- and water-tolerant varieties. Similarly, more heat-tolerant native livestock breeds often have lower levels of productivity.

\section{Planned Adaptation}

Autonomous adaptations may not be fully adequate for coping with climate change, thus necessitating deliberate, planned measures. Many options for policy-based adaptation to climate change have been identified for agriculture, forests and fisheries. These can either involve adaptation activities such as developing infrastructure or building the capacity to adapt in the broader user community and institutions, often by changing the decision-making environment under which management-level, autonomous adaptation activities occur. Policybased adaptations to climate change will interact with, depend on, or perhaps even be just a subset of policies on natural resource management, human and animal health, governance and human rights, among many others (Yohe et al., 2007).

\section{Mitigation Strategies}

Agriculture, land use and waste account for some 35 percent of the GHG emissions that contribute to climate change (Stern, 2006). At the same time, improved agricultural practices can make a significant contribution at low cost to increasing soil carbon sinks and to GHG emission reductions (Metz et al., 2007). Key mitigation strategies in the agriculture sector include: improved crop and grazing land management to increase soil carbon sequestration, restoration of degraded lands, improved rice cultivation and livestock and manure management to reduce methane emissions and improved nitrogen fertilizer management to reduce nitrous oxide emissions in some agricultural systems (Metz et al., 2007). ${ }^{7}$

Improved management of tropical land offers a promising agriculture-based mitigation strategy. Reduced deforestation, more sustainable forest management and adoption of agroforestry (integration of tree and crop cultivation) have particularly good potential to capture significant amounts of carbon and other GHGs and, at the same time, to contribute to poverty reduction (CGIAR, 2008). Cultivation of productive forage grasses that sequester carbon can be combined with tree planting in silvopastoral systems of cultivation. Agroforestry not only captures carbon and helps maintain soil health through nitrogen fixation and use of cuttings as fertilizer and mulch, but it also provides fodder, fruit, timber, fuel, medicines and resins. This can help improve nutrition in cultivator households through higher incomes and by directly adding diversity to diets (CGIAR, 2008).

Agricultural research can help create new technologies that will facilitate agriculture-based mitigation strategies. For example, research is underway at CGIAR-supported international agricultural research centres to breed new, drought-tolerant varieties of sorghum that will provide food, feed and fuel all from a single plant, without current tradeoffs among uses.

\footnotetext{
7 Ordinarily, nitrogen fertilizer tends to break down into nitrous oxide, a greenhouse gas that also contributes to ozone depletion and nitrate, which aids crop growth, but also contaminates streams and groundwater, thereby threatening health and nutrition.
} 
In the waste management sector, existing technologies for mitigation are available that can contribute to improved public health as an input into good nutrition. These include waste incineration with energy recovery, composting of organic waste, controlled waste water treatment and recycling to minimize waste (Metz et al., 2007). 


\section{Nutrition and Bioenergy}

\section{Overview}

Bioenergy is energy produced from organic matter, or biomass. Biofuels are energy carriers derived from biomass. A wide range of biomass sources can be used to produce energy. Some have been used for millennia, such as fuelwood, charcoal and animal dung. Newer sources include ethanol, biodiesel and biogas. These new sources depend on natural vegetation, crops grown specifically for energy, or agricultural or other biological forms of wastes and residues. Processing makes these biofuels cleaner and more efficient than traditional biofuels and if they are produced in a way that reduces net carbon emissions, they could contribute to mitigating climate change. Ethanol, for instance, can be made from sugars (e.g., sugar beets, sugarcane and sweet sorghum), grains (such as maize and wheat), root crops (such as cassava), cellulose and waste products. Biodiesel is made from vegetable oils or animal fats. Bioethanol production is mostly concentrated in Brazil and the United States, while the European Union produces most biodiesel (FAO, 2008d, 2008e; von Braun, 2007b).

Rising petrol prices have made the new biofuels an attractive alternative energy source. Technological development has recently made them more cost-effective and energy-efficient. Nevertheless, biofuels offer only a very small gain in energy efficiency over petrol and their production only minimally reduces GHG emissions. Research is underway to develop cellulosic biofuels from low value non-food crops, such as grasses or wood. These feedstocks are, however, more difficult to process than starch or sugar crops and it is not clear that their production will expand significantly in the near future (von Braun, 2007b; FAO, 2008e).

\section{Nutrition Impacts}

Biofuel production can have negative impacts on nutrition through three main pathways: increased GHG emissions, direct effects on health and sanitation and reduced food availability and associated price effects. To the extent that biofuel production exacerbates climate change, for example, because of burning of forests to clear land for production of bioenergy crops (UN-Energy, 2007; Easterling et al., 2007), that will indirectly contribute to malnutrition, as explained in Chapter 4.

Growth of the biofuel sector may lead to water shortages and water contamination. Use of sugarcane as a feedstock, as in Brazil, is particularly water-intensive. The availability of water in developing countries is a cause of concern for agricultural productivity and for health and sanitation. In underdeveloped rural areas, where there is very high demand for access to water for irrigation, cooking and drinking, bioenergy crop production would compete for scarce water supplies. An acceleration of biofuel expansion in areas requiring additional irrigation water from already depleted aquifers could cause much greater water scarcity problems and further push up cereal prices. Poorly managed use of inputs to cultivate energy crops could pollute drinking water, adversely affecting human and animal health (UN-Energy, 2007; Easterling et al., 2007; Rosegrant et al., 2006). 
Biofuel demand puts additional pressure on limited land and water resources. Increasing prices are leading to the diversion of food and feed crops to biofuel production, with some 24 percent of the 2008 U.S. maize crop projected to go into ethanol production (Trostle, 2008). In developing countries, there is intense pressure on farm land from current food crop needs, but expanded bioenergy crop production could divert land away from foods crops.

Diverting cereal from food and feed to fuel use has the potential to reduce food availability. In addition, there is a risk that food and feed production will be consigned to less productive land, which may result in lower yields, while the most fertile hectares support high-value fuel crops.

Related to such effects, IFPRI estimates that rising bioenergy demand contributed significantly to the jump in global food prices between 2000 and 2007. Increased biofuel demand, compared with previous historical rates of growth, is estimated in IFPRI's analysis to have accounted for 30 percent of the increase in weighted average grain prices. The impact was even higher for maize prices, for which growing biofuel demand is estimated to have accounted for 39 percent of the real increase. The figures are 21 percent for rice, 22 percent for wheat prices (Rosegrant, 2008).

A rise in the food bill for households that are net buyers of food will tend to result in reduced demand for foods of higher value and increased demand for staples within a given set of taste and food preferences. Bennett's Law describes this relationship between income and the share of starchy staples in the diet (Bennett, 1941). In many situations, depending upon local market conditions, food price increases may lead not only to a reduction in the average number of meals and the amount of food consumed but also to the substitution of cereals, root crops and cheaper cuts for higher value foods such as animal products, legumes, processed foods, fruits and vegetables. For rural communities, greater reliance upon gathered seasonal wild foods may occur. As prices continue to rise, poor people will experience a worsening of dietary quality and micronutrient intake and extremely poor people will experience an additional decrease in food energy consumption. Decreased overall food consumption in terms of calories, as well as of other essential nutrients including protein, fat and micronutrients, can lead to weight loss; impaired developmental, mental and physical growth in children; and either sub-clinical or clinical micronutrient deficiency in all age groups. For adults, prolonged periods of inadequate nutrition reduce productivity through reduction in the physical ability to do work both by increasing the number of days taken by sick leave and reducing the rate and the amount of work that can be accomplished (Geissler and Powers, 2005). As The Economist magazine (2008) recently editorialized, this can have devastating effects on nutrition, poverty and political stability:

"Famine traditionally means mass starvation. The measures of today's crisis are misery and malnutrition. The middle classes in poor countries are giving up health care and cutting out meat so they can eat three meals a day. The middle poor, those on $\$ 2$ a day, are pulling children out of school and cutting back on vegetables so they can afford rice. Those on \$1 a day are cutting back on meat, vegetables and one or two meals, so they can afford one bowl. The desperate - those on 50 cents a day-face disaster.

Roughly a billion people live on $\$ 1$ a day. If, on a conservative estimate, the cost of their food rises $20 \%$ (and in some places, it has risen a lot more), 100 million people could be forced 
back to absolute poverty. In some countries, that would undo all the gains in poverty reduction they have made during the past decade of growth. Because food markets are in turmoil, civil strife is growing; and because trade and openness itself could be undermined, the food crisis of 2008 may become a challenge to globalisation."

We can examine the impact of increased food prices using the price elasticities of different food groups. For example, we can compare South Africa and Malawi: South Africa is a middle-income, net-maize exporting country. Though clearly not all households within South Africa are middle-income and food-secure, we can get an impression of food security status from the country's aggregate food balance sheet data. Malawi, in contrast, is a net maize importer with high prevalence of food insecurity and malnutrition. Figure 9 shows the different effects in the two countries of a 30 percent price increase for all food groups (a modest escalation compared to the actual price rises of 2006 to early 2008). Food and calorie data are taken from FAO country food balance sheets. ${ }^{8}$ Elasticites were estimated using IFPRI's International Model for Policy Analysis of Agricultural Commodities and Trade (IMPACT). ${ }^{9}$ In this figure, own-price elasticities by country and specific food groups are used.

The baseline data for Malawi in 2003 estimate per capita calorie consumption to be just above the 2,100 kilocalorie daily minimum required for an adult. Though we see slivers of consumption of fruit, dairy and meat, the bulk of calories come from cereals and other starchy staples and pulses, indicating a lack of dietary diversity. The price increase squeezes consumption in all food groups, worsening dietary diversity. The largest drop is seen in cereals and starchy roots, significantly decreasing calorie consumption well below the required minimum.

On the other hand, South Africa starts out well above the minimum daily calorie requirements, with much higher consumption of meat as well as dairy and eggs, though still limited consumption of fruits and vegetables. With the price increase, calorie consumption is shown to decrease in South Africa as well; however, the higher status at baseline of food energy consumption and dietary diversity mean that the impacts are not as damaging for nutrition status; calorie consumption remains close to the minimum required level and meat and dairy products still form a substantial part of the diet.

Figure 9 gives a revealing snapshot of how food price increases will have different effects on nutrition and food security depending on the baseline consumption basket. However, actual household food budgeting is more complex than a simple response to own-price elasticity. Furthermore, price changes due to rising biofuel demand and other factors are not equal across all foods. Thus the changes in price of one food may impact spending on another food, as households maximize utility according to budget and preferences. For instance, when the price of maize rises, rather than simply decreasing consumption of starchy staples, a household may substitute another less preferred staple. Figure 10 compares the impact on calorie intake from higher prices using own-price and cross-price elasticities. Cross-price elasticities show the impact of consumers substituting other starchy staples for maize when its price increases by 30 percent. Note how calories from the cereals and starchy roots food group increase slightly when cross-price elasticities are used to allow for substitution.

\footnotetext{
8 These data can be accessed at HTTP:/ /FAOSTAT.FAO.ORG/SITE/345/DEFAULT.ASPX.

${ }^{9}$ For details on IMPACT, see Appendix 2.
} 
Looking ahead, Figures 11 and 12 report IMPACT projections of the effects of two different scenarios of biofuel demand on calorie availability and underweight preschool children in 2020 (as compared to 2000). The first scenario is based on actual biofuel investment plans, with assumed biofuel expansion in countries that have not specified plans. The second scenario assumes a doubled rate of biofuel expansion (von Braun, 2007a).

\section{Mitigation of Negative Impacts of Biofuels}

Appropriate policies can make bioenergy development more pro-poor and environmentally sustainable. Poor farmers might be able to grow energy crops on degraded or marginal land not suitable for food production, but appropriate soil and fertilizer management practices will have to be tailored to soil type and climatic conditions, otherwise bioenergy production may aggravate land degradation, generate GHG emissions and cause environmental problems through soil erosion and degradation of water quality. Also, further investment is needed in developing technologies to convert cellulose to energy. This could provide developingcountry farmers, including smallholders, with a use for crop residues like stalks and leaves, which would be converted into ethanol for electricity, thereby benefiting both poor farmers with additional income and also poor consumers with cheaper energy. This has positive food security implications because it has the potential to improve access to food and it would also

Figure 9: Impact of Food Price Increases on Calorie Consumption

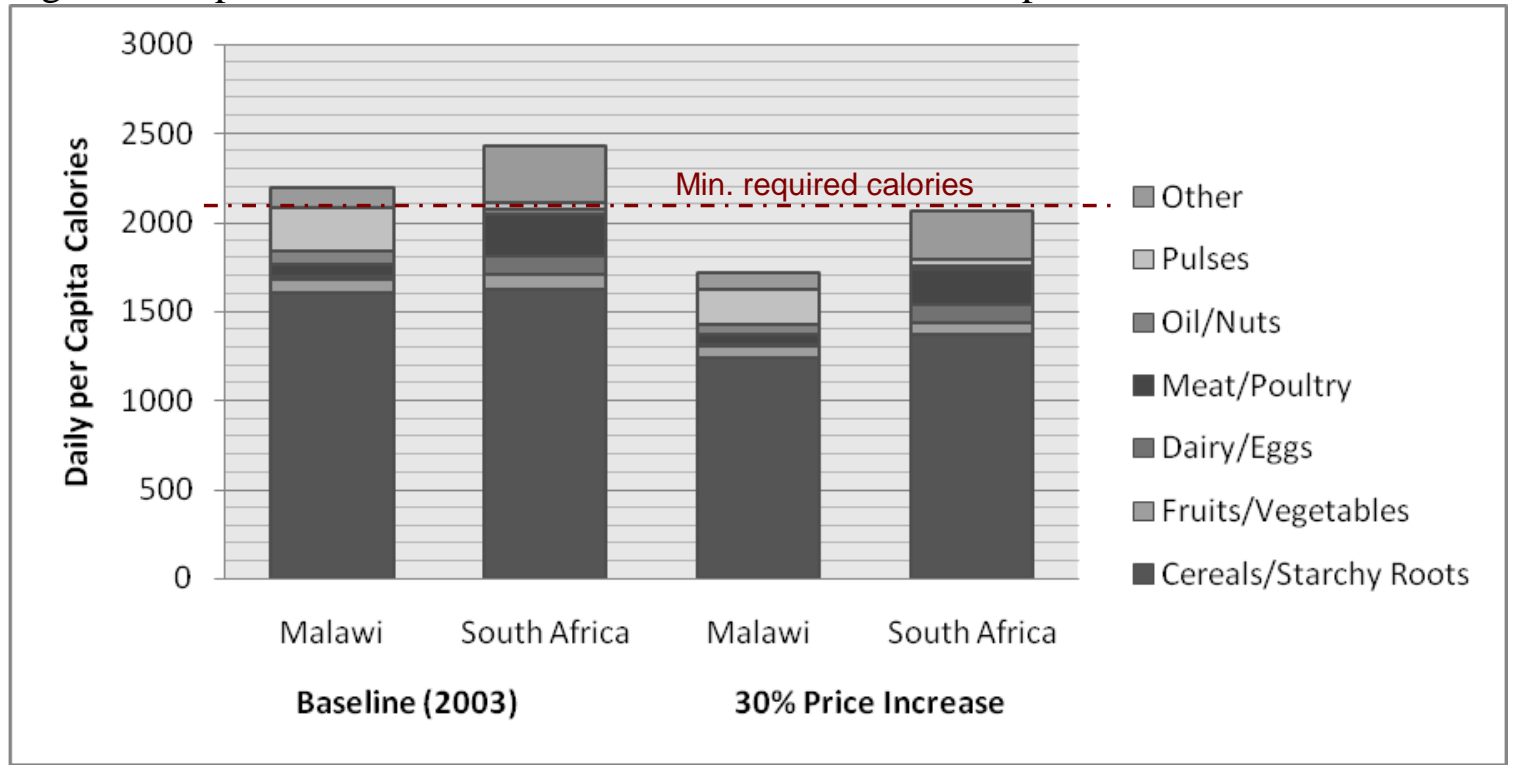

Source: Authors' calculations using FAOSTAT database and IFPRI IMPACT model.

reduce the impact of biofuel production on food systems and prices (von Braun and Pachauri, 2006). However, if the valuation of crop residues for biofuel increases significantly, this might reduce the availability of green manure for fertilizer.

Because biofuel production is labour-intensive, it could be a boon to rural areas with abundant labour. In Brazil, one study showed that in 1997, the ethanol sector employed about one million people. Thirty-five percent of these jobs were temporary harvesting jobs employing many poor migrant labourers from the northeast (Brazil's poorest region), but 65 percent were permanent (von Braun and Pachauri, 2006). This also has positive food-security implications. 
Smaller-scale and rural-based production will open up opportunities for biofuel to be propoor. Organizing groups of smallholders through contract farming schemes to grow and market biomass to processing plants may be most effective for this (Hazel, 2006). For example, substantial investments in biofuels are currently in process in Mozambique. Some 6 million hectares are already planted to biofuel crops and the government has received requests for use rights (as all land is state-owned) for more than 12 million additional hectares for this purpose. Preliminary results from an IFPRI macroeconomic analysis suggest that expansion via either plantation production of sugarcane for ethanol or outgrower cultivation of an oil-bearing crop called Jatropha curcas for biodiesel will lead to increased welfare and reduced poverty, due to income-earning opportunities, with positive implications for food security (Arndt et al., 2008).

However, technologies and institutional arrangements are important to determining the impact on poverty. The outgrower scheme is considerably more pro-poor, as it uses more unskilled labour and permits smallholders, rather than plantation owners, to reap land rents. Moreover, such schemes have the potential for technology to spill over to other crops, including food crops, with additional growth and poverty reduction benefits resulting, as well as increased food availability. Jatropha also is more environment-friendly than sugarcane, as it requires far less water, grows in infertile soil, even in drought conditions, animals do not graze on it and it produces non-polluting biodiesel (Arndt et al., 2008).

A considerable body of research indicates that women are more likely than men to use income for the wellbeing of children, including nutrition (Quisumbing, 2003). There may be barriers to female farmers taking advantage of opportunities created by biofuel demand. Women often have less access than men to land, water, credit, inputs and services, even when they are responsible for much of the agricultural work. In Cameroon, for instance, women provide 75 percent of the agricultural labour, but own less than 10 percent of the land. In Brazil, women own 11 percent of the land. These disparities make it difficult for women and especially female heads of household, to benefit from energy crop production. Even use of marginal lands for biofuel crops may work against women. Such land is often considered common property and in both South Asia and West Africa, women and children are responsible for gathering on and use of common property resources, but women often do not have decision-making authority over such resources. Thus, expansion of bioenergy crop production on such land could adversely affect women's ability to produce food (Rossi and Lambrou, 2008). 
Figure 10: Impact of Price Increase on Root and Grain Consumption in Malawi: Cross-price vs. Own-price Elasticity

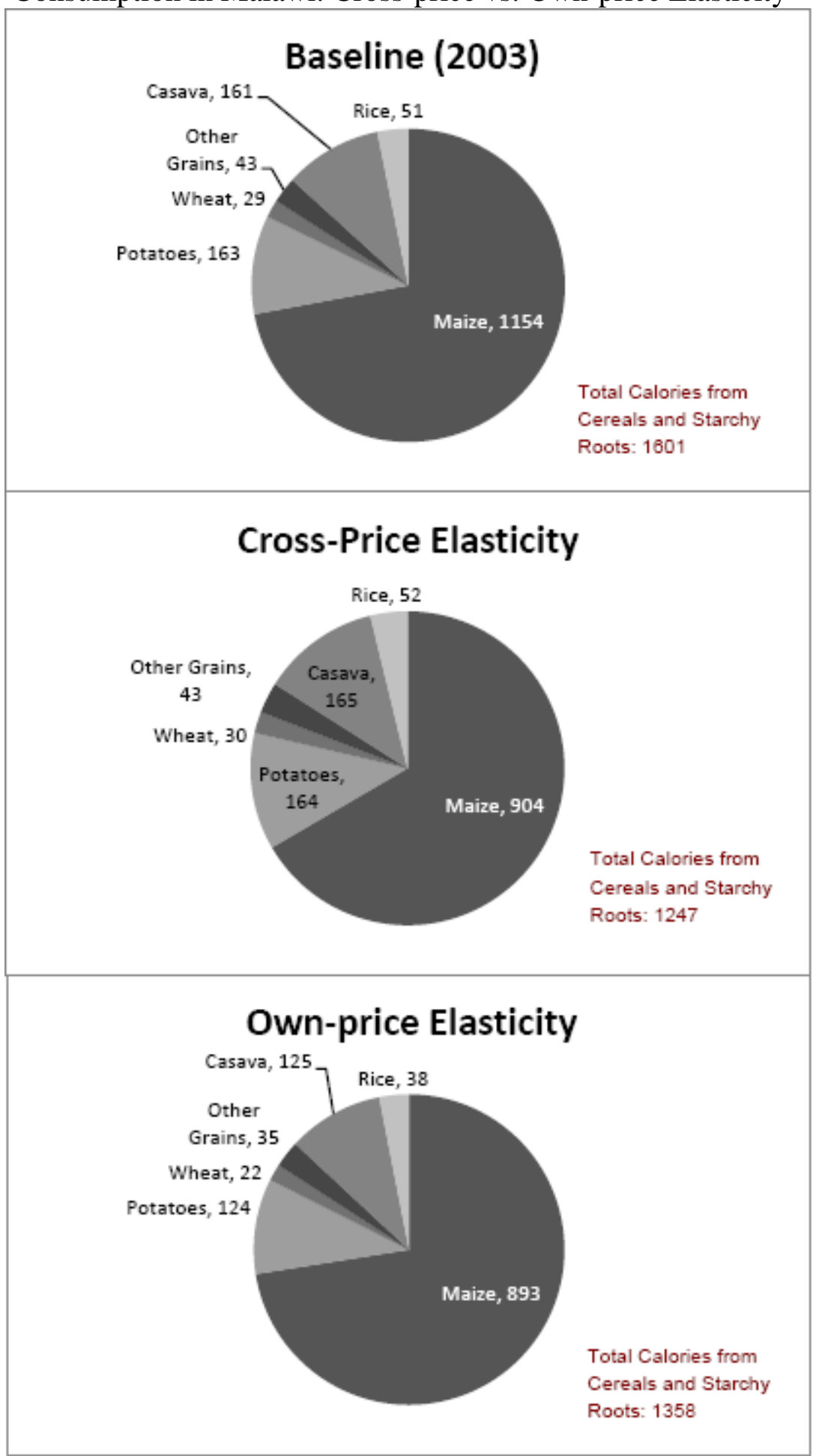

Source: Authors' calculations. 
Figure 11

\section{Impact of Biofuel Demand on Calorie Availability in 2020 (\% change)}

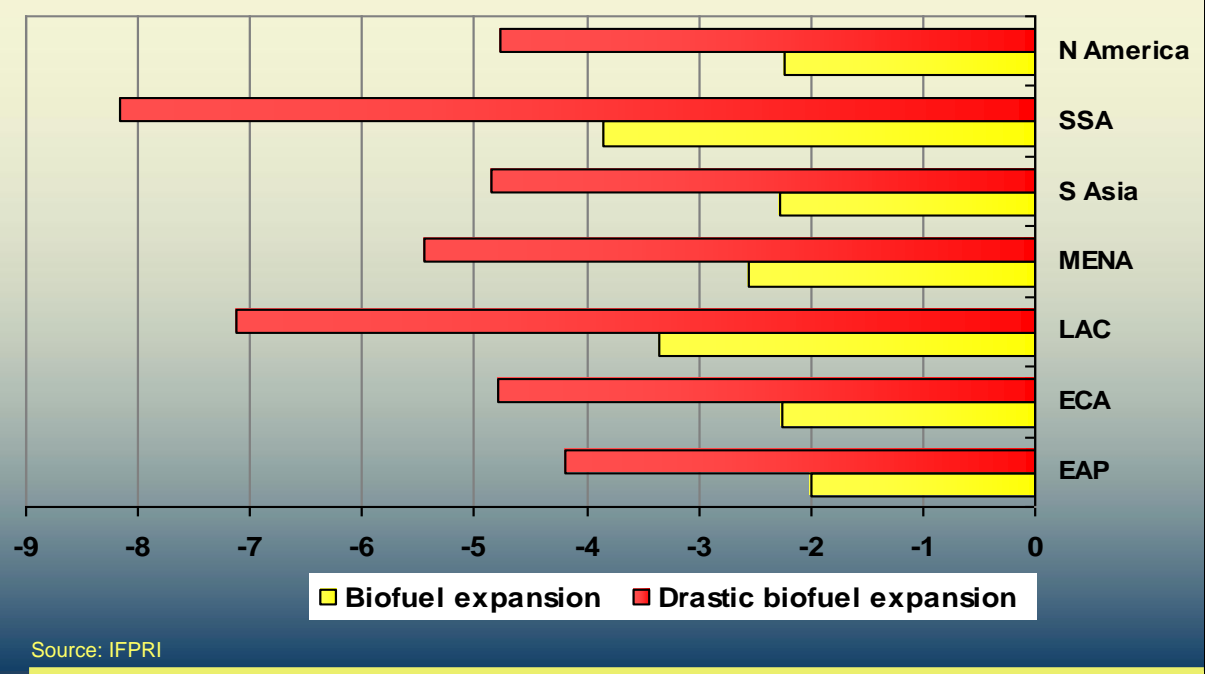

Figure 12: Changes in number of malnourished preschool children from baseline by 2020 (thousands) under two biofuel scenarios

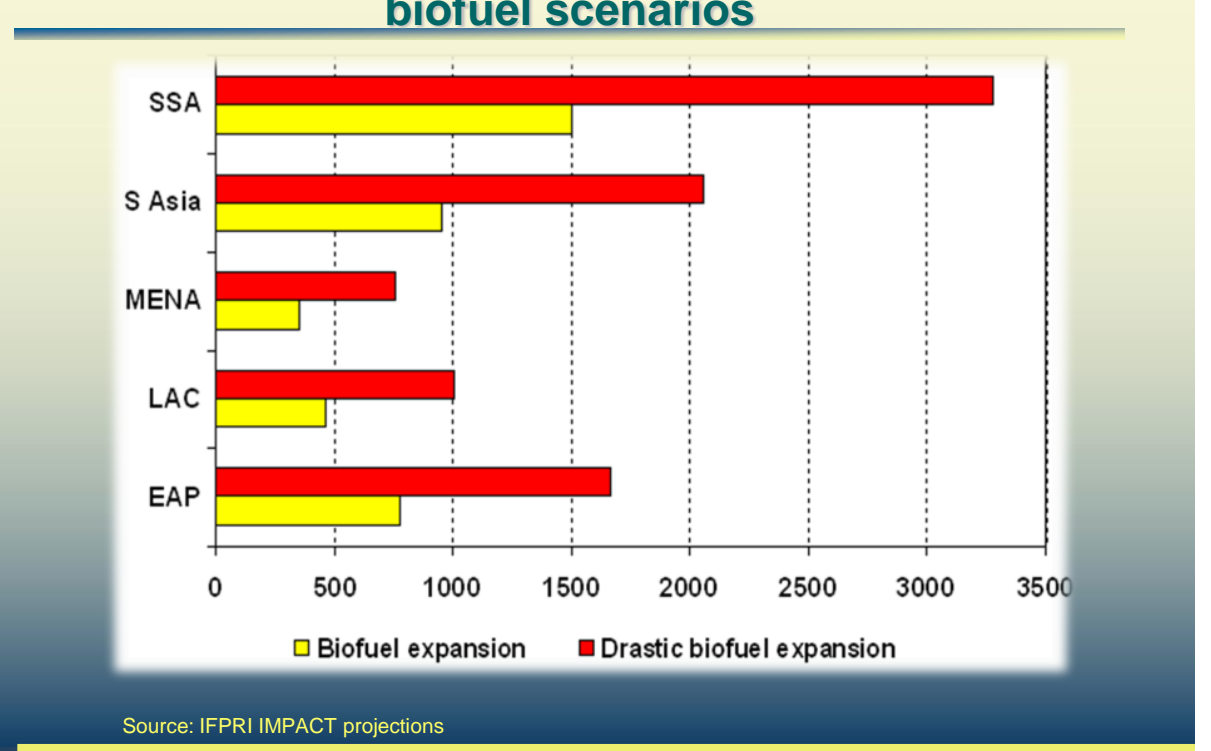




\section{Policies and Programmes for Improving Nutrition}

\section{International Initiatives}

For nearly two decades, the international community has repeatedly reaffirmed its commitment to eradicating malnutrition and assuring food security for all at high-level meetings attended by heads of state and government. These have issued declarations and detailed plans of action, setting goals and timetables for achieving significant improvements. The 1992 International Conference on Nutrition, sponsored by FAO and the World Health Organization (WHO), met in Rome to discuss ways to eradicate hunger and malnutrition and unanimously adopted a World Declaration and Plan of Action for Nutrition (FAO, 1992). Subsequently, the World Food Summit (FAO, 1996) and its follow-up, the World Food Summit: five years later (FAO, 2002), affirmed the ICN goals and adopted the Rome Declaration on World Food Security and the World Food Summit Plan of Action, which pledged concerted efforts towards eradicating hunger and as an essential first step, set a target of reducing the number of hungry people by half by 2015. The Millennium Summit (2000) and a series of follow-up meetings have repeated the commitments to achieve food security and good nutrition for all. A major milestone was the unanimous adoption, after two years of negotiations, of the Voluntary Guidelines to Support the Progressive Realization of the Right to Adequate Food in the Context of National Food Security (Right to Food Guidelines) by FAO's Council in 2004 (FAO, 2005b).

All of these declarations and plans of action strongly endorsed a rights-based approach to food security and nutrition. This entails a change in perspective: steps to achieve food security are no longer a matter of policy discretion but a legal obligation. Moreover, a rights-based perspective proceeds from the understanding that the realisation of the right to food is not only a function of improving the availability of key livelihood assets such as food or the means to procure it. It is also requires institutions and processes that empower people, increase transparency and accountability and ensure access to those assets for poorer and more vulnerable groups. This has implications for the formulation of policies, laws and programmes - in terms of both content and process. This approach views the achievement of food security and good nutrition as part and parcel of the state's efforts to protect and promote internationally recognized human rights, including the right to life, the right to adequate food, the fundamental right of everyone to be free from hunger and the right to the highest attainable standard of health. A rights-based framework considers states the primary dutybearers with regard to human rights and it empowers citizens - as the holders of rights - to hold states accountable for their actions. In particular, this framework stresses the importance of empowering mothers to nourish themselves and their children with support from their families and communities, as well as their governments.

Despite the repeated agreement of the world's leaders on the urgent need to reduce hunger and malnutrition, progress in achieving the internationally endorsed goals and targets has been extremely disappointing, notwithstanding great strides in a number of individual countries (see Chapter 3, above).

On the positive side, since the 1990s, widespread consensus has developed on the causes and consequences of malnutrition and therefore on the tools necessary to overcome it. The conceptual framework used by the Food Insecurity and Vulnerability Information and Mapping System, managed by FAO (see Figure 1) and the closely related UNICEF 
conceptual framework (SCN 2004: 65) reflect this consensus. In particular, this framework insists that the ultimate causes of food insecurity and undernutrition are social, economic, cultural and political. Therefore, although technical nutrition considerations and direct nutrition interventions remain crucial to devising solutions, it is also absolutely essential that efforts to achieve food security and good nutrition address these ultimate causes. Among other things, this requires policies that treat poor, food-insecure and malnourished people as primary actors in creating and implementing the solutions, not mere passive vessels into which technical quick-fixes are to be poured. This perspective is consistent with the rightsbased approach.

There are also regional food security and nutrition initiatives. For example, the African Union (AU) has adopted the New Partnership for Africa's Development (NEPAD) as a vision and framework for development on the continent. NEPAD includes a Comprehensive Africa Agricultural Development Programme (CAADP) and one of its strategic pillars focuses on increasing food supply and reducing hunger, with a nutrition component. The AU has devised a regional nutrition strategy under this framework. However, implementation has suffered from inadequate leadership, lack of capacity within the region (including at the AU Commission and in the regional offices of international organizations, as well as within national governments) and inadequate financial resources. ${ }^{10}$

At the national level, many developing countries have issued national policies and plans of action on nutrition. Moreover, a recent review of Poverty Reduction Strategy Papers (PRSPs) for 40 developing countries, half of them in Sub-Saharan Africa, found that most of the papers identify nutrition as a key development issue and many propose strategies to address nutrition problems. However, most of the papers do not prioritize nutrition actions or propose processes to assure adequate budgetary allocations and many of the PRSPs reviewed do not incorporate appropriate specific actions to address the problems identified even if they do include a nutrition strategy (Shekar and Lee, 2006). This analysis (which is preliminary) is significant, since PRSPs, developed through multi-stakeholder processes that include developing-country governments, civil society and donors (particularly the international financial institutions) have become a key device for planning and executing development cooperation. At the local level, community-centred food-based strategies for alleviating and preventing malnutrition in which communities are empowered to take action through a process of social mobilisation to translate the nutrition improvement strategies into action are considered a best bet for improving nutrition (Thompson, 2004).

Accelerated progress against food insecurity and malnutrition requires that governments put appropriate policy responses much higher on their agendas, with adequate resources provided. Donors must provide technical and financial support to these efforts. The potential impacts of climate change and bioenergy demand, discussed in Chapters 4 and 5 above, increase the urgency of action. The remainder of this chapter will examine promising policies and programmes to reduce food insecurity and malnutrition, both in general and in light of the likely impacts of climate change and bioenergy demand.

10 The discussion of regional initiatives in Africa is drawn from the draft report of the Africa regional meeting held at the $35^{\text {th }}$ Annual Session of the Standing Committee on Nutrition of the U.N. System, Hanoi, Vietnam, March 3-6, 2008. 


\section{Policies and Programmes}

There is broad consensus on the strategies for ending hunger. These have emerged from a number of international conferences and summits referred to above. The Millennium Summit processes, FAO's Anti-Hunger Programme, the report of the UN Millennium Project Hunger Task Force (2005) and NEPAD's CAADP all point in the same direction. Harmonised largescale multi-component programmes are required if we are to make a difference. Harmonisation means that aid agencies and donors must work together to reinforce national programmes built around PRSPs, national Anti-Hunger Programmes, or equivalent national MDG programmes. The key elements of such programmes are:

- create an enabling environment to promote peace, eradicate poverty and remove gender inequality;

- promote a fair and market-oriented world trade system;

- increase investments in human resources, sustainable food production systems and rural development;

- implement policies to improve physical and economic access by all to sufficient, nutritionally adequate, wholesome and safe food and its effective utilization;

- focus on participatory and sustainable agriculture, recognising the multifunctional nature of agriculture;

- use a "nutrition lens" to direct multi-sectoral actions to improve household food security; improve food quality and safety; prevent, control and manage infectious diseases and micronutrient deficiencies; promote appropriate diets, including breastfeeding and healthy lifestyles; provide care for the vulnerable, including people living with HIV/ AIDS; introduce productive safety nets; and provide direct assistance;

- prevent and prepare for emergencies; and

- build anti-hunger alliances.

\section{Governance Issues}

A number of governance issues have a considerable bearing on food security and nutrition. First, in many developing countries, there is a serious problem of institutional design. Both food security and nutrition are multi-sectoral issues, but developing country governments are almost always composed of sectoral ministries that frequently view budgetary allocation as a zero-sum game. In such an environment, it is difficult to achieve cross-sectoral collaboration. In the case of nutrition, whether responsibility falls to an inter-ministerial committee or a single ministry, it is seldom the top priority at the ministerial level. Nor do senior policymakers tend to recognize the costs of undernutrition. In many developing countries, a lack of adequate human resources and "nutrition champions" complicates these problems (Benson, 2008).

The problems are worsened by an international nutrition system (UN and bilateral donor agencies, academic institutions, civil society organizations and private firms) that is "fragmented and dysfunctional." Normative guidance is therefore incoherent and programme evaluation is weak (Morris, Cogill and Uauy, 2008: 608).

Secondly and not surprising, given these institutional issues, donors and developing-country governments have failed to make food security and nutrition high policy priorities, despite repeated pledges to do so. Annual donor funding for basic nutrition in low- and middleincome countries has run at less than US\$300 million during the present decade, compared to 
US\$2.2 billion per year for HIV/AIDS and several billion dollars annually in food aid (Morris, Cogill and Uauy, 2008). In real terms, aid to agriculture is about half the level of 25 years ago (FAO, 2006b). Governments of low-income countries devote 19 percent of their budgets to military expenditures, compared to less than 5 percent for agriculture. Military expenditures account for 2.6 percent of GDP in low-income countries, compared to one percent for public health spending (World Bank, 2007; FAO, 2001). However, there are some indications that priorities are changing. CAADP seeks to boost African government expenditures on agriculture to 10 of their budgets and to bring agricultural growth rates to 6 percent per year. The World Bank is putting renewed stress on agriculture as a development priority after years of relative neglect and has also put greater emphasis on nutrition in recent years (World Bank, 2006, 2008). Box 6.1 illustrates the difference it makes when a government puts food security and nutrition high on its policy agenda.

Thirdly, the current rise in food prices offers an important rationale for developed-country governments to eliminate trade barriers and domestic farm subsidies that depress world market prices. A fair global trading system can help advance food security and nutrition (von Braun, 2007a).

Lastly, there is an urgent need to reform global humanitarian response. Addressing hunger crises depends in part on more effective global peace-making and conflict resolution, as well as more timely response to early warnings of natural disasters. The current system depends on the ad hoc willingness of donors to meet appeals for assistance. Moving towards a more insurance-oriented approach that guarantees a response to emergency needs would protect the right to food in emergency situations. 


\section{Box 6.1: Cutting Hunger in Brazil}

Nearly one of every five Brazilians lives in poverty and 8 percent of the population (14 million people) is undernourished. The country is characterized by extreme income inequality. People in rural areas, the northern and north-eastern parts of the country, periurban zones, indigenous people, descendants of escaped slaves, homeless urban dwellers and the 24 million Brazilians living in semi-arid parts of the country all experience higher rates of poverty than the national average.

According to a 1996 survey, 11 percent of Brazilian children were stunted, but the figure rose to 34 percent in the north-east and 55 percent among indigenous children. High rates of micronutrient malnutrition are found among children in the north and north-east and among indigenous children.

Beginning in the early 1990s, Brazilian civil society and the Catholic Church (to which 75 percent of Brazilians belong) began to engage in a combination of hunger relief activities and food security advocacy. Civil society remains actively engaged in food security policy.

Since the election of President Luiz Inácio Lula da Silva in 2002, the Brazilian Government has made its Fome Zero (Zero Hunger) programme a top policy priority and has emphasized achieving the progressive realization of the right to adequate food. The Government has taken many of the steps recommended in the Right to Food Guidelines (FAO, 2005c). The centrepiece of Fome Zero is Bolsa Familia, a conditional cash transfer programme that benefits 42 million low-income Brazilians and encourages them to send their children to clinics and school. Recipient families report access to increased quantities of food and more diverse diets. Fome Zero includes both direct assistance and long-term poverty alleviation. It requires coordinated action by all areas of government at federal, state and municipal levels as well as extensive participation of civil society.

The government devotes 6 percent of its expenditures to health and another 6 percent to education, compared to just 3 percent for the military.

Brazil has one of the largest school feeding programmes in the world and provides free meals in all public schools. The programme emphasizes the use of locally produced fruits and vegetables and tries as much as possible to purchase food from local smallholders, in order to bolster small farmers' incomes as well as school enrolments and the nutrition of school-aged children.

The government has also set ambitious anaemia control targets. Since April 2004, all wheat and corn flour in Brazil is by law fortified with iron and folic acid.

The combination of this high-priority targeted effort to reduce poverty and hunger and strong economic growth has paid dividends in Brazil. Inequality and poverty have declined, while food security has increased. 


\section{A Revitalised Twin-Track Approach}

At the International Conference on Financing for Development held in Monterrey, Mexico, in 2002, FAO, the International Fund for Agricultural Development and the World Food Programme agreed upon a practical and affordable "twin-track approach" for combating hunger and poverty and for reaching the World Food Summit goals and the MDG targets. Track one is to strengthen the productivity and incomes of hungry and poor people, targeting the rural areas where the vast majority of them live and the agriculture sector on which their livelihoods depend (see IFAD, 2001; von Braun et al., 2005; Ahmed et al., 2007). Track two meanwhile provides direct and immediate access to food by hungry people and social safety nets for the neediest.

Track one involves improving agricultural productivity through investing in agriculture and encouraging the expansion of domestic agricultural production, improving infrastructure, distribution, preservation, processing and storage systems. It includes:

- simple, inexpensive technology packages (water management, soil fertility management, use of green and animal manures, cover crops, crop rotation including legumes, agroforestry and conservation tillage);

- rural infrastructure (roads, water, etc.);

- improved small-scale irrigation and soil quality;

- $\quad$ sustainable natural resource use and management (including forestry and fisheries);

- market and private sector development;

- food safety and quality; and

- Farmer Field Schools, participatory training.

Track two involves the putting in place of mechanisms to ensure that vulnerable population groups - the hungry and malnourished, the landless, marginalised, smallholders, fisher-folk and urban poor - are protected from falling further into poverty/food insecurity. It includes:

- unemployment and pension benefits;

- targeted conditional cash transfers or food voucher programmes for the most vulnerable, perhaps in exchange for a socially desirable activity such as children attending school or visiting health centres and receiving vaccinations;

- food-for-work or food-for-education using locally sourced food where possible;

- mother-and-infant feeding programmes (including nutritional supplements) using locally sourced food where possible;

- school gardens and school meals, ensuring school attendance especially of the girl child;

- feeding and other support programmes for people living with HIV/AIDS, their families and orphans; and

- emergency rations.

Although the twin-track approach was proposed primarily as a way to combat hunger, many of its key elements contribute to several MDGs simultaneously. Introducing improved water management, use of green manures, agroforestry and other low-cost, simple technologies, for example, not only enhances the productivity and incomes of small farmers, but also their role as custodians of land, water, forests and biodiversity. Similarly, investing in rural 
infrastructure such as roads and improved water facilities can reduce the lethal impact of water-borne illnesses, improve access to health care, prevent thousands of needless child and maternal deaths and open links to markets where farmers can sell surplus produce and acquire fertilizer and other inputs at reasonable prices. Measures to provide direct access to food for the neediest families such as feeding programmes for mothers and infants target the hub of the vicious cycle that perpetuates hunger and malnutrition from one generation to the next, undermining maternal health, stunting children's physical and cognitive growth, impairing school attendance and performance and impeding progress towards gender equality and the empowerment of women.

However given the unacceptably slow progress in reducing hunger and malnutrition referred to in Chapter 3 and the recent unprecedented sharp increases in staple food prices, unless targeted direct action is taken to ease the constraint of low purchasing power of consumers and improve diets, malnutrition levels are unlikely to fall and may even rise in some regions.

High food prices exacerbate food insecurity and create social tensions, but high agricultural commodity prices also present a potential opportunity for re-financing agriculture, especially for developing countries. To ensure that small farmers and rural households benefit from higher food prices, a favourable policy environment is needed that relaxes the constraints facing the private sector, farmers and traders. This means reversing the decline in the level of public resources spent on agriculture and rural development and investing more in agriculture. Investments by the private sector in agriculture and related sectors would be forthcoming if appropriate investments in public goods are put in place. With the rise in food prices, now is the time to invest in irrigation and agricultural research and set the stage for rapid productivity growth targeted to lift millions out of poverty and hunger, particularly in Sub-Saharan Africa.

In light of the alarming decline in cereal stocks, policies should emphasise the rebuilding of stocks at a national and regional level. Such food security stocks can not only help manage price volatility, but can help address humanitarian emergencies. Governments could consider holding a mix of cash and commodities in reserves. In addition, the development of commodity exchanges and future markets, as in Ethiopia, may likewise offer a means to moderate price volatility. Establishing such exchanges requires a transparent system of accounting.

The development of well-functioning and well-integrated markets for agricultural inputs, commodities and processed goods, especially in rural areas, will contribute enormously to poverty alleviation, food security and the overall quality of life in developing countries. Market performance improves and marketing costs fall when the government no longer monopolizes trade and a competitive private sector emerges. Yet even as the government reduces its role, competent and honest public administration will remain essential to assure that:

- contracts are enforced;

- grading and quality control standards are enacted and implemented (especially for export crops);

- market conduct and investment are appropriately and fairly regulated; and

- public health and safety are maintained. 
If developing-country governments implement credible and sustainable macroeconomic policies, these will provide a favourable environment for savings and investment and accurate and transparent incentives for consumers and producers alike (Kherallah et al., 2002).

The international community needs to take immediate action to defuse the current world food emergency and to seize the opportunities offered by higher food prices for re-investing in agriculture and thereby prevent similar dramatic situations occurring in the future. More food needs to be produced where it is urgently needed to contain the impact of soaring prices on poor consumers and simultaneously boost productivity and expand production to create more income and employment opportunities for rural poor people. Smallholder farmers need to be specifically targeted as beneficiaries to ensure they have proper access to land, water resources, credit, essential inputs such as seeds and fertilizers and services such as research, extension and training. In some instances, subsidies targeted to poor farmers may be a costeffective way to assure access to inputs. In many developing countries, access to land and other productive resources is extremely disparate. In such countries, agrarian reforms will not only boost food production, but can help reduce poverty by expanding livelihood options for landless rural people. When smallholders have access to resources, services and infrastructure, they are better able to increase their supply response to higher prices, boosting their incomes and improving their livelihoods.

Broad-based, sustainable agricultural development requires public investment in agricultural research aimed at enhancing smallholder productivity. Such research can generate scaleneutral technologies that smallholders can readily adapt to address their current constraints. Developing country governments and donors both need to increase investment in public agricultural research beyond current stagnant levels (von Braun, 2007a). Agricultural research also needs to enhance its focus on mitigation of and adaptation to climate change and on propoor biofuel development.

Increased agricultural productivity can improve food availability, rural employment and access to food by reducing prices, which will benefit consumers. Even if farm-gate prices fall, farmers may still enjoy increased incomes (which will allow them to diversify their own diets beyond subsistence staples) if productivity enhancements lower production costs. In lowincome countries, where agriculture and related activities account for a high percentage of the overall economy and employment, agricultural growth will stimulate growth in other sectors (Adato and Meinzen-Dick, 2007). If policies ensure that growth is broad-based, incomes are likely to rise for poor people, allowing them to invest in improved nutrition, health and other aspects of wellbeing. Policies can also encourage diversification of production, to increase availability of non-staple foods, both for farmers' own consumption and as an income-earning strategy (Hawkes and Ruel, 2006a). Policies should ensure that smallholders are able to participate in new agricultural opportunities, including production of biofuel crops.

A number of policies and institutions can help facilitate smallholder participation in value chains on a fair basis. Promoting organization and collective action, for example by encouraging farmers to form co-operatives and associations, can also help improve access to inputs, credit, services and markets. Other mechanisms to facilitate participation in value chains include improved access to information, weather and price risk management and contract farming (Minot and Hill, 2007). Despite the constraints, in parts of East Africa, Southeast Asia and Central America, smallholders have succeeded in getting a foothold in export markets for fresh fruits and vegetables. In Uganda and Vietnam, this had important poverty-reducing effects and has gone hand-in-hand with increased production of staples for 
local consumption. In Guatemala, cooperatives have enabled small farmers to gain income from the global value chain, improve their access to healthcare and enhance the nutritional status of their children (Watkins and von Braun, 2003; von Braun et al., 1989).

Agricultural and rural development strategies must recognize the important roles that women play in food security and nutrition, as farmers, marketing agents, stewards of natural resources, providers of childcare and chief preparers of meals within the household. In Kenya, for example, a programme to promote production of orange-flesh sweet potatoes (a good source of pro-vitamin A) among women farmers had a substantial impact on nutrition because it also included strategies to promote appropriate child feeding and caring practices (Hawkes and Ruel, 2006a).

Attention to sustainability is important not only for sound management of the natural resource base upon which agriculture depends, but also to maintain human health and nutrition. Agricultural practices, such as poor irrigation management and inappropriate use of synthetic pesticides, can have adverse effects on human health (e.g., by expanding malarial mosquito habitat or poisoning water with pesticides) (Hawkes and Ruel, 2006b).

Member Governments and FAO need to retain their focus on a twin-track approach, where improving agricultural productivity and promoting better nutritional practices at all levels takes place while, at the same time, promoting programmes that enhance direct and immediate access to food by the neediest. This now needs to be made more explicit to ensure that policies and programmes are put into effect to boost supply, not only by the larger commercial farmers but also by smallholders, while at the same time designing social protection and safety nets that protect the vulnerable. The revitalised twin-track approach should continue to provide emergency assistance to the poorest and help developing-world farmers take advantage of the new situation, but would also ensure that smallholder farmers and those involved in local food systems are specifically targeted to benefit from efforts in boosting supply. Indeed the inclusion of such groups through policies and support programmes for agricultural development acts as an effective safety net assisting millions of poor people whose livelihoods are at risk.

Improvements in the productivity of agriculture and related sectors directly increase farm and rural incomes and household food security. At the same time, targeted agricultural growth focused on small farmers promotes overall rural and non-farm employment and has a strong poverty-reducing effect. Emergency relief and rehabilitation operations aim to reduce the vulnerability of those affected by natural and human-induced disasters. By facilitating better access to the skills, tools, services and rights that help the rural poor make lasting improvements in their own livelihoods, programmes addressing this overarching goal increase the impact of work directly targeted to other goals.

Pro-poor agricultural growth alone will not eliminate malnutrition and its public health consequences. Some of the additional policies and programs that are needed are discussed below. Unless specific and direct action is taken to improve nutrition, the MDGs which aim to reduce the numbers of the undernourished by half by the year 2015 will not be achieved. Income and Employment Generation for Nutritional Improvement

In low-income developing countries, landless rural dwellers and most urban poor people rely on income from secure employment or business ownership to access food, health care and other necessities. Policies and programmes, therefore, need to create employment and 
microenterprise opportunities. Policies that support agricultural productivity should provide incentives for technologies that will create jobs for landless people rather than those that reduce employment. Likewise policies aimed at stimulating private investment - both foreign and domestic - should provide incentives for investment in labour-intensive ventures rather than capital intensive projects.

\section{Safety Net Programmes}

"Safety nets" are government programmes aimed at transferring resources to poor and foodinsecure people or people who are vulnerable to poverty, food insecurity and shocks. In addition to providing immediate resources that boost purchasing power, these programs help poor people to manage risk, cope with dislocations resulting from policy reforms such as structural adjustment or trade liberalization, boost their livelihoods (for example by providing public works employment or microcredit) and invest in the next generation's human capital, thereby breaking the inter-generational transmission of poverty. ${ }^{11}$ Some common forms of safety net programmes are food transfer programmes, cash transfers (which may or may not include conditions) and public works employment. Programmes may be targeted on the basis of such criteria as geographic location, occupation (e.g., targeting smallholders, artisanal fisherfolk, landless rural labourers and unemployed and underemployed people in both the countryside and cities), income, assets, nutritional status, gender, or membership in a socially excluded group; or they may be universal.

Universal programmes such as untargeted food subsidies or controls on the price of food may prove extremely costly to governments, but they also tend to enjoy a much more powerful political constituency than targeted programmes, as wealthier citizens may resent having to pay tax to support the latter schemes (Pinstrup-Andersen, 1993). Even targeted income or food transfers may place a substantial charge on the treasury. Mexico's Oportunidades cash transfer programme, ${ }^{12}$ for example, benefits 5 million families (one of every four Mexican households) at a cost of nearly $\$ 4$ billion annually. Nevertheless, such safety net programmes may be the most cost-effective interventions to improve nutrition. One reason that conditional cash transfer (CCT) programmes have become popular is that the conditions help gain political support from non-poor citizens. In a rights-based approach to development, the state has a duty to protect the vulnerable, who, in turn, have a right to social security. Any government subsidies to powerful urban elites should not be at the expense of low-income and food-insecure citizens.

Oportunidades (previously known as Progresa) is the oldest CCT programme in the developing world and the template for many others; numerous governments in the Western hemisphere and beyond have adopted similar schemes. The programme transfers funds to female caregivers in low-income households with children, based on research findings that women are more likely than men to invest in the wellbeing of their children. In exchange for the funds (which they may use as they please), families are expected to regularly send their children to health clinics and enrol them in school. The programme also includes mandatory nutrition and hygiene education for recipient parents and provides supplemental food to malnourished beneficiary children. The Mexican Government strictly enforces the conditions,

\footnotetext{
${ }^{11}$ For more detail, see WWW.WORLDBANK.ORG/SAFETYNETS.

12 Unless otherwise noted, the discussion of cash transfers which follows is drawn from Cohen et al. (2008 forthcoming).
} 
although such enforcement is more lax in some other countries. Evaluations have shown that the programme has boosted schooling and improved health and nutrition (Skoufias, 2005).

Some developing-country governments, particularly in Sub-Saharan Africa, have implemented unconditional cash transfers. In general, these are much less complex to administer and focus on improving food security and nutrition rather than investment in human capital. Also, if low-income people do not have ready access to health and education, then Oportunidades-type conditions make little sense. Evaluations have found South Africa's unconditional child support grant programme to be effective in improving child nutrition.

Food transfer programmes include food aid (drawing on either local supplies or external, inkind resources; Figure 13 indicates some of the many possible uses of food aid), supplementary feeding, targeted subsidies for the most vulnerable households, food stamps or coupons (or, where feasible, electronic benefit transfer cards similar to a debit card), etc. For example, India's main Public Distribution System in theory makes subsidized food available to all citizens, but in effect targets the food to lower-income and disadvantaged Indians by offering less preferred commodities and grades of commodities. In addition, the Targeted Public Distribution System offers additional subsidised cereal grains only to low-income families (Viswanathan, 2006). Food stamps and vouchers are easier to administer and less expensive than subsidies.

Public works programmes offer citizens who have lost their jobs or suffered a crop failure government-paid employment, usually for a limited period of time. Such schemes help people affected by shocks to maintain their purchasing power while developing publicly funded infrastructure, such as roads, or common pool assets, such as replanted forests, rehabilitated rangeland, or water harvesting structures. Employees may receive wages in the form of food, cash, or a combination. A large-scale example of such a programme is Ethiopia's Productive Safety Nets Programme, which utilizes substantial locally generated resources as well as donor funds and emphasises the use of cash payments (although payment is sometimes in food as well) as part of an effort to move the country away from dependence on external food aid (UNDP, 2007). 
Figure 13

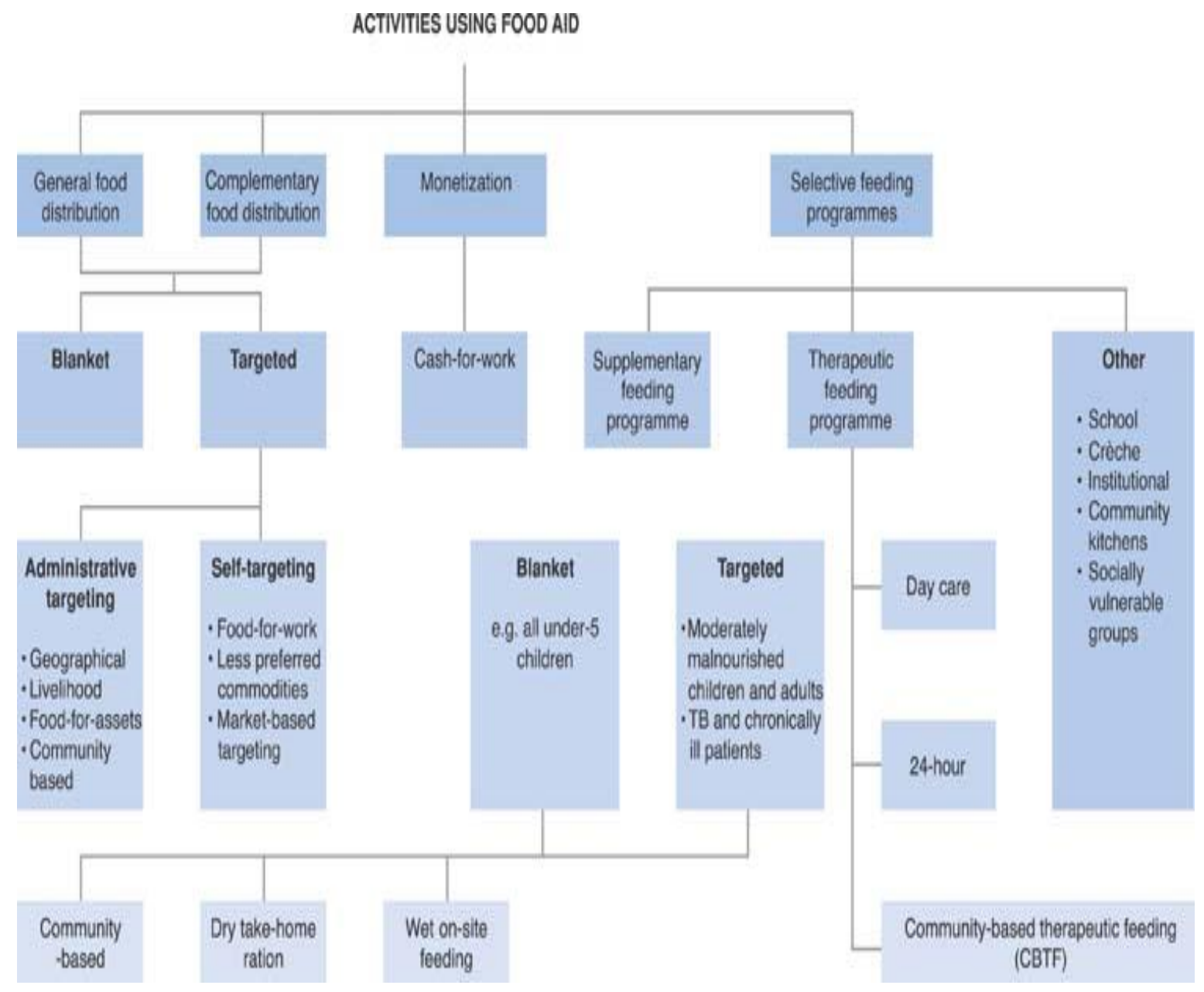

Source: FAO. ${ }^{13}$

\section{Insurance to Preserve Assets against Shocks}

Agriculture is a risky business, due to variable weather and fluctuating prices. Whereas farmers in developed countries can rely on well-established crop insurance mechanisms, as well as government subsidies in many countries, to insulate them from the catastrophic effects of shocks, smallholders in developing countries usually lack such protections, as insurance markets are largely missing, especially in rural areas. A shock may result from extreme weather, such as drought or flooding, another natural disaster, such as an earthquake or tsunami, or human-induced events, such as war. Because of high levels of risk and lack of insurance, poor farmers are often reluctant to adopt innovative technologies. Risk management and mitigation can help reduce this aversion (Dercon, 2004).

In order to maintain minimal levels of consumption of food and other necessities, poor people often respond by selling off their productive assets, such as land, tools and implements, livestock, labour, children and property (jewellery, homes, building materials, land), or by consuming seeds, the migration of some family members for remittances, or even prostitution.

13 Protecting and promoting good nutrition in crisis and recovery, Resource Guide. FAO/AGN, 2005. 
Such coping behaviours frequently make it much more difficult to resume previous livelihoods once the shock has passed. As a result, such shocks often lead to increased malnutrition, with long-lasting impacts on children. In the absence of insurance, safety-net programmes may help with risk mitigation. There are some simple forms of insurance that governments and aid agencies could implement in poor rural areas in developing countries. Saving schemes would permit poor people to engage in a certain measure of self-insurance. In addition, many developing countries have developed rainfall insurance (often in the form of lottery tickets), where there is an exceedingly low premium and a payout if rainfall is below a certain level deemed "normal" (Dercon, 2004). The World Food Programme carried out a more elaborate version of this with a pilot drought insurance scheme in Ethiopia in 2006; WFP in effect served as the insurer, backed up by commercial reinsurance (WFP, 2007). Such an approach overcomes some of the deficiencies of the current humanitarian response system by eliminating the need to appeal to donors and speeding up the provision of aid. Enhanced response to shocks will be important in the future, given the likelihood that climate change will lead to more frequent and severe extreme weather events.

\section{Direct Nutrition Interventions}

Direct nutrition interventions play a key role in improving nutrition as part of the comprehensive approach outlined above.

With regard to malnutrition among preschool children, a strong consensus has emerged that there is a crucial and narrow, "window of opportunity" for action: from conception through the first 18-24 months of a child's life (Figure 14). The damage that malnutrition causes to a child's physical and mental development during this time is likely to be considerable and irreversible and possibly fatal. Therefore, interventions should focus on this period (World Bank, 2006) while not neglecting other age groups, other family members, or low-income childless households who may equally be in need of support. In addition, the care of adolescent girls and pregnant women is vital for protecting their own health and that of their future children. Especially because of the importance of good maternal nutrition in achieving normal birth weights and good child health and nutrition, nutrition interventions should also take a life-cycle approach (Figure 4).

A recent study in Guatemala provides the first direct evidence that providing infants and very young children with adequate quantities and a variety of safe, good quality food enhances their productivity and incomes as adults. Previous studies provided substantial, but indirect evidence of this. Hence, investments in early childhood nutrition are an excellent use of scarce public resources in developing countries. The study in Guatemala tracked children who received food supplements fortified with micronutrients between 1969 and 1977. Follow-up research during 2002-2004 found that boys who received the supplements between 6 and 24 months of age on average earned wages 46 percent higher than those of non-recipients. For girls, the supplement seems to have improved school performance, although not adult incomes, probably because of gender differences in labour force participation and work activities. Significantly, children who first received the supplement after age three did not experience any economic gain (Hoddinott et al., 2008; see also Victora et al., 2008). 
Figure 14: Growth Faltering by Age

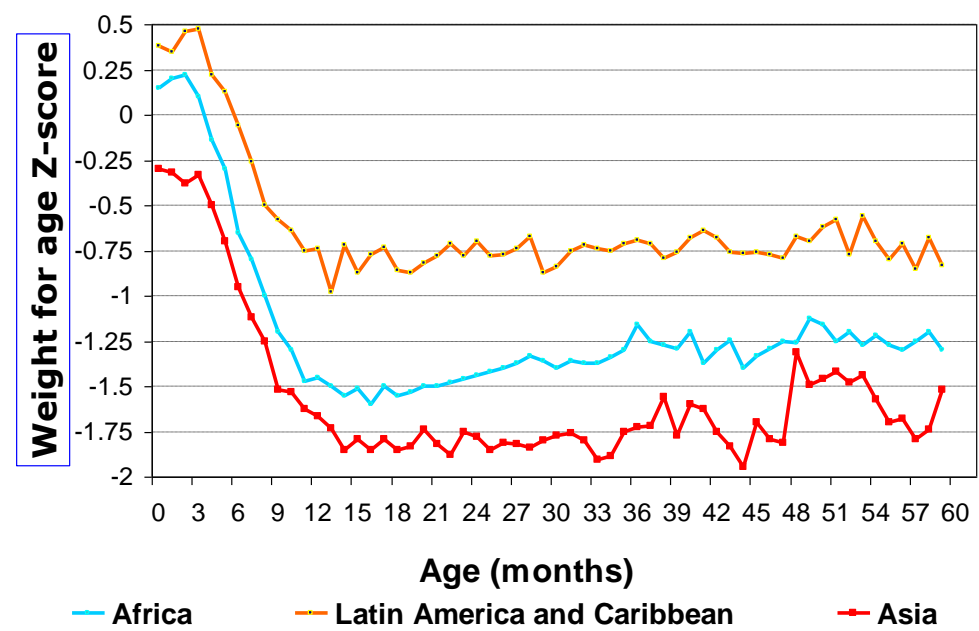

Source: Shrimpton et al. (2001).

Recent research suggests that there are a number of preventive and curative interventions that are effective in reducing maternal and child undernutrition. These are shown in Table 2 (Bhutta et al., 2008).

A number of initiatives have helped to promote exclusive breastfeeding during the first six months of life and continued breastfeeding with complementary foods through age 1 to 2 years. The International Code of Marketing of Breast-milk Substitutes, which includes voluntary industry cooperation with global norms and binding national legislation, is of particular importance in this regard. This legal instrument supports the realisation of the right to food through the promotion and protection of breastfeeding and the informed use of substitutes (where necessary). The UN Children's Programme has also worked to encourage hospitals to promote breastfeeding to new mothers through its baby-friendly hospital initiative. 14

Community-based maternal and child health programs often provide vitamin A and iron supplements along with immunizations, growth monitoring and, frequently, supplemental feeding (World Bank, 2006). Research in Haiti found that such programmes are more effective if they target children between six and 24 months of age and provide health and nutrition services to all low-income children in the community, not just those whose growth has faltered. Such a preventive approach results in greater reductions of stunting, underweight and wasting than the more commonly used recuperative approach, which targets children up to five years of age (Ruel et al., 2008).

In order to assure that working mothers in urban settings are able to provide care to their children, policies and programs need to facilitate the availability of low-cost amenities for the care of preschool children. These could be community based (Ruel and Quisumbing, 2006) or

${ }^{14}$ See HTTP://WWW.UNICEF.ORG/NUTRITION/INDEX_24806.HTML. 
Table 2: Some Effective Interventions to Reduce Maternal and Child Undernutrition

\begin{tabular}{|c|c|}
\hline$\underline{\text { Generally Effective }}$ & $\underline{\text { Effective in Situational Contexts }}$ \\
\hline \multicolumn{2}{|l|}{ Maternal and birth outcomes } \\
\hline Iron folate supplementation & $\begin{array}{l}\text { Maternal supplements of balanced energy and } \\
\text { protein }\end{array}$ \\
\hline Maternal supplements of multiple micronutrients & Matemal iodine supplements \\
\hline Maternal iodine through iodisation of salt & Maternal deworming in pregnancy \\
\hline Maternal calcium supplementation & Intermittent preventive treatment for malaria \\
\hline $\begin{array}{l}\text { Interventionsto reducetobacco consumption or } \\
\text { indoor air pollution }\end{array}$ & Insecticide-treated bednets \\
\hline \multicolumn{2}{|l|}{ Newborn babies } \\
\hline \multirow{2}{*}{$\begin{array}{l}\text { Promotion of breastfeeding (individual and group } \\
\text { counselling) }\end{array}$} & Neonatal vitamin A supplementation \\
\hline & Delayed cord clamping \\
\hline \multicolumn{2}{|l|}{ Infants and children } \\
\hline $\begin{array}{l}\text { Promotion of breastfeeding (individual and group } \\
\text { counselling) }\end{array}$ & $\begin{array}{l}\text { Conditional cash transfer programmes (with } \\
\text { nutritional education) }\end{array}$ \\
\hline \multicolumn{2}{|l|}{$\begin{array}{l}\text { Behaviour change communication for improved } \\
\text { complementary feeding* }\end{array}$} \\
\hline Zinc supplementation & Deworming \\
\hline Zinc in management of dianhoea & Iron fortification and supplementation programmes \\
\hline Vitamin A fortification or supplementation & Insecticide-treated bednets \\
\hline \multicolumn{2}{|l|}{ Universal salt iodisation } \\
\hline \multicolumn{2}{|l|}{ Handwashing or hygiene interventions } \\
\hline Treatment of severe acute malnutrition & \\
\hline
\end{tabular}

Source: Bhutta et al. (2008).

based at workplaces, although the latter approach is less common in the urban areas of most developing countries.

Micronutrient malnutrition may be tackled through improving dietary diversity, supplementation, or food fortification. The latter two approaches are frequently implemented through public-private partnerships. A new form of fortification is "biofortification," which involves the use of conventional plant breeding or agricultural biotechnology to develop crops high in nutrients such as iron, zinc and pro-vitamin A. Farmers have not yet widely planted such crops in their fields, but breeding efforts also aim to develop varieties with agronomically desirable traits, such as higher yield. Biofortification may be more sustainable than supplementation or standard fortification, as it has lower recurrent costs. ${ }^{15}$ Deployment of genetically modified crops in developing countries requires the establishment of sound biosafety systems, including the capacity to assess environmental risks that may indirectly affect human health and development (WHO, 2005b).

In the case of children who are severely wasted, if there are no medical complications, community-based therapeutic care is preferable to treatment in a hospital or clinic. Lowincome families often cannot readily reach such in-patient facilities. Ready to use therapeutic foods (RUTFs) play an important role in community-based treatment. Children with moderate

15 See HTTP://WWW.HARVESTPLUS.ORG for more information. 
acute malnutrition may be provided with traditional blended and fortified food aid, such as corn-soya blend (Bhutta et al., 2008; Wiesmann et al., 2007).

For refugees and internally displaced people in camp settings, fortification of rations, frequently using enterprises located in the host countries, has helped reduce "hidden hunger" (UNHCR, 2005).

Nutrition interventions should encourage health-seeking and health promoting behaviours through policy support, capacity building and advocacy - information, education and communication. Efforts to improve access to health services should include support for the production and use of acceptable traditional medicines and practices and indigenous health knowledge.

Nutrition education can promote nutritional knowledge and appropriate attitudes of caregivers about foods, social and dietary customs, family/child care and feeding practices, household hygiene and the competing demands on women's and other caregivers' time that may constrain their ability to secure, prepare and serve food. Even though poor households may not be able to afford to increase the amount of food they consume, with enhanced nutritional knowledge they may be able to change the way it is allocated among household members, the type of food that is consumed, or the way that it is prepared and served, in ways that can enhance nutrition.

Access to clean water and safe sanitation is crucial for both good health and good nutrition. Rapid urbanization in developing countries presents new challenges to governments to assure clean and safe environments, particularly in low-income communities. Climate change stiffens this challenge as it contributes to water scarcity and also will lead to more frequent flooding and therefore increased risk of contaminated urban water sources.

For those living with the disease, better nutrition can postpone HIV/AIDS-related illnesses, such as diarrhoea, pneumonia and tuberculosis and prolong life. Nutrition policies can provide incentives for improving diets, for strengthening the nutrition focus of health services (particularly in the context of anti-retroviral therapy and home-based care) and for ensuring nutritionally balanced food aid as a safety net for people who are acutely food-insecure or at risk of becoming so, such as households hosting AIDS orphans (Gillespie and Kadiyala, 2005). There is evidence that community-based therapeutic care, using RUTFs, may be helpful in the treatment of HIV/AIDS in both children and adults (Wiesmann et al., 2007).

\section{Education for All}

IFPRI research has shown that there were four drivers of the reductions in child malnutrition achieved in developing countries during 1970-95 (Figure 15). Improvements in female education had the biggest impact, followed by increases in food availability, improvements in the health environment and improvements in women's social status relative to that of men. This means that accelerating progress against child malnutrition will require changes in policy and practices that discriminate against women, as well as increased public expenditures to assure access to health services and universal primary education.

Educating girls has beneficial effects on family size, birth spacing, child care practices and household income, as well as child nutrition, particularly when education promotes good nutrition, use of preventive health care facilities and other caring practices. Yet the 
international community has failed to deliver on its commitment to universal primary education, first made at the 1990 World Conference on Education for All and more recently included in the MDGs. At present, 100 million primary school-aged children are not enrolled, accounting for 13 percent of the children in that age group. A sizeable majority, 57 percent, of the primary level out-of-school children are girls (UNESCO, 2008). School meals and foodfor-education programs can help achieve full enrolments, educational gender equality and improved food security.

One can also look at this educational gender gap through the lens of outcomes. The adult literacy rates for all low- and middle-income countries are 85 percent for men and 72 percent for women. In Sub-Saharan Africa, the figures are 70 and 53 percent and in South Asia, 70 and 45 percent (World Bank, 2007).

Figure 15

\section{Sources of Reduction in Developing Country Child Malnutrition, 1970-95}

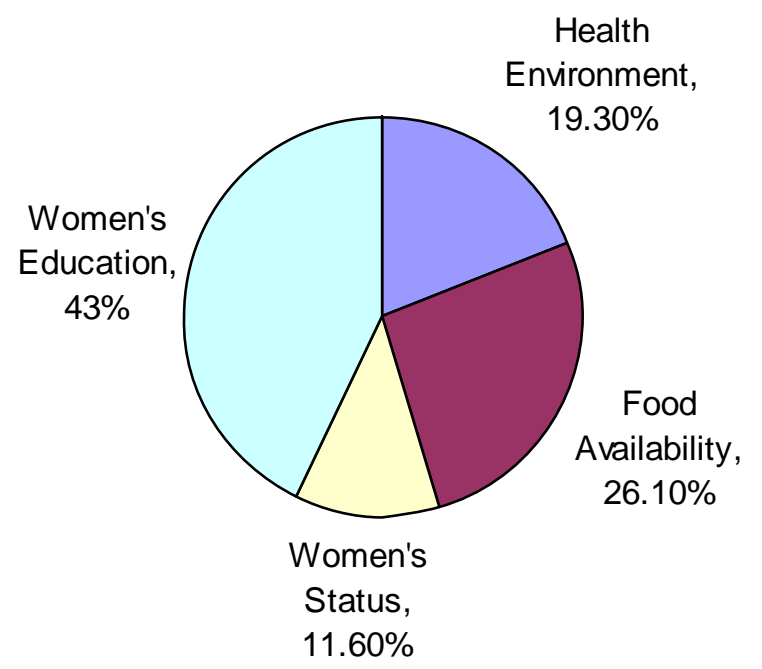

Source: Smith and Haddad (2000).

Priorities and Approaches for Responding to Threats to Nutrition from Climate Change and Biofuel Demand

Need for serious global governance with regard to climate change

A combination of adaptation and mitigation measures, sustainable development and research to enhance both adaptation and mitigation can diminish the threats to nutrition from climate change. The human rights framework offers the means to explicitly link environmental concerns to good governance and the inherent emphasis of human rights on "humans." The 
rights-based approach to climate change can trigger the development of national normative frameworks and tools.

There are multiple adaptation options that imply different costs, ranging from changing practices in place to changing locations of food, fibre, forestry and fishery activities. The potential effectiveness of the adaptations varies from only marginally reducing negative impacts to, in some cases, changing a negative impact into a positive impact. On average, cereal cropping system adaptations such as changing varieties and planting times enable avoidance of a 10-15 percent reduction in yield corresponding to a $1-2^{\circ} \mathrm{C}$ local temperature increase (Easterling et al., 2007). The benefits of adaptation tend to increase with the degree of climate change up to a point; adaptive capacity in low latitudes is exceeded at $3^{\circ} \mathrm{C}$ local temperature increase (Easterling et al., 2007).

Changes in policies and institutions will be needed to facilitate adaptation for food security to climate change. Adaptation measures should be integrated with development strategies and programmes, country programmes and Poverty Reduction Strategies.

Adaptation is "shared responsibility," and stakeholders represent a variety of sectoral interests, including agriculture, human health, water supply, coastal management, urban planning and nature conservation.

With regard to mitigation, financial incentives can help promote improved land management, maintenance of soil carbon content and efficient use of fertilizers and irrigation. This could encourage synergy with sustainable development and reducing vulnerability to climate change. It can also help improve the health environment. Incentives to improved waste and wastewater management, as well as stronger regulation, would improve the sanitary environment (Metz et al., 2007). Both outcomes will contribute to better nutrition.

\section{Policies for Responding to Rising Bioenergy Demand}

Biofuel development in developing countries should be carefully designed, so as not to crowd out investments in roads, more general agricultural development, health, nutrition and other efforts aimed at climate change mitigation and adaptation. Policy should ensure that smallholders, including women farmers, have access to resources, infrastructure, services and organizations so that they can participate in biofuel production on a fair basis. Policies need to examine the environmental consequences of biofuel development and avoid unsustainable practices.

Increased investment in agricultural productivity for developing countries will help them both to increase their own food production and be able to engage in the biofuel market. It may even be possible for developing country farmers to leap-frog to second generation cellulosic biofuel technologies, creating energy and emission efficiency gains. Therefore, donors and developing-country governments must reverse the neglect of agriculture and rural development of the past 25 years (von Braun, 2008).

Creating a biofuels industry that helps the neediest people improve their lives and livelihoods will require careful management at all levels. This management includes taking the necessary steps to develop a global market and trade regime with transparent standards for biofuels (von Braun and Pachauri, 2006). Developed-country governments should move rapidly towards 
market-oriented biofuel production and processing, removing subsidies and ending trade barriers to developing-country biofuels.

Global cooperation is needed on $R \& D$ to bring technologies on line that will allow production of biofuels from non-food crops, thereby avoiding tradeoffs among food, feed, fibre and fuel uses of staple crops.

Participatory decision-making and cross-sectoral policy coordination should be institutionalized in the area of bioenergy. The clear allocation of the roles of duty-bearers and rights-holders may also increase government responsiveness, as well as accountability and transparency.

To protect the poor and food- insecure people from adverse effects of the rapid growth of the biofuel sector there is a need to develop policies for food and fuel to be linked to safeguard food security, to assist those negatively impacted by climate change and the expansion of biofuels production and to raise awareness among policymakers to provide for integration of local, regional or international policies that affect the agricultural sector and the rural economy (FAO, 2008f). 


\section{Conclusions and Recommendations}

Efforts to assure food security and good nutrition in the face of current challenges, including climate change and rising bioenergy demand, must continue to place the achievement of the MDGS, as internationally agreed-upon development targets, at the centre of human endeavour. In particular, it remains essential to accelerate progress in reducing poverty, hunger and malnutrition while mitigating risk and protecting the environment. A rights-based approach engages affected stakeholders - particularly smallholder farmers, including women and poor rural and urban consumers - as active participants in this process. Civil society organizations have a key role to play.

\section{Responding to Climate Change}

Climate change is projected to affect the health status of millions of people, particularly those with low adaptive capacity, through increases in malnutrition and consequent disorders, with implications for child growth and development, as well as through an increase in diarrhoeal disease. The $4^{\text {th }}$ IPCC assessment report has concluded that, due to the very large number of people that may be affected, malnutrition linked to extreme climatic events may be one of the most important health consequences of climate change.

Agricultural production, including access to food, is projected to be severely compromised by climate variability and change in many African countries and Southeast Asia. This would further adversely affect food security and exacerbate malnutrition.

Agriculture, food and nutrition issues need to be placed onto national and international climate change agendas, in order to devise effective and pro-poor policies. The expiration of the Kyoto Protocol in 2012 offers an opportunity to bring these issues to the table as a new agreement is negotiated.

Sustainable economic development and poverty reduction remain top priorities for developing countries. Climate change could exacerbate climate-sensitive impediments to sustainable development faced by developing countries. To address this challenge requires integrated approaches for adaptation, mitigation and sustainable development. Strategies should include measures that would simultaneously reduce pressures on biodiversity and food security and contribute to carbon sequestration.

Adaptation is a key factor to address the impacts climate change will have on food production and food insecurity. Early impacts of climate change can be effectively addressed through adaptation; however, options for successful adaptation diminish and associated costs increase, with increasing climate change impacts. Prioritization of investment needs aimed at improving adaptation of food security to climate change is crucial. The development of adaptation strategies should consider that adaptation capacity depends on geographical situation, economic development, natural resources, social context, institutions, governance and technology of the countries.

Sustainable development can reduce vulnerability to climate change by enhancing adaptive capacity and increasing resilience. Plans for sustainable development should promote adaptive and mitigation strategies, for example, by including adaptation and mitigation measures in 
land-use planning and infrastructure design or including measures to reduce vulnerability in existing disaster risk reduction plans.

Mitigation in agriculture has a significant potential and uses technologies which can be implemented immediately. Agricultural mitigation measures often have synergy with sustainable development policies and many influence social, economic and environmental aspects of sustainability. In order to improve the mitigation potential in this sector, synergies between climate change policies, sustainable development and improvement of environmental quality should be promoted.

Adaptation and mitigation measures should be developed as part of overall and countryspecific development programmes such as Poverty Reduction Strategy Papers, pro-poor strategies and national Food and Nutrition Action Plans. In this framework, FAO and other international organizations should assist countries to assess their capacity building needs for the development of integrated adaptation, mitigation and sustainable development strategies to address food security and nutrition challenges from climate change and biofuel demand.

Adopting a human rights' perspective when tackling the challenge of climate change puts people at the centre of attention of decision-making. Sustaining and protecting the environment against degradation will be enhanced through the protection and promotion of human rights. At the same time, human rights cannot be fully realized without securing the environmental dimensions of ecosystem services essential to the right to life, the right to food and all other human rights.

Priority research needs for the assessment of climate change impacts on food, fibre, forestry and fisheries have been identified in the 4th IPCC assessment report. Attribution of current and future climate-change-related malnutrition burdens is problematic because the determinants of malnutrition are complex. Research and information on the links between climate change-related food insecurity and malnutrition are necessary.

\section{Assuring Pro-Poor and Sustainable Biofuel Development}

A number of steps must be taken in order to assure that biofuel development is pro-poor, environment friendly and supports food security and nutrition:

- developed-country governments should remove trade barriers to developing-country biofuel exports;

- developed-country governments and international organizations such as FAO and the international financial institutions should also provide financial and technical assistance to pro-poor, sustainable biofuel projects in developing countries;

- developing-country governments need to conduct food security and nutrition impact assessments before launching biofuel development projects;

- developing-country government policies should make opportunities available to smallholders, including women farmers, to participate in biofuel production, such as incentives to encourage outgrower schemes and labour-intensive processing plants;

- policies should also encourage technology spillovers from biofuel production that can enhance food crop production;

- research is needed on non-food crop sources of bioenergy, e.g., cellulosic biofuels, to minimize food-feed-fuel tradeoffs; and 
- policies should favour production of biofuel crops with a small environmental footprint that can contribute to climate change adaptation and mitigation strategies.

\section{Making Nutrition a Development Priority}

Direct nutrition improvement programmes have a unique, essential role to play in efforts to reach the MDGs. Good nutrition makes an essential contribution to the fight against poverty. It protects and promotes health; reduces mortality, especially among mothers and children; encourages and enables children to attend and benefit from school; and enhances productivity and incomes in adulthood. By indirectly strengthening communities and local economies, good nutrition contributes to the achievement of other development objectives which, in turn, impact upon the MDGs. For example, the increased participation of poor and vulnerable people and of women in the development process that may arise from effective community nutrition programmes will likely lead to more effective demands for improved services and to better use of existing resources. The use of nutritional goals and indicators and of participatory community nutrition approaches to design and monitor interventions would facilitate the development and implementation of such interventions. It is also essential to recognize and address the social, economic, cultural and political determinants of undernutrition. National nutrition data should be disaggregated with regard to groups presumed to be vulnerable, in order to establish whether and to what extent nutritional discrepancies exist and to inform policies towards realizing the right to food and the highest attainable standard of health.

Developing-country governments should give high priority to implementing proven nutrition interventions on a national scale. Donors should substantially increase support for efforts to improve nutrition. Improved policy coherence and international cooperation are required to eradicate malnutrition in all its forms (Morris, Cogill and Uauy, 2008). Key elements of an intervention strategy for making nutrition a development priority include:

- setting targets, agreeing on coordinated actions in each country and mobilizing resources;

- using participatory approaches that build local institutions and skills, strengthen legal rights and access to resources and empower women, indigenous people and other vulnerable groups;

- giving priority to "hot spots" where a high proportion of the population suffers from malnutrition, hunger and extreme poverty and often also from illiteracy, disease, social marginalization and child and maternal mortality;

- using food assistance to develop and enhance skills or to create physical assets, such as food storage facilities or soil and water conservation structures that will help communities weather crises and build the foundation for longer-term development;

- focusing people-centred policies and investments in rural areas and on agriculture in ways that promote sustainable use of natural resources, improve rural infrastructure, facilitate the functioning of markets and enhance rural institutions;

- supporting dynamic rural growth by improving the productivity of smallholder agriculture and by diversifying into rural non-farm activities and strengthening microenterprises in which rural women play a major role;

- strengthening poor urban livelihoods with an urban twin-track approach that combines pro-poor employment and asset generation programmes with measures to help the poor meet their basic needs for food, shelter, water, health and education; and 
- accelerating progress towards an open and fair international trading system, with special attention to improving market access and reducing export subsidies and tradedistorting domestic support in agriculture (FAO, 2005a).

All of these approaches are proven, practical and affordable. All can be effectively adapted and applied to meet local requirements, monitored to ensure that they are effective and scaled up as they prove successful and sufficient resources are mobilized. If developing countries gear up their efforts to revitalize agricultural and rural development and ensure that hungry people have access to food and if donor countries fulfil their pledges to increase development assistance substantially, we can reach the WFS and MDG hunger reduction targets and by doing so, shift progress towards reaching all of the other MDGs into high gear. 


\section{References}

Abramovitz, J. 2001. "Unnatural Disasters." Worldwatch Paper No. 158. Washington, DC: Worldwatch Institute.

ACC/SCN (UN Administrative Committee on Coordination/Subcommittee on Nutrition) and IFPRI (International Food Policy Research Institute). 2000. 4th Report on the World Nutrition Situation. Geneva and Washington: ACC/SCN and IFPRI. HTTP://WWW.UNSYSTEM.ORG/SCN/PUBLICATIONS/4RWNS/4RWNS.PDF.

ACIA (Arctic Climate Impact Assessment). 2005. Arctic Climate Impact Assessment. New York: Cambridge University Press.

Adato, M. and R. Meinzen-Dick, eds. 2007. Agricultural Research, Livelihoods, and Poverty: Studies of Economic and Social Impacts in Six Countries. Baltimore: The Johns Hopkins University Press for IFPRI.

Ag Bendech M., M. Chauliac, P. Gerbouin-Rerolle, N. Kante and D. Malvy D. 2000. "Les enjeux de la consommation alimentaire en milieu urbain à Bamako." Santé Publique 12(1): 45-53. In: Food Based Approaches for a Healthy Nutrition in West Africa, Ouagadougou, 23-28 Nov 2003, Proceedings of the $2^{\text {nd }}$ International Workshop. Ouagadougou: Presses Universitaires. HTTP://WWW.MPL.IRD.FR/FN2OUAGA/P2IW_OUAGA_A4.PDF.

Ahmed, A.U., R.V. Hill, L.C. Smith, D.M. Wiesmann and T. Frankenberger. 2007. "The World's Most Deprived: Characteristics and Causes of Extreme Poverty and Hunger." 2020 Vision for Food, Agriculture, and the Environment Discussion Paper No. 43. Washington, DC: International Food Policy Research Institute.

Anisimov, O.A., D.G. Vaughan, T.V. Callaghan, C. Furgal, H. Marchant, T.D. Prowse, H. Vilhjálmsson and J.E. Walsh. 2007. "Polar Regions (Arctic and Antarctic)." In M.L. Parry, O.F. Canziani, J.P. Palutikof, P.J. van der Linden and C.E. Hanson, eds. Climate Change 2007: Impacts, Adaptation and Vulnerability, Contribution of Working Group II to the Fourth Assessment Report of the Intergovernmental Panel on Climate Change. Cambridge, UK: Cambridge University Press. Pp. 653-685.

Arndt, C., R. Benfica, J. Thurlow and R. Uaiene. 2008. "Biofuels, Poverty and Growth: A Computable General Equilibrium Analysis of Mozambique.” Photocopy. Washington, DC: IFPRI.

Avery, D. 2006. "Biofuels, Food, or Wildlife: The Massive Land Costs of U.S. Ethanol.” Issue Analysis No. 5. Washington, DC: Competitive Enterprise Institute.

Aziz, K.M.A., B.A. Hoque, S. Huttly, K.M. Minnatullah, Z. Hasan, M.K. Patwary, M.M. Rahaman and S. Cairncross. 1990. "Water supply, Sanitation and Hygiene Education: Report of a Health Impact Study in Mirzapur, Bangladesh." Water and Sanitation Report Series No. 1. Washington, DC: The World Bank.

Behrman, J.R., H. Alderman and J. Hoddinott. 2006. "Hunger and Malnutrition.” In B. Lomborg, ed. How to Spend \$50 Billion to Make the World a Better Place. Cambridge, UK: Cambridge University Press. Pp. 95-107.

Bennett, M.K. 1941. “International Contrasts in Food Consumption.” Geographical Review 31: 365-374.

Benson, T. 2008. "Improving Nutrition as a Development Priority: Addressing Undernutrition in National Policy Processes in Sub-Saharan Africa.” Research Report No. 156. Washington, DC: IFPRI.

Bhutta, Z.A., T. Ahmed, R.E. Black, S. Cousens, K. Dewey, E. Giugliani, B.A. Haider, B. Kirkwood, S.S. Morris, H.P.S. Sachdev and M. Shekar. 2008. "What Works? Interventions for Maternal and Child Undernutrition and Survival." The Lancet 371 (9610, February 2): 417-440.

Biggs, R., E. Bohensky, P.V. Desanker, C. Fabricius, T. Lynam, A. Misselhorn, C. Musvoto, M. Mutale, B. Reyers, R.J. Scholes, S. Shikongo and A.S. van Jaarsveld. 2004. Nature Supporting People: The Southern Africa Millennium Ecosystem Assessment. Pretoria: Council for Scientific and Industrial Research.

Bioversity International. 2008. “Conservation and Use." HTTP://WWW.BIOVERSITYINTERNATIONAL.ORG/THEMES/CONSERVATION_AND_USE/INDEX.ASP. 
Black, R.E., L.H. Allen, Z.A. Bhutta, M. de Onis, C. Mathers and J. Rivera. 2008. "Maternal and Child Undernutrition: Global and Regional Exposures and Health Consequences." The Lancet 371 (9608, January 19): 243-260.

Boko, M., I. Niang, A. Nyong, C. Vogel, A. Githeko, M. Medany, B. Osman-Elasha, R. Tabo and P. Yanda. 2007. "Africa." In M.L. Parry, O.F. Canziani, J.P. Palutikof, P.J. van der Linden and C.E. Hanson, eds. Climate Change 2007: Impacts, Adaptation and Vulnerability, Contribution of Working Group II to the Fourth Assessment Report of the Intergovernmental Panel on Climate Change. Cambridge, UK: Cambridge University Press. Pp. 433-467.

Booth, S. and D. Zeller. 2005. "Mercury, Food Webs and Marine Mammals: Implications of Diet and Climate Change for Human Health. Environmental Health Perspectives 113 (5): 521-526.

Bryce, J., D. Coitinho, I. Darton-Hill, D. Pelletier and P. Pinstrup-Andersen. 2008. "Maternal and Child Undernutrition: Effective Action at National Level.” The Lancet 371 (9611, February 8): 510-526.

Butt, T., B. McCarl, J. Angerer, P. Dyke and J. Stuth. 2005. "The Economic and Flood Security Implications of Climate Change in Mali. Climatic Change 68 (3): 355-378.

Campbell-Lendrum, D., A. Pruss-Ustun and C. Corvalan, 2003. "How Much Disease Could Climate Change Cause? In A. McMichael, D. Campbell-Lendrum, C. Corvalan, K. Ebi, A. Githeko, J. Scheraga and A. Woodward, eds. Climate Change and Human Health: Risks and Responses. Geneva: World Health Organization/ World Meteorological Organization/U.N. Environment Programme. Pp. 133- 159.

CE-DAT (Complex Emergency Database). 2006. "Refugees and Emergency Thresholds in 2005." CE-DAT Brief: Issue 1. Brussels: Centre for Research on the Epidemiology of Disasters.

CGIAR (Consultative Group on International Agricultural Research). 2008. Global Climate Change: Can Agriculture Cope? Washington, DC: CGIAR. HTTP://WWW.CGIAR.ORG/IMPACT/GLOBAL/CLIMATE.HTML

Checkley, W., L.D. Epstein, R.H. Gilman, D. Figueroa, R.I. Cama, J.A. Patz and R.E. Black. 2000. Effects of El Niño and Ambient Temperature on Hospital Admissions for Diarrhoeal Diseases in Peruvian Children. The Lancet 355: 442-450.

Cline, W.R. 2007. Global Warming and Agriculture: Impact Estimates by Country. Washington, DC: Center for Global Development and Peterson Institute for international Economics.

Cohen, M.J., D. Wiesmann, P. Menon, M.T. Ruel, N. Smith, J.M. Charles, M.J. Augustin and D.P. Lenz. 2008, forthcoming. "Implementing a Conditional Cash Transfer Program in Haiti: Opportunities and Challenges." IFPRI Discussion Paper. Washington, DC: IFPRI.

Confalonieri, U., B. Menne, R. Akhtar, K.L. Ebi, M. Hauengue, R.S. Kovats, B. Revich and A. Woodward. 2007. "Human Health.” In M.L. Parry, O.F. Canziani, J.P. Palutikof, P.J. van der Linden and C.E. Hanson, eds. Climate Change 2007: Impacts, Adaptation and Vulnerability, Contribution of Working Group II to the Fourth Assessment Report of the Intergovernmental Panel on Climate Change. Cambridge, UK: Cambridge University Press. Pp. 391-431.

Cruz, R.V., H. Harasawa, M. Lal, S. Wu, Y. Anokhin, B. Punsalmaa, Y. Honda, M. Jafari, C. Li and N. Huu Ninh. 2007. "Asia.” In M.L. Parry, O.F. Canziani, J.P. Palutikof, P.J. van der Linden and C.E. Hanson, eds. Climate Change 2007: Impacts, Adaptation and Vulnerability, Contribution of Working Group II to the Fourth Assessment Report of the Intergovernmental Panel on Climate Change. Cambridge, UK: Cambridge University Press. Pp. 469-506.

De Benoist, B., I. Darnton-Hill, L. Davidsson, O. Fontaine and C. Hotz. 2007. "Conclusions of the Joint WHO/UNICEF/IAEA/IZiNCG Interagency Meeting on Zinc Status Indicators." Food and Nutrition Bulletin 28 (3): S480-S484. 
Delgado, C., M. Rosegrant, H. Steinfeld, S. Ehui and C. Courbois. 1999. "Livestock to 2020: The Next Food Revolution." 2020 Vision for Food, Agriculture, and the Environment Discussion Paper No. 28. Washington, DC: IFPRI.

Dercon, S., ed. 2004. Insurance Against Poverty. Oxford, U.K.: Oxford University Press.

Ding, Chengri. 2004. "Farmland Preservation in China." Land Lines 16:3 (July). Cambridge, MA: Lincoln Institute. HTTP://WWW.LINCOLNINST.EDU/PUBS/PUBDETAIL.ASPX?PUBID=913.

Easterling, W.E., P.K. Aggarwal, P. Batima, K.M. Brander, L. Erda, S.M. Howden, A. Kirilenko, J.Morton, J-F. Soussana, J. Schmidhuber and F.N. Tubiello. 2007. "Food, Fibre and Forest Products." In M.L. Parry, O.F. Canziani, J.P. Palutikof, P.J. van der Linden and C.E. Hanson, eds. Climate Change 2007: Impacts, Adaptation, and Vulnerability, Contribution of Working Group II to the Fourth Assessment Report of the Intergovernmental Panel on Climate Change, ed.. Cambridge, U.K.: Cambridge University Press. Pp. 273-314.

ETC Group. 2005. “Oligopoly, Inc." Communique No. 91 (November/December). HTTP://WWW.ETCGROUP.ORG/UPLOAD/PUBLICATION/PDF_FILE/44.

ETC Group. 2007. "The World's Top 10 Seed Companies - 2006." HTTP://WWW.ETCGROUP.ORG/UPLOAD/PUBLICATION/PDF_FILE/656.

FANTA (Food and Nutrition Technical Assistance). 2006. "Food Security." HTTP://WWW.FANTAPROJECT.ORG/FOCUS/FOODSECURITY.SHTML.

FAO (Food and Agriculture Organization of the United Nations). 1992. International Conference on Nutrition. Rome: FAO. FTP://FTP.FAO.ORG/ES/ESN/NUTRITION/ICN/ICNCONTS.HTM

FAO. 1996. World Food Summit Plan of Action. HTTP://WWW.FAO.ORG/WFS/INDEX_EN.HTM.

FAO 2000. "Guidelines for National FIVIMS" HTTP://WWW.FAO.ORG/DOCREP/003/X8346E/X8346E00.HTM.

FAO. 2001. Mobilizing the Political Will and Resources to Banish Hunger: Technical Background Documents, The World Food Summit: five years later. Rome: HTTP://WWW.FAO.ORG/DOCUMENTS/SHOW_CDR.ASP?URL_FILE=/DOCREP/004/Y1780E/Y1780E00.HTM.

FAO. 2002. World Food Summit: five years later. HTTP://WWW.FAO.ORG/WORLDFOODSUMMIT/ENGLISH/INDEX.HTML.

FAO. 2003a. "Strengthening Coherence in FAO's Initiatives to Fight Hunger." Conference, Thirty-second Session, 29 November to 10 December. Rome: FAO.

FAO. 2003b. "Impact of Climate Change on Food Security and Implications for Sustainable Food Production." Committee on World Food Security. Conference, Twenty-ninth Session, 12 to 16 May. Rome: FAO.

FAO. 2003c. "Future Climate Change and Regional Fisheries: A Collaborative Analysis. FAO Fisheries Technical Paper No. 452. Rome: FAO.

FAO. 2004. The State of Food Insecurity in the World 2004. Rome: FAO. FTP://FTP.FAO.ORG/DOCREP/FAO/007/Y5650E/Y5650E00.PDF.

FAO. 2005a. The State of Food Insecurity in the World 2005. Rome: FAO. HTTP://WWW.FAO.ORG/DOCREP/008/A0200E/A0200E00.HTM.

FAO. 2005b. Voluntary Guidelines to Support the Progressive Realization of the Right to Adequate Food in the Context of National Food Security. Rome: FAO.

FAO. 2006a. The State of Food Insecurity in the World 2006. Rome: FAO. HTTP://WwW.FAO.ORG/SOF/SOFI/.

FAO. 2006b. The State of Food and Agriculture 2006. Rome: FAO. 
FAO. 2007. The State of Food and Agriculture 2007. Rome: FAO.

FAO 2008a. "Wheat Killer Detected in Iran." Press Release. March 5. HTTP://WWW.FAO.ORG/NEWSROOM/EN/NEWS/2008/1000805/INDEX.HTML.

HTTP://WWW.FAO.ORG/NR/WATER/AQUASTAT/MAIN/INDEX.STM.

Database. Available

at

FAO. 2008c. "Expert Meeting on Climate-Related Transboundary Pests and Diseases Including Relevant Aquatic Species, Food and Agriculture Organization of the United Nations, 25-27 February 2008, Options for Decision Makers."

HTTP://WWW.FAO.ORG/FILEADMIN/USER_UPLOAD/FOODCLIMATE/PRESENTATIONS/DISEASES/OPTIONSEM3.PDF.

FAO. 2008d. "Bioenergy.” HTTP://WWW.FAO.ORG/NR/BEN/BEN_EN.HTM.

FAO. 2008e. "Bioenergy, Food Security and Sustainability - Towards an International Framework." Information Paper No. 3 for the High Level Conference on World Food Security: The Challenges of Climate Change and Bioenergy, HLC/08/INF/3. Rome: HTTP://WWW.FAO.ORG/FILEADMIN/USER_UPLOAD/FOODCLIMATE/HLCDOCS/HLC08-INF-3-E.PDF.

FAO. 2008f. "Expert Meeting on Bioenergy Policy, Markets and Trade and Food Security and Global Perspectives on Fuel and Food Security FAO Headquarters, Rome, 18-20 February 2008, Options for Decision Makers."

HTTP://WWW.FAO.ORG/FILEADMIN/USER_UPLOAD/FOODCLIMATE/PRESENTATIONS/EM56/OPTIONSEM56.PDF.

Ferrett, G. 2007. "Biofuels “Crime Against Humanity.” BBC News. October 27.

Fischer, G., M. Shah, F.N. Tubiello and H. Van Velthuizen, 2005. "Integrated Assessment of Global Crop Production." Philosophical Transactions of the Royal Society B 360: 2067-2083.

Fischlin, A., G.F. Midgley, J.T. Price, R. Leemans, B. Gopal, C. Turley, M.D.A. Rounsevell, O.P. Dube, J. Tarazona and A.A. Velichko. 2007. "Ecosystems, Their Properties, Goods and Services." In M.L. Parry, O.F. Canziani, J.P. Palutikof, P.J. van der Linden and C.E. Hanson, eds. Climate Change 2007: Impacts, Adaptation and Vulnerability, Contribution of Working Group II to the Fourth Assessment Report of the Intergovernmental Panel on Climate Change. Cambridge, UK: Cambridge University Press. Pp. 211-272.

Forster, P., V. Ramaswamy, P. Artaxo, T. Berntsen, R. Betts, D.W. Fahey, J. Haywood, J. Lean, D.C. Lowe, G. Myhre, J. Nganga, R. Prinn, G. Raga, M. Schulz and R. Van Dorland. 2007. "Changes in Atmospheric Constituents and in Radiative Forcing." In S. Solomon, D. Qin, M. Manning, Z. Chen, M. Marquis, K.B. Averyt, M. Tignor and H.L. Miller eds. Climate Change 2007: The Physical Science Basis, Contribution of Working Group I to the Fourth Assessment Report of the Intergovernmental Panel on Climate Change. Cambridge, UK: Cambridge University Press. Pp. 129-234.

Fothergill, A. 1998. "The Neglect of Gender in Disaster Work: An Overview of the Literature.” In E. Enarson and B. Morrow, eds. The Gendered Terrain of Disaster: Through Women's Eyes. Westport, Conn.: Praeger. Pp. 9-25.

Garrett, J.L. and M.T. Ruel, eds. 2000. "Achieving Urban Food and Nutrition Security in the Developing World." 2020 Vision Focus No. 3. Washington, DC: IFPRI. HTTP://WWW.IFPRI.ORG/2020/FOCUS/FOCUS03/FOCUS03.PDF.

Geissler, C. and H. Powers, eds. 2005. Human Nutrition, $11^{\text {th }}$ Edition. Edinburgh, UK: Elsevier.

Gillespie, S. and S. Kadiyala. 2005. "HIV/AIDS and Food and Nutrition Security: From Evidence to Action." Food Policy Review No. 7. Washington: IFPRI. HTTP://WWW.IFPRI.ORG/PUBS/FPREVIEW/PV07/PV07.PDF.

Gleditsch, N.P., Ragnhild Nordås and Idean Salehyan. 2007. Climate Change and Conflict: The Migration Link. Coping with Crisis Working Paper. New York: International Peace Institute. HTTP://WWW.IPACADEMY.ORG/ASSET/FILE/169/CWC_WORKING_PAPER_CLIMATE_CHANGE.PDF. 
Hari Kumar, R., K. Venkaiah, N. Arlappa, S. Kumar, G. Brahmam and K. Vijayaraghavan. 2005. "Diet and Nutritional Status of the Population in the Severely Drought Affected Areas of Gujarat." Journal of Human Ecology 18 (4): 319-326.

HarvestPlus. 2007. "Micronutrient Malnutrition.” HTTP://WwW.HARVESTPLUS.ORG/.

Hawkes, C. and M.T. Ruel. 2006a. "Agriculture and Nutrition Linkages: Old Lessons and New Paradigms." In C. Hawkes and M.T. Ruel, eds. "Understanding the Links Between Agriculture and Health." 2020 Vision Focus No. 13, Brief 4 of 16. Washington, DC: IFPRI. HTTP://WWW.IFPRI.ORG/2020/FOCUS/FOCUS13.ASP\#DL.

Hawkes, C. and M.T. Ruel. 2006b. “Overview.” In C. Hawkes and M.T. Ruel, eds. "Understanding the Links Between Agriculture and Health." 2020 Vision Focus No. 13, Brief understanding the Links Between Agriculture and Health, 2020 Vision Focus No. 13, Brief 1 of 16. Washington, DC: IFPRI. HTTP://WWW.IFPRI.ORG/2020/FOCUS/FOCUS13.ASP\#DL.

Hazell, P.B.R., C. Poulton, S. Wiggins and A. Dorward. 2007. "The Future of Small Farms for Poverty Reduction and Growth." 2020 Vision for Food, Agriculture, and the Environment Discussion Paper No. 42. Washington, DC: IFPRI. HTTP://WWW.IFPRI.ORG/2020/DP/VP42.PDF.

Hitz, S. and J. Smith. 2004. "Estimating Global Impacts from Climate Change." Global Environmental Change 14 (3): 201-218.

Hoddinott, J., J.A. Maluccio, J.R. Behrman, R. Flores and R. Martorell. 2008. "Effect of a Nutrition Intervention During Early Childhood on Economic Productivity in Guatemalan Adults." The Lancet 371 (9610, February 2): 411-416.

IFAD (International Fund for Agricultural Development). 2001. Rural Poverty Report 2001. New York: Oxford University Press. HTTP://WWW.IFAD.ORG/POVERTY/INDEX.HTM.

IFPRI (International Food Policy Research Institute). 2002. "Living in the City: Challenges and Options for the Urban Poor." IFPRI Issue Brief No. 9. Washington, DC: IFPRI.

IFPRI. 2005. The Future of Small Farms: Proceedings of a Research Workshop. Washington, DC: IFPRI. HTTP://WWW.IFPRI.ORG/EVENTS/SEMINARS/2005/SMALLFARMS/SFPROC/SFPROC.PDF.

Kherallah, M., C. Delgado, E. Gabre-Madhin, N. Minot and M. Johnson. 2002. Reforming Agricultural Markets in Africa. Baltimore and London: The Johns Hopkins University Press for IFPRI.

Kovats, R.S., S. Edwards, S. Hajat, B. Armstrong, K.L. Ebi and B. Menne, 2004. "The Effect of Temperature on Food Poisoning: Time Series Analysis in 10 European Countries.” Epidemiology and Infection 132 (3): 443-453.

Kuhnlein, H.V., H.M. Chan, D. Leggee, and V. Barthet. 2002. "Macronutrient, Mineral and Fatty Acid Composition of Canadian Arctic Traditional Food." Journal of Food Composition and Analysis 15 (5): 545-566.

Kuhnlein, H.V. 2003. "Micronutrient Nutrition and Traditional Food Systems of Indigenous Peoples." Food, Nutrition and Agriculture No. 32. Rome: FAO. Pp. 33-39.

Kundzewicz, Z.W., L.J. Mata, N.W. Arnell, P. Döll, P. Kabat, B. Jiménez, K.A. Miller, T. Oki, Z. Sen and I.A. Shiklomanov. 2007. "Freshwater Resources and their Management." In M.L. Parry, O.F. Canziani, J.P. Palutikof, P.J. van der Linden and C.E. Hanson, eds. Climate Change 2007: Impacts, Adaptation and Vulnerability, Contribution of Working Group II to the Fourth Assessment Report of the Intergovernmental Panel on Climate Change. Cambridge, UK: Cambridge University Press. Pp. 173-210.

Lambrou, Y. and G. Piana. 2006. Energy and Gender Issues in Rural Sustainable Development. Rome: FAO.

Lazo, A. 2008. "Pressure on Economy Mounts as Oil Rises, Home Sales Drop." The Washington Post. April 23. P. D2. 
LEAD (The Livestock, Environment and Development LEAD Initiative). 2007. "Livestock's Long Shadow: Environmental Issues and Options." Rome: FAO. HTTP://WWW.FAO.ORG/DOCREP/010/A0701E/A0701E00.HTM.

Lemke, P., J. Ren, R.B. Alley, I. Allison, J. Carrasco, G. Flato, Y. Fujii, G. Kaser, P. Mote, R.H. Thomas and T. Zhang. 2007. "Observations: Changes in Snow, Ice and Frozen Ground.” In S. Solomon, D. Qin, M. Manning, Z. Chen, M. Marquis, K.B. Averyt, M. Tignor and H.L. Miller, eds. Climate Change 2007: The Physical Science Basis, Contribution of Working Group I to the Fourth Assessment Report of the Intergovernmental Panel on Climate Change. Cambridge, UK: Cambridge University Press. Pp. 337-384.

Mason, J.B., A. Bailes, K.E. Mason, O. Yambi, U. Jonsson, C. Hudspeth, P. Hailey, A. Kendle, D. Brunet and P. Martel. 2005. "AIDS, Drought and Child Malnutrition in Southern Africa." Public Health Nutrition 8 (6): 551 563.

McMichael, A., D. Campbell-Lendrum, S. Kovats, S. Edwards, P. Wilkinson, T. Wilson, R. Nicholls, S. Hales, F. Tanser, D. Le Sueur, M. Schlesinger and N. Andronova. 2004. "Global Climate Change." In M. Ezzati, A. Lopez, A. Rodgers and C. Murray, eds. Comparative Quantification of Health Risks: Global and Regional Burden of Disease due to Selected Major Risk Factors, Vol. 2, Geneva: World Health Organization. Pp. 15431649.

Meehl, G.A., T.F. Stocker, W.D. Collins, P. Friedlingstein, A.T. Gaye, J.M. Gregory, A. Kitoh, R. Knutti, J.M. Murphy, A. Noda, S.C.B. Raper, I.G. Watterson, A.J. Weaver and Z.-C. Zhao. 2007. "Global Climate Projections." In S. Solomon, D. Qin, M. Manning, Z. Chen, M. Marquis, K.B. Averyt, M. Tignor and H.L. Miller, eds. Climate Change 2007: The Physical Science Basis, Contribution of Working Group I to the Fourth Assessment Report of the Intergovernmental Panel on Climate Change. Cambridge, UK: Cambridge University Press. Pp. 747-846.

Metz, B., O.R. Davidson, P.R. Bosch, R. Dave and L.A. Meyer, eds. 2007. Climate Change 2007: Mitigation. Contribution of Working Group III to the Fourth Assessment Report of the Intergovernmental Panel on Climate Change. Cambridge, UK: Cambridge University Press.

MI (Micronutrient Initiative) and UNICEF (United Nations Children's Fund). 2005. Vitamin and Mineral Deficiency. A Global Progress Report. Ottawa and New York: MI and UNICEF. HTTP://WWW.UNICEF.ORG/MEDIA/FILES/VMD.PDF.

Millennium Ecosystem Assessment. 2005. Ecosystems and Human Well-being: Synthesis. Washington, DC: Island Press.

Mimura, N., L. Nurse, R.F. McLean, J. Agard, L. Briguglio, P. Lefale, R. Payet and G. Sem. 2007. "Small Islands.” In M.L. Parry, O.F. Canziani, J.P. Palutikof, P.J. van der Linden and C.E. Hanson, eds. Climate Change 2007: Impacts, Adaptation and Vulnerability, Contribution of Working Group II to the Fourth Assessment Report of the Intergovernmental Panel on Climate Change. Cambridge, UK: Cambridge University Press. Pp. 687-716.

Minot, N. and R.V. Hill. 2007. "Developing and Connecting Markets for Poor Farmers." 2020 Focus Brief on the World's Poor and Hungry People. Washington, DC: IFPRI.

Morris, S.S., B. Cogill and R. Uauy. 2008. "Effective International Action Against Undernutrition: Why Has it Proven so Difficult and What Can be Done to Accelerate Progress?." The Lancet 371 (9612, February 16): 608621.

Nicholls, R.J., P.P. Wong, V.R. Burkett, J.O. Codignotto, J.E. Hay, R.F. McLean, S. Ragoonaden and C.D. Woodroffe. 2007. "Coastal Systems and Low-lying Areas.” In M.L. Parry, O.F. Canziani, J.P. Palutikof, P.J. van der Linden and C.E. Hanson, eds. Climate Change 2007: Impacts, Adaptation and Vulnerability, Contribution of Working Group II to the Fourth Assessment Report of the Intergovernmental Panel on Climate Change. Cambridge, UK: Cambridge University Press. Pp. 315-356.

Nori, M., J. Switzer and A. Crawford. 2005. "Herding on the Brink: Towards a Global Survey of Pastoral Communities and Conflict." WWW.IISD.ORG/NATRES/SECURITY/PASTORALISM.ASP. 
OCHA (UN Office for the Coordination of Humanitarian Affairs). 2008. Data on appeals and donor response for 2007. HTTP://OCHA.UNOG.CH/FTS2/PAGELOADER.ASPX?PAGE=EMERG-EMERGENCIES\&SECTION=CE\&YEAR=2007.

OCHA. 2007. Humanitarian Appeal $2008 . \quad$ Geneva: HTTP://OCHAONLINE.UN.ORG/HUMANITARIANAPPEAL/WEBPAGE.ASP?PAGE=1637.

OECD (Organisation for Economic Co-operation and Development). 2007. Agricultural Policies in OECD Countries: Monitoring and Evaluation 2007. Paris: OECD.

Pardey, P.G., J.M. Alston and R.R. Piggott, eds. 2006. Agricultural R\&D in the Developing World: Too Little, Too Late? Washington, DC: IFPRI.

Parikh, J. K. and F. Denton. 2002. "Gender and Climate Change." HTTP://WWW.CRU.UEA.AC.UK/TIEMPO/FLOOR0/RECENT/ISSUE47/T47A7.HTM.

Parry, M., C. Rosenzweig and M. Livermore. 2005. "Climate Change, Global food Supply and Risk of Hunger." Philosophical Transactions of the Royal Society B 360: 2125-2138.

Parry, M.L., O.F. Canziani, J.P. Palutikof, P.J. van der Linden and C.E. Hanson, eds. 2007. Climate Change 2007: Impacts, Adaptation and Vulnerability, Contribution of Working Group II to the Fourth Assessment Report of the Intergovernmental Panel on Climate Change. Cambridge, UK: Cambridge University Press.

Pender, J. and P.B.R. Hazell, eds. 2000. "Promoting Sustainable Development in Less-Favored Areas." 2020 Vision Focus No. 4. Washington, DC: IFPRI.

Pinstrup-Andersen, P., ed. 1993. The Political Economy of Food and Nutrition Policies. Baltimore, MD and London: The Johns Hopkins University Press for IFPRI.

Quisumbing, A.R., ed. 2003. Household Decisions, Gender, and Development: A Synthesis of Recent Research. Baltimore and London: The Johns Hopkins University Press for IFPRI.

Rahman, A. (Policy Division, International Fund for Agricultural Development). 2008. Personal communication. 9 May.

Ravaillion, M., S. Chen and P. Sangraula. 2007. "New Evidence on the Urbanization of Global Poverty." World Bank Policy Research Working Paper No. 4199 (April). Washington, DC: The World Bank.

Reuters. 2008. "Manila Halts Farmland Conversion Amid Rice Pressure." Straits Times. April 16. HTTP://WWW.STRAITSTIMES.COM/LATEST\%2BNEWS/ASIA/STISTORY_227913.HTML.

Rockstrom, J. 2003. "Water for Food and Nature in Drought-prone Tropics: Vapour Shift in Rain-fed Agriculture.” Philosophical Transactions of the Royal Society B 358: 1997-2009.

Rodriguez, E. 2007. "Notes on Mexico's Oportunidades (Progresa) Program." HTTP://INFO.WORLDBANK.ORG/ETOOLS/DOCS/LIBRARY/240841/ZIP2_DAY\%201\%20RODRIGUEZ.PDF.

Rosegrant, M.W. 2008. "Biofuels and Grain Prices: Impacts and Policy Responses." Statement prepared for presentation to the Committee on Homeland Security and Governmental Affairs, U.S. Senate. May 7. HTTP://WWW.IFPRI.ORG/PUBS/TESTIMONY/ROSEGRANT20080507.PDF.

Rosegrant, M. W., M.S. Paisner, S. Meijer and J. Witcover. 2001. Global Food Projections to 2020: Emerging Trends and Alternative Futures. Washington, DC: IFPRI.

Rosegrant, M.W., T. Zhu, S. Msangi and T. Sulser. 2006. "Global Scenarios for Biofuels: Impacts and Implications." Photocopy. Washington, DC: IFPRI.

Rossi, A. and Y. Lambrou. 2008. Gender and Equity Issues in Liquid Biofuels Production: Minimizing the Risks to Maximize the Opportunities. Rome: FAO. 
Ruel, M.T., P. Menon, J.-P. Habicht, C. Loechl, G. Bergeron, G. Pelto, M. Arimond, J. Maluccio, L. Michaud and B. Hankebo. 2008. "Age-based Preventive Targeting of Food Assistance and Behaviour Change and Communication for Reduction of Childhood Undernutrition in Haiti: A Cluster Randomised Trial." The Lancet 371 (9612, February 16): 588-595.

Ruel, M.T. and A.R. Quisumbing. 2006. "The Guatemala Community Day Care Program: An Example of Effective Urban Programming." Research Report No. 144. Washington: IFPRI. HTTP://WWW.IFPRI.ORG/PUBS/ABSTRACT/RR144.ASP.

Sample, I. 2007. "Scientists Offered Cash to Dispute Climate Study.” The Guardian. February 2.

Scherr, S.J. "Soil Degradation: Threat to Developing-country Food Security by 2020?" 2020 Vision for Food, Agriculture, and the Environment Discussion Paper No. 27. Washington, DC: IFPRI.

Science Daily. 2007. “'Big Five' Oil Companies Limit Exploration.” November 13. HTTP://WWW.SCIENCEDAILY.COM/RELEASES/2007/11/071112140720.HTM.

SCN (United Nations System Standing Committee on Nutrition). 2004. 5th Report on The World Nutrition Situation.

HTTP://WWW.UNSYSTEM.ORG/SCN/PUBLICATIONS/ANNUALMEETING/SCN31/SCN5REPORT.PDF.

SCN. 2006. "Tackling the Global Burden of Malnutrition." Media Advisory. HTTP://WWW.UNSYSTEM.ORG/SCN/PUBLICATIONS/ANNUALMEETING/SCN33/SCN\%20MEDIA\%20ADVISORY\%20( F)\%20MARCH\%2006.DOC.

Shekar, M. and Y.K. Lee. 2006. "Mainstreaming Nutrition in Poverty Reduction Strategy Papers: What Does it Take? A Review of the Early Experience." HNP Discussion Paper. Washington, DC: The World Bank. HTTP://SITERESOURCES.WORLDBANK.ORG/HEALTHNUTRITIONANDPOPULATION/RESOURCES/2816271095698140167/NUTRITIONINPRSPSFINAL.PDF.

Shrimpton, R., C.G. Victora, M. de Onis, R.C. Lima, M. Blössner, and G. Clugston. 2001. "Worldwide Timing of Growth Faltering: Implications for Nutritional Interventions." Pediatrics 107(5): e75.

Skoufias, E. 2005. "PROGRESA and its Impacts on the Welfare of Rural Households in Mexico." Research Report No. 139. Washington: IFPRI.

Smith, L.C., H. Alderman and D. Aduayom. 2006. "Food Insecurity in Sub-Saharan Africa: New Estimates from Household Expenditure Surveys.” Research Report No. 146. Washington: IFPRI.

Smith, L.C. and L. Haddad. 2000. "Explaining Child Malnutrition in Developing Countries: A Cross-country Analysis." Research Report No. $111 . \quad$ Washington: HTTP://WWW.IFPRI.ORG/PUBS/ABSTRACT/111/RR111.PDF.

Stern, N. 2006. Stern Review on the Economics of Climate Change. Cambridge, UK: Cambridge University Press. $\quad$ HTTP://WWW.HMTREASURY.GOV.UK/INDEPENDENT_REVIEWS/STERN_REVIEW_ECONOMICS_CLIMATE_CHANGE/STERN_REVIEW_REP ORT.CFM.

Sullivan, K. 2008. "Food Crisis is Depicted as 'Silent Tsunami."” The Washington Post. April 23. P. A1.

The Economist. 2008. "The Silent Tsunami.” The Economist. April 17.

The Royal Society 2005. Ocean Acidification Due to Increasing Atmospheric Carbon Dioxide. Cardiff, UK: The Clyvedon Press.

Thompson, B. 2004. "Community-centred Food-based Strategies for Alleviating and Preventing Malnutrition, and Impacts of Agriculture on Human Health and Nutrition." In R.M. Welch and I. Çakmak, eds. Encyclopaedia of Life Support Systems (EOLSS). Oxford, UK: EOLSS Publishers for the U.N. Educational, Scientific, and Cultural Organization. HTTP://WWW.EOLSS.NET 
Tirado, M.C., J.M. Lotz, J.T. Ogle and W.D. Youngs, 1993. "Effect of Temperature on the Growth and Survival of Penaeus Vannamei Postlarvae in Closed Systems. Special Publication European Aquaculture Society 19: A176.

Trenberth, K.E., P.D. Jones, P. Ambenje, R. Bojariu, D. Easterling, A. Klein Tank, D. Parker, F. Rahimzadeh, J.A. Renwick, M. Rusticucci, B. Soden and P. Zhai. 2007. "Observations: Surface and Atmospheric Climate Change.” In S. Solomon, D. Qin, M. Manning, Z. Chen, M. Marquis, K.B. Averyt, M. Tignor and H.L. Miller, eds. Climate Change 2007: The Physical Science Basis, Contribution of Working Group I to the Fourth Assessment Report of the Intergovernmental Panel on Climate Change. Cambridge, UK: Cambridge University Press. Pp. 235-336.

Trostle, R. 2008. "Global Agricultural Supply and Demand: Factors Contributing to the Recent Increase in Food Commodity Prices," WRS 0801. Washington: U.S. Department of Agriculture, Economic Research Service. HTTP://WWW.ERS.USDA.GOV/PUBLICATIONS/WRS0801/WRS0801.PDF.

Trowbridge, F. and R. Martorell. 2002. "Forging Effective Strategies to Combat Iron Deficiency." Journal of Nutrition 132: 875S-879S.

UNAIDS (Joint UN Programme on HIV/AIDS). 2007. 2007 AIDS Epidemic Update. Geneva: UNAIDS. HTTP://WWW.UNAIDS.ORG/EN/KNOWLEDGECENTRE/HIVDATA/EPIUPDATE/EPIUPDARCHIVE/2007/DEFAULT.ASP.

UNCESCR (UN Committee on Economic, Social and Cultural Rights). 1999. "Substantive Issues Arising in the Implementation of the International Covenant on Economic, Social and Cultural Rights: The Right to Adequate Food (art. 11)," General Comment $\quad$ No. HTTP://WWW.UNHCHR.CH/TBS/DOC.NSF/0/3D02758C707031D58025677F003B73B9?OPENDOCUMENT.

UNDP (UN Development Programme). 2006. Human Development Report 2006. New York: Oxford University Press.

UNDP. 2007. Human Development Report 2007-2008. Basingstoke, UK: Palgrave Macmillan.

UNDP-Global Environmental Facility. 2004. Reclaiming the Land, Sustaining Livelihoods. New York: UNDP. WWW.UNDP.ORG/GEF/UNDP-GEF_PUBLICATIONS/PUBLICATIONS/LANDDEG_BROCHURE2004.PDF.

UN-Energy. 2007. Sustainable Bioenergy: A Framework for Decision Makers. New York: United Nations. FTP://FTP.FAO.ORG/DOCREP/FAO/010/A1094E/A1094E00.PDF.

UNEP (United Nations Environmental Programme). 2007. Sudan Post-Conflict Environmental Assessment. Nairobi: United Nations Environmental Program.

UNESCO (UN Educational, Scientific and Cultural Organization). 2008. Education for All Global Monitoring Report 2008: Education for All by 2015 - Will We Make It? Paris: UNESCO. HTTP://PORTAL.UNESCO.ORG/EDUCATION/EN/EV.PHP-

URL ID=49591\&URL DO=DO TOPIC\&URL SECTION=201.HTML.

UNHCR (UN High Commissioner for Refugees). 2005. "UN Agencies Highlight Dangers of Increasing Malnutrition in Refugee Camps." October 7. HTTP://WWW.UNHCR.ORG/CGIBIN/TEXIS/VTX/NEWS/OPENDOC.HTM?TBL=NEWS\&ID=4346AC9A4.

UN Millennium Project. 2005. Halving Hunger: It Can be Done: Report of the Task Force on Hunger. New York: The Earth Institute at Columbia University. HTTP://WWW.UNMILLENNIUMPROJECT.ORG/DOCUMENTS/MAINREPORTCOMPLETE-LOWRES.PDF.

UN Population Division. 2007. World Population Prospects: The 2006 Revision, Highlights. New York: United Nations Department of aconomic and Social HTTP://WWW.UN.ORG/ESA/POPULATION/PUBLICATIONS/WPP2006/WPP2006.HTM

UN Population Division. 2008. World Urbanization Prospects: The 2007 Revision, Highlights. New York: United Nations Department of Economic and Social Affairs. HTTP://WWW.UN.ORG/ESA/POPULATION/PUBLICATIONS/WUP2007/2007WUP_HIGHLIGHTS_WEB.PDF. 
Van de Poel, E., A.R. Hosseinpoor, N. Speybroeck, T. van Ourti and J. Vega. 2008. "Socioeconomic Inequality in Malnutrition in Developing Countries." Bulletin of the World Health Organization 86(4): 282-291.

Victora, C.G., L. Adair, C. Fall, P.C. Hallal, R. Martorell, L. Richter and H.S. Sachdev. 2008. "Maternal and Child Undernutrition: Consequences for Adult Health and Human Capital.” The Lancet. 371 (9609, January 26): $340-357$.

Viswanathan, B. 2006. "Income Support, Food Subsidies and Nutritional Programmes." Presentation prepared for University of Florence-Unicredit Foundation Summer School on Food Security. HTTP://WWW.DSE.UNIFI.TT/SVILUPPO/FOOD_SECURITY_ENG.HTML\#MOYO.

Von Braun, J. 2007a. "The World Food Situation: New Driving Forces and Required Actions." Food Policy Report. Washington, DC: IFPRI. HTTP://WWW.IFPRI.ORG/PUBS/FPR/PR18.PDF.

Von Braun, J. 2007b. "When Food Makes Fuel: The Promises and Challenges of Biofuels." Keynote Address at the Crawford $\quad$ Fund Annual Conference. 15 . HTTP://WWW.IFPRI.ORG/PUBS/SPEECHES/VONBRAUN/2007JVBCRAWFORDKEYNOTE.PDF

Von Braun, J. 2008. “Rising Food Prices: What Should Be Done?” IFPRI Policy Brief. April. Washington, DC: IFPRI.

Von Braun, J., D. Hotchkiss and M. Immink. 1989. "Nontraditional Export Crops in Guatemala: Effects on Production, Income and Nutrition.” Research Report No. 73. Washington, DC: IFPRI.

Von Braun, J. and R.K. Pachauri. 2006. Essay: The Promises and Challenges of Biofuels for the Poor in Developing Countries. Washington, DC: IFPRI. HTTP://WWW.IFPRI.ORG/PUBS/BOOKS/AR2005/AR05E.PDF.

Von Braun, J., M.W. Rosegrant, R. Pandya-Lorch, M.J. Cohen, S.A. Cline, M.A. Brown and M.S. Bos. 2005. "New Risks and Opportunities for Food Security: Scenario Analyses for 2015 and 2050." 2020 Discussion Paper No. 39. Washington, DC: IFPRI. HTTP://WWW.IFPRI.ORG/2020/DP/DP39/2020DP39.PDF.

Washington Post Staff and Wire Reports. 2008. “Earnings.” The Washington Post. April 15. P. D 2.

Watkins, K. and J. von Braun. 2003. "Time to Stop Dumping on the World's Poor." In IFPRI Annual Report, 2002-2003. Washington, DC: IFPRI. HTTP://WWW.IFPRI.ORG/PUBS/BOOKS/AR2002/AR02.PDF.

WFP (World Food Programme). 2007. "Final Report on the Ethiopia Drought Insurance Pilot Programme." HTTP://WWW.WFP.ORG/EB/DOCS/2007/WFP113643 1.PDF.

WHO (World Health Organization). 1997. "Fact Sheet: Reducing Mortality from Major Childhood Killer Diseases.” HTTP://WwW.WHO.INT/CHILD-ADOLESCENT-HEALTH/NEW_PUBLICATIONS/IMCI/FS_180.HTM.

WHO. 2001. "Combating Vitamin A Deficiency.” HTTP://WwW.WHO.INT/NUT/VAD.HTM.

WHO. 2005a. Ecosystems and Human Wellbeing: Health Synthesis, A Report of the Millennium Ecosystem Assessment. Geneva: WHO.

WHO. 2005b. Modern Food Biotechnology, Human Health and Development: An Evidence-based Study. Geneva: WHO.

WHO. 2006. "Micronutrient Malnutrition: Iodine Deficiency Disorders." HTTP://WWW.WHO.INT/NUTRITION/TOPICS/IDD/EN/INDEX.HTML.

Wiesmann, D., I. Schöninger, A.K. Sost, H. Dalzell, S. Collins, L. Kiess and T. Arnold. 2007. The Challenge of Hunger 2007. Bonn: Deutsche Welthungerhilfe, IFPRI and Concern.

World Bank. 2006. Repositioning Nutrition as Central to Development: A Strategy for Large-scale Action. Washington, DC: The World Bank. HTTP://SITERESOURCES.WORLDBANK.ORG/NUTRITION/RESOURCES/2818461131636806329/NUTRITIONSTRATEGY.PDF. 
World Bank. 2007. World Development Indicators 2007. CD-ROM.

World Bank. 2008a. World Development Report 2008. Washington, DC: The World Bank.

World Bank. 2008b. "Rising Food Prices: Policy Options and World Bank Response.” World Bank Background Note. Washington, DC: The World Bank.

Yohe, G.W., R.D. Lasco, Q.K. Ahmad, N.W. Arnell, S.J. Cohen, C. Hope, A.C. Janetos and R.T. Perez. 2007. "Perspectives on Climate Change and Sustainability." In M.L. Parry, O.F. Canziani, J.P. Palutikof, P.J. van der Linden and C.E. Hanson, eds. Climate Change 2007: Impacts, Adaptation and Vulnerability, Contribution of Working Group II to the Fourth Assessment Report of the Intergovernmental Panel on Climate Change. Cambridge, UK: Cambridge University Press. Pp. 811-841.

Zimmerman, M., A. DePaola, J. C. Bowers, J. A. Krantz, J. L. Nordstrom, C. N. Johnson and D. J. Grimes. 2007, "Variability of Total and Pathogenic Vibrio Parahaemolyticus Densities in Northern Gulf of Mexico Water and Oysters." Applied and Environmental Microbiology 73 (23): 7589-7596. 


\section{Scenarios of the IPCC's Special Report on Emissions Scenarios (SRES) ${ }^{16}$}

A1. The A1 storyline and scenario family describes a future world of very rapid economic growth, global population that peaks in mid-century and declines thereafter and the rapid introduction of new and more efficient technologies. Major underlying themes are convergence among regions, capacity building and increased cultural and social interactions, with a substantial reduction in regional differences in per capita income. The A1 scenario family develops into three groups that describe alternative directions of technological change in the energy system. The three A1 groups are distinguished by their technological emphasis: fossil intensive (A1FI), non-fossil energy sources (A1T), or a balance across all sources (A1B) (where balanced is defined as not relying too heavily on one particular energy source, on the assumption that similar improvement rates apply to all energy supply and end use technologies).

A2. The A2 storyline and scenario family describes a very heterogeneous world. The underlying theme is self-reliance and preservation of local identities. Fertility patterns across regions converge very slowly, which results in continuously increasing population. Economic development is primarily regionally oriented and per capita economic growth and technological change more fragmented and slower than other storylines.

B1. The B1 storyline and scenario family describes a convergent world with the same global population, that peaks in mid-century and declines thereafter, as in the A1 storyline, but with rapid change in economic structures towards a service and information economy, with reductions in material intensity and the introduction of clean and resource efficient technologies. The emphasis is on global solutions to economic, social and environmental sustainability, including improved equity, but without additional climate initiatives.

B2. The B2 storyline and scenario family describes a world in which the emphasis is on local solutions to economic, social and environmental sustainability. It is a world with continuously increasing global population, at a rate lower than A2, intermediate levels of economic development and less rapid and more diverse technological change than in the B1 and A1 storylines. While the scenario is also oriented towards environmental protection and social equity, it focuses on local and regional levels.

An illustrative scenario was chosen for each of the six scenario groups A1B, A1FI, A1T, A2, B1 and B2. All should be considered equally sound.

The SRES scenarios do not include additional climate initiatives, which means that no scenarios are included that explicitly assume implementation of the United Nations Framework Convention on Climate Change or the emissions targets of the Kyoto Protocol.

${ }^{16}$ Source: M.L. Parry et al. (2007). 
Appendix 2

\section{IFPRI IMPACT Model17}

IFPRI's International Model for Policy Analysis of Agricultural Commodities and Trade (IMPACT) is a partial equilibrium agricultural model for crop and livestock commodities, including cereals, soybeans, roots and tubers, meats, milk, eggs, oilseeds, oilcakes/meals, sugar/sweeteners and fruits and vegetables. It is specified as a set of 115 country and regional sub-models, within each of which supply, demand and prices for agricultural commodities are determined. The model links the various countries and regions through international trade using a series of linear and non-linear equations to approximate the underlying production and demand functions. The current starting year is 2000 and the baseline incorporates FAOSTAT data on commodity, income and population; projections from the World Bank and the United Nations; a system of supply and demand elasticities from literature reviews and expert estimates; and rates for malnutrition from the UN Standing Committee on Nutrition and the World Health Organization. World agricultural commodity prices are determined annually at levels that clear international markets. Growth in crop production in each country is determined by crop and input prices, the rate of productivity growth, investment in irrigation and water availability. Demand is a function of prices, income and population growth.

\footnotetext{
17 Additional information about the model and its formulation can be found in Rosegrant et al. (2001) and documentation posted at HTTP:// WWW.IFPRI.ORG/THEMES/IMPACT.HTM.
} 